University of Louisville

ThinkIR: The University of Louisville's Institutional Repository

Electronic Theses and Dissertations

$12-2017$

\title{
The role of kinases and phosphatases in the pathobiology of porphyromonas gingivalis.
}

\author{
Sarah Whitmore \\ University of Louisville
}

Follow this and additional works at: https://ir.library.louisville.edu/etd

Part of the Oral Biology and Oral Pathology Commons

\begin{abstract}
Recommended Citation
Whitmore, Sarah, "The role of kinases and phosphatases in the pathobiology of porphyromonas gingivalis." (2017). Electronic Theses and Dissertations. Paper 2839.

https://doi.org/10.18297/etd/2839
\end{abstract}

This Doctoral Dissertation is brought to you for free and open access by ThinkIR: The University of Louisville's Institutional Repository. It has been accepted for inclusion in Electronic Theses and Dissertations by an authorized administrator of ThinkIR: The University of Louisville's Institutional Repository. This title appears here courtesy of the author, who has retained all other copyrights. For more information, please contact thinkir@louisville.edu. 
THE ROLE OF KINASES AND PHOSPHATASES IN THE PATHOBIOLOGY OF PORPHYROMONAS GINGIVALIS

By

Sarah Whitmore

\begin{abstract}
A Dissertation
Submitted to the Faculty of the

School of Interdisciplinary and Graduate Studies

In Partial Fulfillment of the Requirement for the Degree of
\end{abstract}

Doctor of Philosophy in Interdisciplinary Studies

Department of Oral Immunology and Infectious Diseases

University of Louisville, School of Dentistry

Louisville, KY

December 2017 
Copyright by Sarah Whitmore

All Rights Reserved 

THE ROLE OF KINASES AND PHOSPHATASES IN THE PATHOBIOLOGY OF PORPHYROMONAS GINGIVALIS

By

Sarah Whitmore

D.M.D., University of Louisville, 2016

A Dissertation approved on November 14, 2017

By the following Dissertation Committee:

Dr. Richard J. Lamont (Mentor)

Dr. David A. Scott

Dr. Yousef Abu-Kwaik

Dr. Donald R. Demuth 


\section{ACKNOWLEDGEMENTS}

Firstly, I would like to thank my research mentor, Dr. Richard Lamont, for his continued patience, guidance and unconditional support throughout my studies. Had it not been for Dr. Lamont's dedication and commitment to seeing me succeed I would not have accomplished this goal and for that I am forever grateful. Thank you Dr. Lamont for never giving up on me and for providing me with invaluable research experience. I would like to thank the other committee members, Dr. Scott, Dr. Demuth and Dr. Abukwaik for their time and assistance during my studies. I would like to extend a special thank you to my husband, Alex for his emotional support, love, understanding and patience during those stressful times when I worked tirelessly into the night. I would also like to thank my father, Dr. Thomas Whitmore, for his support, encouragement and advice over these past seven years. My father is an excellent role model for me both personally and professionally. He always taught me to visualize a positive outcome and success and to embrace challenges rather than shy away. But most importantly, to remain calm at all times and realize this is simply a test of my will and determination. A special thanks to all my extended family and friends who encouraged me throughout. And lastly, I would like to thank my daughter, Milana who may only be one year old but her existence has given me the inner strength to remain focused and steadfast and successfully reach this goal that l've been working towards for many years. Thank you Milana from the bottom of my heart. 


\title{
ABSTRACT \\ THE ROLE OF KINASES AND PHOSPHATASES IN THE PATHOBIOLOGY OF PORPHYROMONAS GINGIVALIS
}

\author{
Sarah Whitmore
}

November 14, 2017

Periodontal diseases result from the interplay between the dysregulation of the host inflammatory response and the actions of a dysbiotic bacterial community. These chronic inflammatory conditions affect persons on a worldwide scale. $P$. gingivalis is strongly implicated as a key periodontal pathogen in the more severe manifestations of periodontal diseases such as periodontitis. A core element of $P$. gingivalis pathogenicity is its dysregulation of innate immunity, including suppression of IL-8 production by gingival epithelial cells. The NF-kB family of related transcription factors plays a central role in regulating many important aspects of innate immune responses. NF-kB RelA/p65 homodimers regulate transcription of IL-8. Here we show that SerB, a serine phosphatase secreted by $P$. gingivalis, is produced intracellularly and can specifically dephosphorylate S536 of p65 in gingival epithelial cells. A P. gingivalis mutant lacking SerB showed diminished ability to dephosphorylate p65 S536. Ectopically expressed SerB bound to p65 and co-localized with p65 in the cytoplasm. Ectopic expression of SerB also resulted in dephosphorylation of p65 with reduced nuclear translocation in TNF-stimulated epithelial cells. Conversely, the p105/50 subunit of NF-KB was unaffected by the presence of SerB. Co-expression of a constitutively active p65 mutant (S536D) relieved inhibition of nuclear translocation. IL-8 promoter activity and the 
production of IL-8 were both found to be inhibited by SerB. This study also characterized a bacterial tyrosine kinase in $P$. gingivalis, designated Ptk1, and demonstrated its involvement in interspecies signaling in the context of dual species $P$. gingivalis-S. gordonii communities. Our findings show that Ptk1 is capable of autophosphorylation, and is one of the substrates of $P$. gingivalis tyrosine phosphatase Ltp1, as it is dephosphorylated by Ltp1. In the $\Delta p t k 1$ mutant (no active Ptk1) there was significantly reduced accumulation of $P$. gingivalis on the $S$. gordonii substrate indicating that tyrosine kinase activity is required for optimal polymicrobial synergy. Collectively these findings illustrate (1) the molecular mechanisms underlying a bacterial strategy to manipulate the innate host response and host inflammatory pathways, and (2) that Ptk1 is an important component in the signaling networks that regulate synergistic interactions between $P$. gingivalis and S. gordonii. 


\section{TABLE OF CONTENTS}

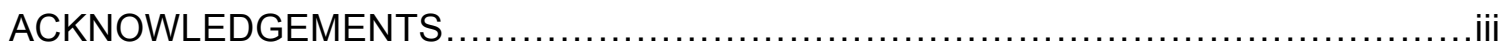

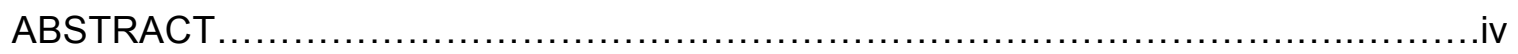

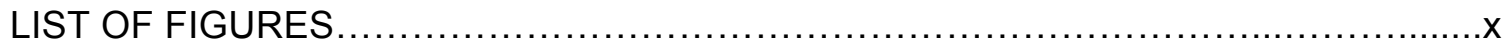

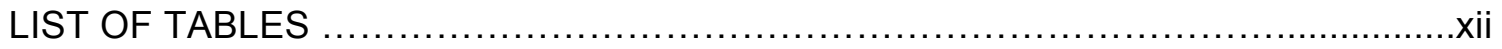

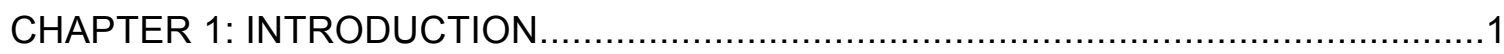

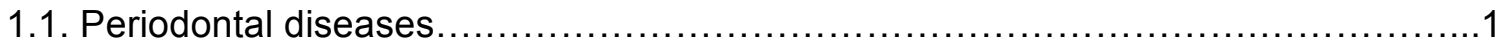

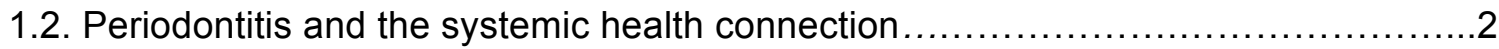

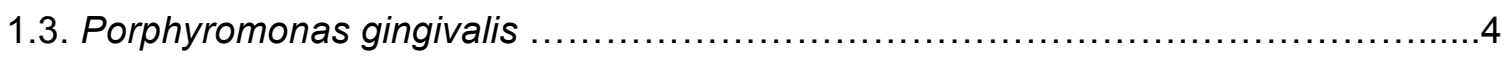

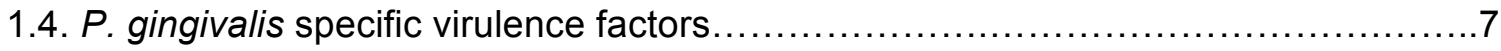

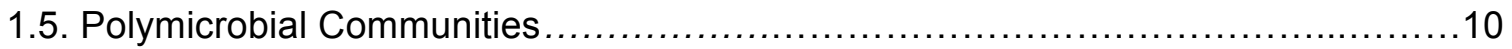

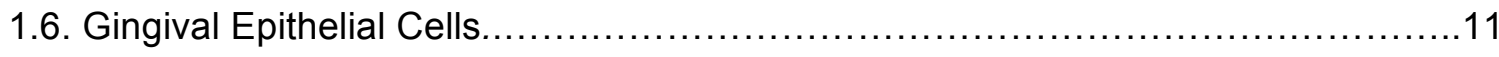

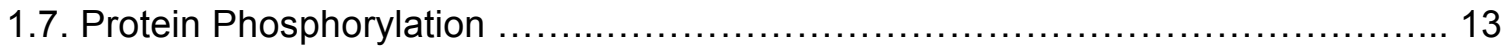

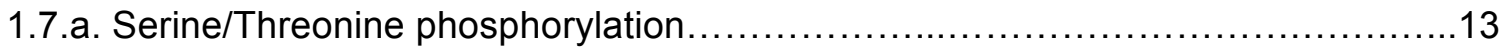

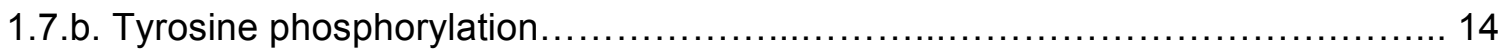




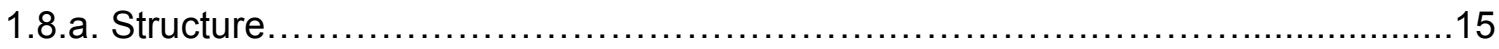

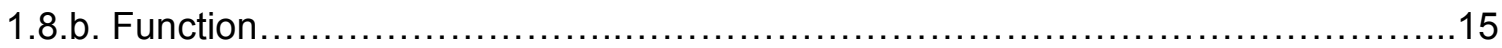

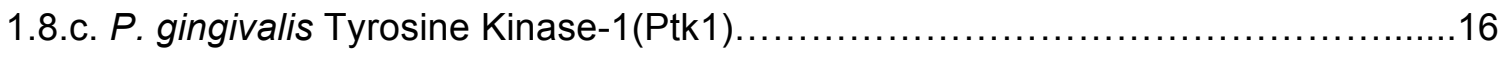

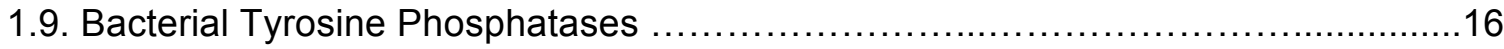

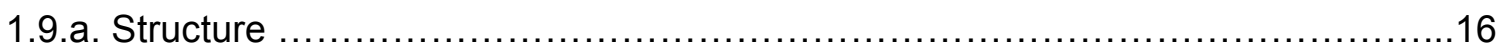

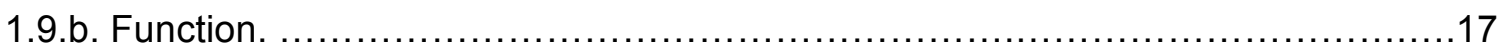

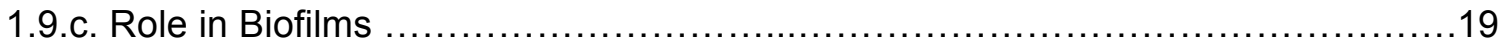

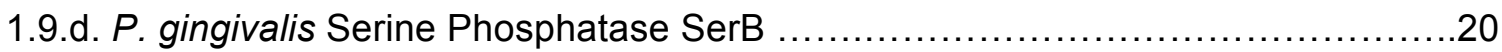

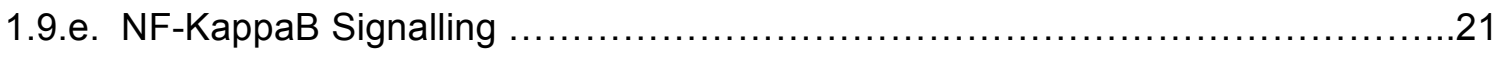

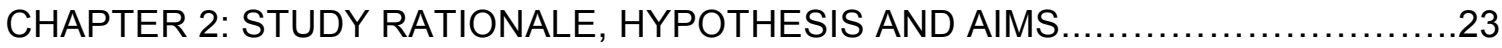

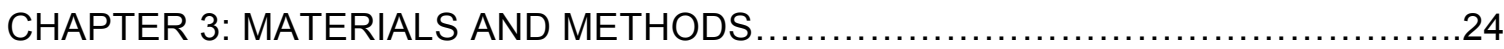

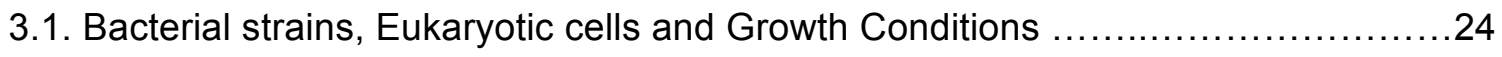

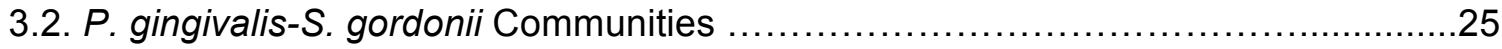

3.3. Expression/Purification of Recombinant Proteins.............................. 25

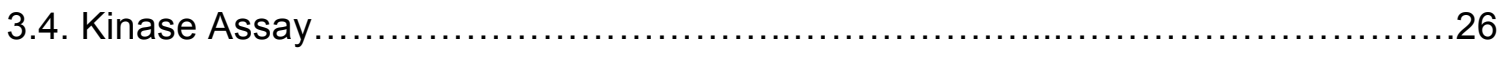

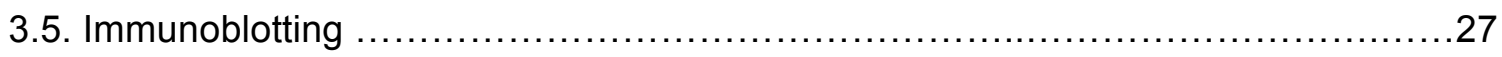




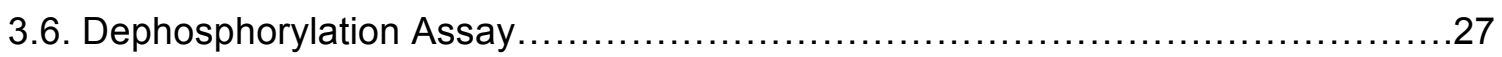

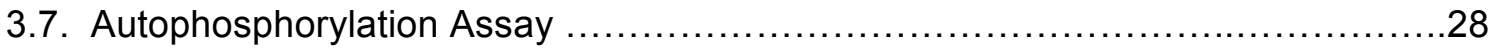

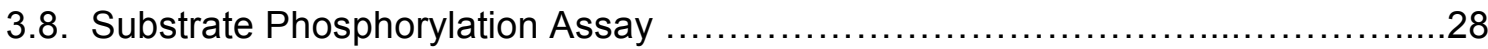

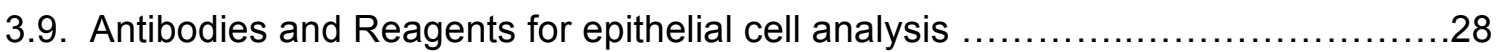

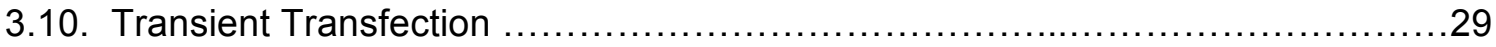

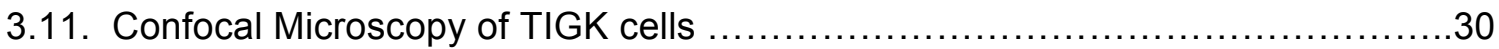

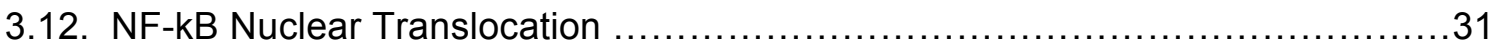

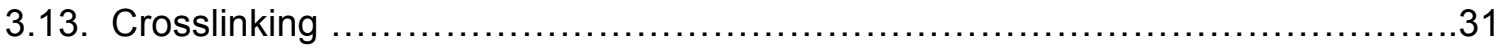

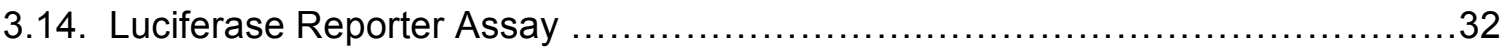

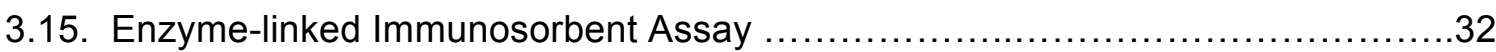

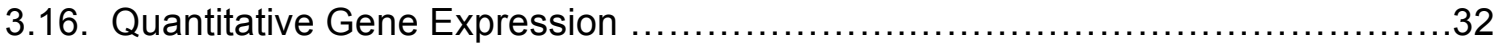

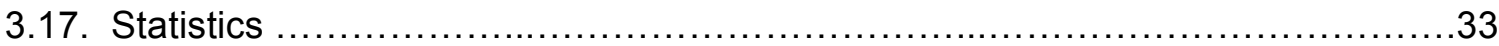

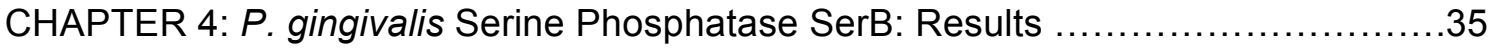

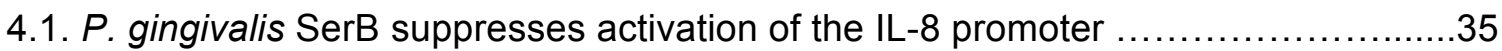

4.2. P. gingivalis SerB dephosphorylates the NF-кB p6 subunit......................37

4.3. SerB is produced and secreted by intracellular $P$. gingivalis ............................40 
4.4. SerB directly binds to and dephosphorylates NF-к B p65

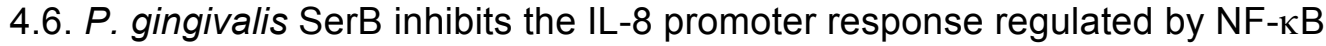
p65. .65

CHAPTER 5: P. gingivalis Tyrosine Kinase-1: Results 71

5.1. PGN_1524 is a Bacterial Tyrosine (BY) kinase present in P. gingivalis ... 71

5.2. P. gingivalis tyrosine phosphatase, Ltp1, dephosphorylates Ptk1 .76

5.3. Ptk1 is required for optimal $P$. gingivalis-S. gordonii community development .....82

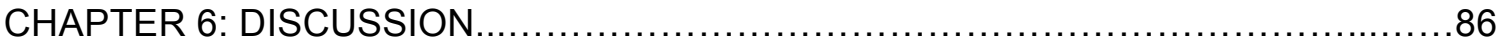

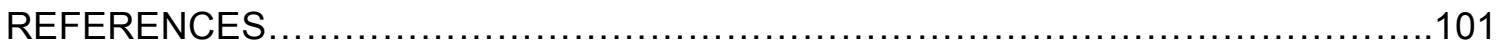

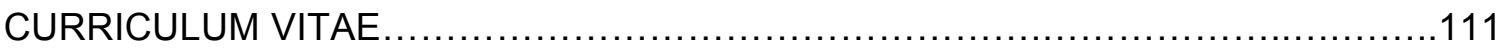




\section{LIST OF FIGURES}

1. Infection of TIGK cells with $P$. gingivalis expressing SerB reduces IL-8 promoter activity

2. Infection of TIGK cells with $P$. gingivalis expressing SerB diminishes phosphorylation of NF-KB p65 .38

3. TIGK cells infected with $P$. gingivalis expressing SerB show presence of SerB in cytoplasm of TIGKs

4. Ectopically expressed SerB binds to and dephosphorylates NF-кB p65

5. P. gingivalis SerB dephosphorylates NF-кB p65 but not $\mathrm{p} 105$

6. Effects of ectopic expression of SerB on the phosphorylation of NF-kB p65

S276. .56

7. Effects of ectopic expression of SerB on the phosphorylation of NF-кB p65

S468. .58

8. P. gingivalis SerB inhibits nuclear translocation of NF-kB p65 but not p105/p50

9. SerB dephosphorylation of NF-кB p65 inhibits IL-8 promoter activity and IL-8

production. .67

10. Ptk1 demonstrates substrate- and auto- phosphorylation .73 
11 qRT PCR of Ptk1 mRNA expression in P. gingivalis + S. gordonii compared to

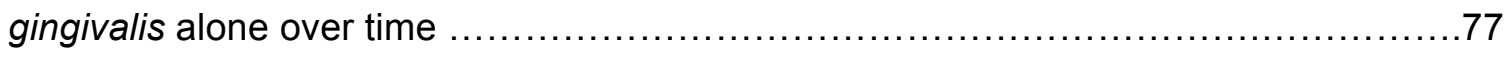

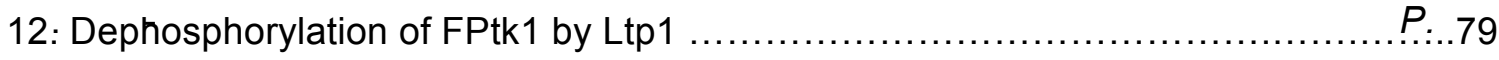

13. Ptk1 is required for maximal $P$. gingivalis-S. gordonii community development

14. Rudimentary model of $P$. gingivalis-S. gordonii signaling related to community development and community pathogenicity 99 


\section{LIST OF TABLES}

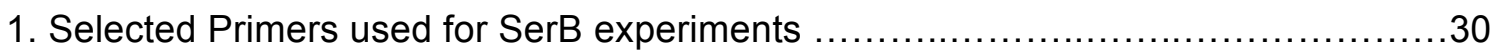

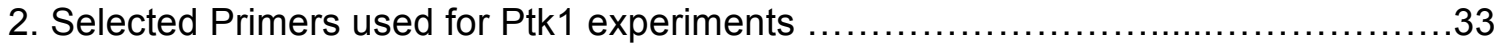




\section{CHAPTER 1}

\section{INTRODUCTION}

\subsection{Periodontal Diseases}

Periodontal diseases encompass a large spectrum of chronic, oral inflammatory conditions resulting from the interplay between the dysregulation of the host inflammatory response and the actions of a dysbiotic bacterial community. Epidemiological studies of periodontitis have identified numerous risk factors, both environmental and genetic; some of which include smoking, poor oral hygiene, stress, genetics, and defects in the host immune response. Periodontal diseases are purportedly the 6th most common condition affecting persons on a worldwide scale [1]. Periodontitis is the more severe clinical manifestation of periodontal diseases and can be classified into 2 distinct forms, chronic and aggressive. Chronic periodontitis is the most common form seen within all populations, usually presenting in individuals over 35 years of age. Periodontal diseases are now more accurately described as bacterial community based opportunistic infections [2]. The bacterial component is mediated by multispecies plaque biofilms which exist in the subgingival crevice of the oral cavity. The oral biofilm that develops on tooth surfaces, colloquially known as dental plaque, is an exemplar of a mixed microbial community. Oral biofilms can contain over 700 bacterial phyla [3]. A populational shift toward inflammophilic and tissue-destructive anaerobes increases the pathogenic potential of the community [4]. In the context of a pathogenic community, the oral organism most strongly implicated in chronic periodontitis is Porphyromonas gingivalis. However, the pathogenicity of $P$. gingivalis is only expressed in the context of a multispecies community (discussed further below). Periodontitis directly affects all tissues of the periodontium, more specifically, the alveolar bone, gingiva, and the periodontal ligament (PDL). Chronic damage to these 
supporting structures leads to tissue destruction, loss of tooth support, loss of alveolar bone and eventual tooth exfoliation.

\subsection{Periodontitis and the Systemic Health Connection}

The prevalence of periodontitis and its close association with systemic diseases certainly underscores the clinical significance of these chronic conditions. A recent review of the literature estimates there are 57 different systemic disease conditions actively being studied in relation to their association with periodontal diseases [5]. Some of the more frequently referenced conditions include diabetes mellitus, atherosclerosis, metabolic syndrome, preterm low birthweight babies, Alzheimers, coronary heart disease, stroke, pulmonary complications, and cancer [6] [7] [8] [9]. A mechanistic underpinning to this systemic connection is provided by findings that periodontal pathogens can cause an imbalance in the amounts and types of inflammatory mediators present within the host, thereby dismantling the normal inflammatory response of the host to infection [10] [11] [12]. A recent study has proposed that the shift towards the presence of more proinflammatory mediators is a potential reason linking periodontal disease and Alzheimers disease [13].

There is growing epidemiological evidence for an association between $P$. gingivalis and oral squamous cell carcinomas (OSCC) [14] [15]. Recent studies have shown a strong positive association between periodontal disease and the risk of developing oral, lung and pancreatic cancers [16] [17]. OSCC surfaces have been reported to harbor significantly higher levels of Porphyromonas and Fusobacterium compared with contiguous healthy mucosa [18]. Immunohistochemistry with $P$. gingivalis antibodies revealed higher levels of detection and intensity of staining in gingival carcinomas compared with healthy gingival tissue [19]. In addition to disruption 
of the inflammatory microenvironment, $P$. gingivalis can have direct effects on epithelial cells that affect cell cycle and cell survival. Suppression of apoptosis is discussed further below, and $P$. gingivalis can also accelerate progression through the S-phase of the cell cycle by manipulation of cyclin/CDK (cyclin-dependent kinase) activity and reducing the level of the p53 tumor suppressor [20]. One study reported that infection of gingival epithelial cells by $P$. gingivalis led to downstream activation of the beta-catenin signaling pathway [21]. Interestingly, this beta-catenin pathway is one of the key pathways involved in controlling cell proliferation and tumorigenesis. Infection of gingival epithelial cells with $P$. gingivalis induces expression and nuclear localization of the ZEB1 transcription factor, which controls epithelial-mesenchymal transition [22]. ZEB1 levels were directly associated with an increase in the expression of mesenchymal markers, in particular, vimentin and MMP-9, and also with enhanced migration of epithelial cells into matrigel.

Recent research has also unveiled a role for periodontitis in autoimmune diseases. One study investigating the connections between Rheumatoid Arthritis and $P$. gingivalis found that $P$. gingivalis possesses a unique ability to citrullinate host proteins in periodontal lesions, thereby making these proteins into targets for the host immune system [23]. This potential role of periodontitis in the generation of host antigens targeted by the host immune system is supported by research which has identified the presence of citrullinated histone H3 proteins found in inflamed periodontal tissues [24].

Additionally, possible associations between periodontal disease and Parkinson's disease are also being investigated based on the premise that systemic inflammation is believed to be a central component responsible for the pathogenesis and progression of Parkinson's disease [25].

The periodontal-systemic health connection has clinically significant implications for the population as a whole, and is rapidly becoming an important public health issue 
for the geriatric population as well. The prevalence of most chronic conditions that afflict the elderly, including periodontal diseases, increase with age [26]. Similarly, disease severity also increases with age and thus in older populations, periodontal diseases can have even more detrimental consequences in terms of their potential to contribute to or exacerbate systemic diseases.

\subsection{Porphyromonas gingivalis}

$P$. gingivalis is a gram-negative, assacharolytic black pigmented anaerobe. A secondary colonizer of subgingival plaque biofilms, $P$. gingivalis has an obligate requirement for iron in the form of hemin for growth, and possesses several hemin acquisition and storage systems with different activities and affinities [27]. $P$. gingivalis is best known for its role in periodontal diseases, as it is strongly implicated as a key periodontal pathogen in chronic and more severe manifestations of periodontal diseases [28-31]. $P$. gingivalis is a host-adapted opportunistic pathogen whose primary niche is the subgingival crevice of the oral cavity. Normally the host maintains a comfortable homeostatic balance between the host cells and microbial species. $P$. gingivalis, however, can disrupt this equilibrium, resulting in a dysbiotic host-microbiota interaction [32-34].

Contributions from both the host as well as the resident microorganisms are essential for transitioning of $P$. gingivalis-containing communities from commensal to pathogenic. $P$. gingivalis has the potential to express a wide array of virulence factors all of which contribute to its ability to effectively disrupt the host innate immune response and thus in turn, facilitate survival and persistence. One of the first host cells encountered by $P$. gingivalis are the gingival epithelial cells (GECs) of the oral cavity found deep within the subgingival crevice. P. gingivalis effectively and efficiently invades these epithelial cells and localizes in the perinuclear area [35]. Not only can this 
pathogen invade GECs but it can also spread intercellularly amongst them [36]. The $P$. gingivalis-epithelial cell interface is comprised of a dynamic interplay of events. During initial contact between $P$. gingivalis and GECs, the major fimbriae of $P$. gingivalis, FimA, mediates adhesion through $\beta 1$ integrin receptors $[37,38]$. During the process of invasion, key changes are evident within the epithelial cells including, induction of actin rearrangements, as well as activation of JNK kinases and conversely, the inactivation of ERK kinases [39]. Following invasion, inhibition of interleukin-8 (IL-8) production by GECs is also evident and this strategy has been coined "localized chemokine paralysis" $[40,41])$. Complete internalization of $P$. gingivalis occurs within 20 minutes. Once internalized within epithelial cells, $P$. gingivalis utilizes all resources at its disposal in order to subvert the host immune surveillance and begin reprogramming the circuitry of the host cell signaling pathways, as well as modulating gene expression to further its own persistence and survival $[42,43]$. P. gingivalis manipulation of epithelial cell signaling pathways is carried out by only a limited number of proteins, primarily the FimA-component fimbriae and the serine phosphatase SerB (discussed further below). In contrast, many other intracellular pathogens often rely on a much larger number of effector proteins to accomplish this same task. Legionella pneumophila, an intracellular pathogen, utilizes an array of effector molecules to infect and survive within amoebae along with human phagocytic and non-phagocytic cells. Legionella pneumophila primarily uses the Dot/Icm type IV secretion system to translocate these effectors into host cells, which then function to establish membrane-bound replication vacuoles through subversion of host process including vesicle trafficking, ubiquitylation, and lipid metabolism [44]. Legionella pneumophila injects approximately 300 effector proteins into host cells to facilitate the subversion and evasion of host cell signaling pathways [45]. Not only do these effector molecules represent more than $10 \%$ of the entire proteinencoding genome of L. pneumophila, but they also establish Legionella as the gram- 
negative pathogen equipped with the largest supply of effector molecules [46]. While other intracellular pathogens may not have as large a number of effector proteins at their disposal as is seen with Legionella, many species still have a far greater number than those used by $P$. gingivalis. Consider for a moment Salmonella enterica, subspecies serovar Typhimurium. S. typhimurium can adhere to and invade the microfold cells of the epithelium in the distal part of the ileum. Coordination of this multi-step process is carried out by a minimum of 30 different effector proteins which are secreted into host cells via two distinct type III secretion systems that are encoded on Pathogenicity Islands 1 and 2 [47].

Another important feature is the capacity for $P$. gingivalis to suppress apoptosis in GECs [48-50]. In primary cultures of gingival epithelial cells, $P$. gingivalis is strongly anti-apoptotic and, indeed, can suppress chemically induced apoptosis [49]. $P$. gingivalis activates Jak1/Akt/Stat3 signaling that controls intrinsic mitochondrial apoptosis pathways [51]. At the mitochondrial membrane, the activity of pro-apoptotic Bad is inhibited, and the Bcl2 (anti-apoptotic):Bax (pro-apoptotic) ratio is increased, consequently curtailing the release of the apoptosis effector cytochrome c [52]. Remarkably, $P$. gingivalis possesses multiple mechanisms for inhibition of apoptosis in epithelial cells. Expression of microRNAs (miRs) is modulated, and up-regulation of miR203 leads to inhibition of the negative regulator SOCS3 and subsequent suppression of apoptosis [53]. P. gingivalis secretes a nucleoside diphosphate kinase (NDK), which can function as an ATPase and prevent ATP-dependent apoptosis mediated through the purinergic receptor $\mathrm{P} 2 \mathrm{X} 7$ [50]. The Ndk enzyme also confers protection to $P$. gingivalis against reactive oxygen species by raising levels of glutathione. 


\subsection{P. gingivalis Specific Virulence Factors}

$P$. gingivalis is well equipped with a multitude of virulence factors, all of which have the potential to contribute to colonization and to periodontal tissue destruction. Collectively these virulence factors help $P$. gingivalis in a variety of ways that include attachment to host surfaces, survival in the oral cavity, tissue destruction and disruption of immune surveillance, to name a few. Some of the more well studied virulence factors include lipopolysaccharide (LPS), outer membrane vesicles, capsule, fimbriae, hemagglutinins and cysteine proteases.

Fimbriae are protein filaments found protruding from the cell surface of $P$. gingivalis. These filamentous structures are critical elements involved in mediating attachment of $P$. gingivalis to host tissues and other bacteria. They are also a necessary requirement for intracellular invasion. For successful adhesion and invasion into host cells, $P$. gingivalis possesses two types of fimbrial structures, commonly referred to as its major and minor fimbriae, FimA and Mfa1. These fimbriae are genetically distinct but exhibit similar structural properties.

The major fimbriae, comprised of the FimA (41 kDa) structural subunit, are long, peritrichous structures. FimA fimbriae mediate attachment to a number of host surfaces and stimulate expression of various inflammatory cytokines such as TNF, IL-6 and IL-1, in epithelial cells, monocytes, macrophages and endothelial cells [54]. The Mfa fimbriae mediate attachment to other oral biofilm bacteria [55], and contribute to auto-aggregation and monotypic biofilm formation [56, 57]. Mfa1 can also selectively engage the dendritic cell (DC) C-type lectin DC-SIGN, leading to evasion of antibacterial autophagy and lysosome fusion, and intracellular persistence in myeloid DCs [58], properties that may contribute to survival in vivo. 
A well-studied example of the important role fimbriae play is exemplified by the coadhesion events that take place between $P$. gingivalis and $S$. gordonii. Binding is effectuated by two sets of interacting adhesins involving streptococcal surface proteins and the major and minor fimbriae of $P$. gingivalis. Glyceraldehyde-3-phosphate dehydrogenase (GAPDH), while primarily a cytoplasmic enzyme, is also expressed on the streptococcal surface where it binds the FimA-subunit fimbriae of $P$. gingivalis [59]. The minor Mfa1-subunit fimbriae engage the SspA/B streptococcal surface proteins [57]. Interaction of the Ssp and Mfa1 proteins is required for the subsequent accumulation of S. gordonii and $P$. gingivalis into heterotypic communities [60].

Lipopolysaccharides (LPS) are lipoglycans found in the outer membrane of gramnegative bacteria. These consist of a polysaccharide, composed of an O-antigen, and an outer core and inner core, which is covalently attached to a lipid. P. gingivalis LPS plays a significant role in the pathogenesis of periodontal disease. The LPS of $P$. gingivalis is structurally unique even among other gram-negative bacterial species. Studies have shown that $P$. gingivalis can actively switch between various structural forms of its Lipid A component based on local environmental cues related to inflammation that are received in the form of hemin concentrations. Moreover, this heterogeneous pool of Lipid A structures from which $P$. gingivalis can choose from, each affect the Toll-Like Receptor (TLR) proteins differently [61]. Select isoforms of $P$. gingivalis LPS directly activate osteoclasts, stimulate the expression of a number of proinflammatory cytokines including TNF, IL-6 and IL-1 $\beta$, and strongly activates complement. These pro-inflammatory cytokines can contribute to periodontal tissue destruction. Animal studies have shown $P$. gingivalis LPS to be a potent stimulator of pro-inflammatory responses as well as the alveolar bone resorption processes [62]. Moreover, the LPS of $P$. gingivalis has been shown to neutralize the stimulatory effects of LPS from other bacterial species [63]. P. gingivalis can produce various isoforms of its 
LPS which differ structurally in their Lipid A cores and O-antigen regions [64]. These variations can modulate the host inflammatory response to $P$. gingivalis infection [65]. $P$. gingivalis expresses two major forms of its Lipid A component through differences in acylation patterns: tetra-acylated and penta-acylated. The penta-acylated form activates TLR4 and when hemin concentrations are high, this form will change into the tetraacylated form [66]. Conversely, this tetra-acylated Lipid A acts as a TLR4 antagonist. The opposing actions that are evident between these two Lipid A structures and their effects on TLRs seems fitting for $P$. gingivalis which prides itself in its selective dysregulation of the host immune response to ensure its survival. $P$. gingivalis produces a second type of LPS known as anionic or A-LPS. A-LPS is a phosphorylated branched mannan [67], that is attached to many proteins translocated through the type IX secretion system (T9SS), thus anchoring them to the bacterial surface [68]. A mutant unable to incorporate A-LPS into T9SS substrates is less virulent in a mouse subcutaneous infection model [69]

Gingipains are yet another important aspect of $P$. gingivalis virulence. These enzymes play important roles in bacterial housekeeping and infection. Gingipains are trypsin-like cysteine proteases secreted by $P$. gingivalis. These proteases have been shown to play roles in $P$. gingivalis invasion, biofilm formation, evasion of host immune response, amino acid uptake from host proteins and fimbriae maturation [70]. Recent studies have proposed these gingipains may be involved in various systemic pathologies [71]. P. gingivalis secretes 3 separate but related cysteine proteases. Two of these enzymes are specific for cleaving after arginine residues and the third enzyme cleaves after lysine residues. These versatile proteases are capable of digesting a large variety of host proteins which in turn provide $P$. gingivalis with necessary nutrients for growth. These gingipains are responsible for as much as $85 \%$ of the proteolytic activity in $P$. gingivalis [72]. 
The capsular polysaccharide (CPS; capsule) or $\mathrm{K}$-antigen of $P$. gingivalis is another major virulence factor which contributes to its pathogenicity. While not all $P$. gingivalis strains are encapsulated, those that do contain a capsule have been shown to be much more systemically invasive and demonstrate higher levels of resistance to phagocytosis [73]. Additionally, encapsulated strains have demonstrated the ability to incite a strong systemic lgG antibody response [74].

\subsection{Polymicrobial Communities}

In vivo, $P$. gingivalis is unlikely to cause disease individually, but rather in the context of a polymicrobial community in which the microbial constituents engage in synergistic interactions. Many organisms have evolved to live in polymicrobial communities where they flourish among other neighboring constituents. This is primarily because these organisms often derive greater benefits from this community lifestyle compared to living separately. This illustrates the idea of polymicrobial synergy. Each individual biofilm resident working in concert to elevate the overall pathogenic potential of the community as a whole. Communities of $P$. gingivalis and $S$. gordonii have demonstrated pathogenic synergism in a murine model of alveolar bone loss [75]. This polymicrobial synergy can also apply to the metabolic needs of organisms as well. For example, P. gingivalis and T. denticola display synergistic pathogenicity in murine models of periodontal disease [76]. The amino acid glycine is utilized as a major carbon source by $T$. denticola and is rapidly metabolized into acetate and lactate. $P$. gingivalis is an important source of free glycine [77]. Moreover, T. denticola has been shown to produce succinic acid that is used by $P$. gingivalis and incorporated into its lipids and phospholipids and important for growth stimulation [78]. In contrast, other polymicrobial communities exhibit antagonistic relationships such as those seen between $P$. gingivalis and Streptococcus cristatus. $S$. 
cristatus produces arginine deiminase which inhibits the synthesis of the $P$. gingivalis FimA adhesin protein [79]. The dynamics at play in these polymicrobial microenvironments, both synergistic and antagonistic interactions, undoubtedly influence the overall pathogenicity of the resident biofilm. And as such, this directly impacts the "nososymbiocity" or disease causing potential of the biofilm as a whole [30]. This is a significant factor in treatment and prevention of human disease considering that the majority of skin and mucosal surfaces in humans are predominantly covered in bacterial biofilms.

\subsection{Gingival Epithelial Cells (GECs)}

The epithelial tissue covering the external surface of the gingiva plus the epithelium lining the junctional epithelium and gingival sulcus, are collectively known as the gingival epithelium of the oral cavity. The gingival epithelium can be identified as 3 separate histological regions: the oral epithelium, sulcular epithelium, and junctional epithelium. The oral epithelium establishes the primary barrier separating the oral environment from the deeper tissues. This epithelium is comprised of tightly attached epithelial cells organized into multiple layers. The oral epithelium is stratified squamous in shape, featuring keratinized as well as non-keratinized areas. Keratinized areas are primarily found on the hard palate and gingiva. Non-keratinized areas include buccal mucosa, soft palate and the floor of the mouth. Gingival epithelial cells have been used successfully for many years as an important study tool for investigating the interaction between oral bacteria, namely periodontal pathogens, and human host cells in vitro. The epithelial cells lining the gingival compartment are one of the first cells to make contact with the oral bacteria, both commensal and pathogenic species. These cells provide important mechanical barriers to microbial invasion, in addition to functioning as key 
sensors of host infection and respond accordingly via expression of various chemical signals. For these reasons, GECs have been used extensively for research purposes as they have proven to be a reliable and accurate study tool for unveiling the intricacies and dynamics of the microbial-host interaction [80-85]. $P$. gingivalis rapidly internalizes within GECs, remaining viable for extended periods of time. The initial step involved in internalization begins with the $P$. gingivalis FimA fimbriae mediated attachment to the ß1-integrin receptors found on the GEC cell surface. This results in subsequent recruitment and activation of the host cell integrin focal adhesion complex. Concomitantly, $P$. gingivalis secretes the serine phosphatase SerB which is able to enter host cells and directly act on the host cell actin depolymerizing molecule cofilin. SerB dephosphorylates cofilin which leads to its activation. This transient and localized disruption in the host cell actin structure facilitates the intracellular entry of $P$. gingivalis. GEC integrin-dependent signaling intersects with cytoskeletal remodeling and thus can restore the overall actin structure. Once internalized, $P$. gingivalis rapidly localizes in the host cell cytoplasm and can also spread intercellularly via autophagosome trafficking $[86,87]$. Intracellular $P$. gingivalis are notorious for their fast acting approach once having gained entry into host cells. GEC infection by $P$. gingivalis results in marked progression through the stages of the cell cycle as well as suppression of apoptosis. As mentioned above, $P$. gingivalis also activates various anti-apoptotic pathways within GECs. The long term co-existence of $P$. gingivalis within GECs gives rise to many subtle yet complex interactions that can directly impact innate immune status.

Our model cell line used for all study experiments were telomerase immortalized gingival epithelial cells (TIGKs). These were generated by immortalization of primary gingival epithelial cells with bmi1/hTERT (Bodnar et al., 1998). 


\subsection{Protein Phosphorylation}

Regulation of protein activity, as orchestrated by the tightly co-ordinated and balanced dynamics between kinases and phosphatases, is one of the critical determinants of normal cellular growth and development. While the addition or removal of phosphoryl groups to/from serine, threonine or tyrosine residues has long been established as one of the predominant mechanisms of post-translational protein modification in eukaryotes, it was not until the 1970s that landmark studies demonstrated its importance in prokaryotes [88]. The first characterized phosphorylation systems in prokaryotic organisms were the two component systems (TCS) and the phosphotransferase system (PTS) [89]. In the basic configuration of TCS, a surface-exposed sensor kinase is first autophosphorylated in response to an external signal. The phosphoryl group is then transferred to the aspartyl residue of a response regulator, which in turn can modulate gene expression. In this manner, signal transduction is effectuated by phosphate flow. TCS are widespread in bacteria, and they control the response to a wide range of environmental stimuli. Remarkably, any one organism can possess up to 50 functionally isolated systems. In another phosphorylation system, the PTS system, a phosphoryl group from Phosphoenol Pyruvate is transferred along a chain of proteins by reversible phosphorylation of histidine residues. The final receptor for the phosphoryl group is a sugar; hence, the PTS is involved in carbohydrate uptake rather than signal transduction.

\section{7.a. Serine/Threonine Phosphorylation}

Bacterial serine/threonine specific phosphorylation as a post-translational modification is now known to be ubiquitous and is involved in a diverse array of physiological processes including secondary metabolism, catabolite repression, oxidative stress responses and 
sporulation [90]. Serine/threonine kinases and phosphatases are also involved in bacterial virulence, in particular through their action on host cell substrates. For example, the YpkA/YopO kinase of Yersinia species is delivered into epithelial cells by type III secretion machinery, whereupon it disrupts actin microfilament structure [91]. Two autophosphorylated Ser/Thr protein kinases, NleH1 and $\mathrm{NleH} 2$, in enterohemorrhagic Escherichia coli, and the OspG protein in Shigella flexneri, inhibit activation of the pro-inflammatory transcription factor NF-KB $[92,93]$. The secretion of serine kinases and/or phosphatases has thus afforded bacterial pathogens the means to interfere with host signal transduction pathways.

\section{7.b. Tyrosine Phosphorylation}

The first definitive evidence of protein tyrosine kinase activity in bacteria was discovered in E. coli with the identification of phosphotyrosine in partial acid hydrolysates of proteins [94]. Protein tyrosine phosphorylation subsequently was shown to direct many essential cellular processes, such as capsule production, growth, proliferation, migration, flagellin export, adaptation to stress and production of secondary metabolites. Moreover, the addition of a bulky, negatively charged phosphoryl group to a protein can influence both cellular location and the overall protein interactome [95]. A number of global phosphoproteome studies have now been conducted in bacteria, including Escherichia coli, Helicobacter pylori, Bacillus subtilis, Streptomyces coelicolor, Mycoplasma pneumoniae, Streptococcus pneumoniae, Klebsiella pneumoniae, Lactococcus lactis, Campylobacter jejuni and Pseudomonas species [96-106]. These databases have shown an increasing number of bacterial proteins that are phosphorylated on Ser/Thr/Tyr residues; and, moreover, these proteins are involved in a variety of important cellular functions, including virulence and cell survival. 


\subsection{Bacterial Tyrosine Kinases}

\section{8.a. Structure}

The bacterial tyrosine (BY) kinase family comprises the major group of bacterial enzymes endowed with tyrosine kinase activity. In most cases, BY kinases possess a transmembrane domain that can function both as an anchor and a sensor, as well as an intracellular catalytic domain [107]. The catalytic domain lacks the distinctive eukaryotic kinase motifs, and is defined by the presence of Walker A (P-loop) and B motifs. In addition, some BY kinases also contain a Walker $A^{\prime}$ motif. BY kinases autophosphorylate at a tyrosine rich cluster in the C-terminal region using adenosine triphosphate as a phosphoryl donor, and the degree of phosphorylation in this region determines the interaction strength with other proteins. Some BY kinases also autophosphorylate on a tyrosine residue in close proximity to the Walker $A^{\prime}$ box. Recent studies have identified other bacterial tyrosine kinases including those that closely resemble eukaryotic-like kinases, and those that utilize guanidino-phosphotransferase domains [107]. Additionally, in some cases, tyrosine can substitute for histidine in TCS.

\section{8.b. Function}

The majority of genes encoding BY kinases reside in operons responsible for regulating the synthesis and secretion of polysaccharides. The autophosphorylation state of the BY kinases exerts control over this process through phosphorylation, and activation, of UDP-sugar dehydrogenases and glucosyltransferases [95]. The extensive phosphotransfer reactions can also modulate a myriad of physiological processes that include resistance to cationic peptides and polymixin, along with heat shock responses. A greater appreciation for the role of tyrosine kinases in prokaryotes has emerged from 
the application of global phosphoproteome technologies. For example, the PtkA BY kinase of Bacillus subtilis can phosphorylate at least nine different protein substrates [108]. Several of these substrates, most notably single-stranded DNA exonuclease York and aspartate semialdehyde dehydrogenase Asd, are activated via phosphorylation. Yet, the activity of many others, such as enolase, YjoA, YnfE, TvyG, Ugd and SsbA, remain unaffected by phosphorylation, and rather the cellular localization of these proteins is governed by phosphorylation status. Hence, BY action can not only regulate the activity of substrates, but also ensure the correct cellular localization of specific protein targets.

\section{8.c. P. gingivalis Tyrosine Kinase-1 (Ptk1)}

Previous studies discovered that the P. gingivalis protein PGN_1524 exhibited homology to a tyrosine kinase $[55,109]$. This predicted tyrosine kinase was later confirmed and as the protein was named P. gingivalis tyrosine kinase-1 (Ptk1). Ptk1 was found to contain a cytoplasmic active domain spanning amino acid residues 541-821. Early investigations of this bacterial tyrosine kinase revealed it was involved in community development with the oral commensal organism, Streptococcus gordonii; however the function of the Ptk1 enzyme is unknown.

\subsection{Bacterial Tyrosine Phosphatases}

\section{9.a. Structure}

Bacterial tyrosine phosphatases catalyze the dephosphorylation of tyrosyl phosphorylated proteins, which in turn can result in either the propagation or inhibition of phospho-dependent signaling. Bacterial tyrosine phosphatases can be categorized into 
three distinct families: (i) the eukaryotic-like phosphatases (PTPs) and dual-specific phosphatases that also display activity against phosphoserine and phosphothreonine; (ii) the low molecular weight protein-tyrosine phosphatases (LMW-PTPs), a family of small acidic enzymes also found in eukaryotes; and (iii) the polymerase-histidinol phosphatases (PHP), a family of phosphoesterases commonly found in Gram-positive bacteria. The PTP, dual-specific phosphatase and LMW-PTP enzymes utilize a common catalytic mechanism that involves the conserved signature $C(X) 5 R$ motif in the phosphate binding loop where cysteine, functioning as a nucleophile, attacks the phosphorus atom of the phosphotyrosine residue of the substrate. The arginine residue interacts with the phosphate moiety of the phosphotyrosine [110]. This motif is flanked, more remotely, by an essential aspartic acid residue, the location of which varies among the families. Protein tyrosine phosphatases are also capable of possessing dual functions, whereby, they can stimulate actions of cognate protein tyrosine kinases, yet in other cases, they may antagonize those actions $[111,112]$. In Gram-negative bacteria, the gene encoding the LMW-PTP generally is upstream of the tyrosine kinase in the same operon. Conversely, in gram-positives, a PHP type phosphatase often is located in the same operon as the BY kinase alongside an adaptor protein, with the gene for the LMW-PTP at a remote site.

\section{9.b. Function}

While bacterial tyrosine phosphatases can be intimately involved in a number of cellular processes, two major themes have become apparent: involvement in polysaccharide production; and as secreted effector proteins with the potential for manipulation of host cell signal transduction pathways. Polysaccharide production, encompassing both exopolysaccharides and capsular polysaccharides, is also a key virulence determinant in 
many organisms and thus tyrosine phosphatase activity is emerging as a central player in the information flow that controls pathogenic activity. Any type of tyrosine phosphorylation activity could prove to be a critical factor in the way an organism regulates its pathogenic mechanisms. A number of BY kinases have been studied previously and found to be involved in production and transport of extracellular polysaccharide [112]. For example, in E. coli, the Wzc BY kinase, regulated by its cognate phosphatase, sits in the membrane and is involved in Group 1 capsule biosynthesis [113]. The majority of BY kinases studied to date regulate the production and export of both extracellular and capsular polysaccharide. The interplay between bacterial tyrosine kinases and their cognate phosphatases confers major advantages in terms of allowing organisms to gain exquisite regulatory control over polysaccharide production based on constantly changing environmental conditions.

The YopH protein tyrosine phosphatase of Yersinia, a member of the PTP family, is an essential virulence factor that is injected into epithelial cells by type III secretion machinery. YopH can uncouple multiple signal transduction pathways [114] and in human epithelial cells, YopH dephosphorylates several focal adhesion proteins, including p130Cas (Cas), focal adhesion kinase and paxillin [115-117]. Similarly, Salmonella 'typhimurium' translocates the PTP tyrosine phosphatase SptP into epithelial cells where it is involved in reversing mitogen-activated protein kinase activation [118]. SptP is required for full virulence in murine models of disease [119]. Shigella flexneri produces a dually specific phosphatase, OspF, that dephosphorylates mitogen-activated protein kinase, which consequently prevents histone H3 phosphorylation [120]. A reduction in the level of histone 3 phosphorylation impedes access of the transcription factor NF-KB to the chromosome and hence transcription of NF-KB responsive genes such as IL-8 is reduced. Thus, OspF activity allows $S$. flexneri to modulate host cell 
epigenetic information as a strategy for repressing innate immunity. In addition to physical protection, exopolysaccharide (EPS) such as capsule is often poorly immunogenic and can mask protein antigens and receptors for complement and phagocytic cells. In many cases, dephosphorylation of tyrosine kinases increases the level of polysaccharide synthesis [90], as evidenced by the activity of the E. coli K-12 BY kinase Wzc-ca, which is regulated by its cognate LMW-PTP, Wzb [121]. In this system, production of the capsular exopolysaccharide colonic acid is maximal when Wzc-ca is dephosphorylated by Wzb. Similarly, in Streptococcus pneumoniae autophosphorylation of the CpsD kinase, when in the presence of its cognate partner, CpsC, results in the attenuation of CpsD kinase activity, as well as a reduction in the level of encapsulation via a negative feedback regulatory loop [122]. Undoubtedly, the interplay among tyrosine kinases, phosphatases and exopolysaccharide is of a nuanced and subtle nature that may be reconfigured according to environmental conditions. Indeed, metabolic activity is one factor that has been shown to influence kinase to phosphatase ratios.

\section{9.c. Role in Biofilms}

A recent study in Pseudomonas aeruginosa demonstrated that tyrosine phosphatase activity is a unifying element that amalgamates polysaccharide production and biofilm formation with quorum sensing [123]. The PTP family tyrosine phosphatase, TpbA, is a negative regulator of 3,5-cyclic diguanylic acid (c-di-GMP), an important second messenger which suppresses transcription across the pel operon that encodes for extracellular matrix polysaccharide. Lower levels of exopolysaccharide in turn lead to reduced biofilm formation. In addition, TpbA responds to acyl homoserine lactone, and $\operatorname{tpbA}$ is regulated positively by the LasR transcriptional regulator. TpbA also regulates cell lysis as a means to control extracellular DNA that is used for complex biofilm 
maturation [124]. These findings also reveal a previously unrecognized ability for phospho-dependent signaling to intersect with other important cellular second messenger systems.

Tyrosine phosphatases can also control heterotypic biofilm formation among oral organisms. $P$. gingivalis accumulates into heterotypic communities with the antecedent oral biofilm colonizer S. gordonii. In 2008, Maeda et al. identified a LMW-PTP, Ltp1, in P. gingivalis which functions as a negative regulator of EPS production, as well as community formation with S. gordonii. Transcription of Itp1 is increased following contact with S. gordonii [125], and Ltp1 is a component of a signaling pathway that converges on the LuxR family transcriptional regulator CdhR [126]. The expression of the $P$. gingivalis Mfa fimbriae and of LuxS, both of which contribute to community development with $S$. gordonii, are negatively regulated by CdhR. Thus, in both $P$. aeruginosa and $P$. gingivalis, tyrosine phosphatase activity results in arrested community development which may maintain optimal biofilm architecture.

\section{9.d. P. gingivalis Serine Phosphatase, SerB}

$P$. gingivalis SerB is the first serine phosphatase with a documented role in bacterial internalization [127]. SerB is a member of the Haloacid Dehalogenase (HAD) superfamily which is widespread in both prokaryotes and eukaryotes. The serine phosphatase SerB is vitally important for intracellular invasion and survival of $P$. gingivalis in gingival epithelial cells. P. gingivalis mutants deficient in SerB secretion were unable to internalize within epithelial cells nor were they able to survive intracellularly [127]. Studies have found that SerB is capable of inducing actin rearrangements in gingival epithelial cells [128]. Secretion of SerB by $P$. gingivalis facilitates invasion into epithelial cells through its activation of the host protein cofilin. It is established that infection of gingival epithelial cells with $P$. gingivalis results in the 
suppression of Interleukin-8 (IL-8) production by the host cells. This inhibitory process, being of central importance to the ability of $P$. gingivalis to disrupt the host innate immunity, is associated with the serine phosphatase SerB. Further study into the mechanistic basis for SerB dependent inhibition of Interleukin-8 is one of the primary subjects of this study.

\section{9.e. NF-кB Signaling}

The Nuclear Factor kappa B (NF-кB) family of related transcription factors plays a central role in regulating the host response to microbial infection. Additionally, NF-кB regulates hundreds of genes which are involved in a myriad of cellular processes, including modulation of inflammatory and host innate immune responses, apoptosis, cell

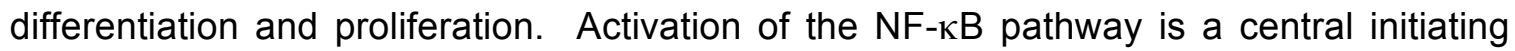
event for host responses to any type of microbial invasion [129-131]. A key feature of this pathway is that the active NF-kB complex can be comprised of homodimers or heterodimers of p65 and p50 subunits. It is the different combinations of these subunits that lead to the regulation of distinct sets of genes [132]. In this way, NF-кB affords cells the versatility necessary to actively adjust their biological response to the outside world through the activation or repression of large subset of genes [133]. Various stimuli trigger activation of the NF-KB pathway which starts with the IKK activation leading to phosphorylation, subsequent ubiquitination and ultimately the degradation of these IKB inhibitory proteins. The NF-KB complex normally remains sequestered in the cytoplasm by inhibitory $І \kappa B$ proteins. Once these $І \kappa B$ proteins become targeted for degradation,

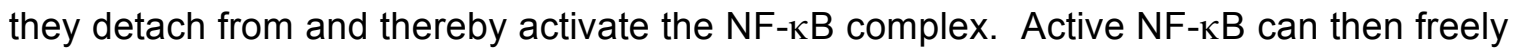
move to the nucleus to induce transcription of important genes. Previous research has 
found that the predominant control of IL-8 production is through the NF-KB p65 homodimers [134]. 


\section{CHAPTER 2}

\section{STUDY RATIONALE, HYPOTHESIS AND SPECIFIC AIMS}

Accumulating evidence reaffirms the notion that bacterial kinases and phosphatases

display exquisite functional specificity; nevertheless, they are still capable of utilizing multiple protein substrates, both endogenous and exogenous, thereby providing versatility in phosphorelay signaling networks. To further advance our knowledge of the role of the specific tyrosine kinase, Ptk1 and the serine phosphatase SerB, of $P$. gingivalis in the selective manipulation of both host cell and bacterial phosphorelay signaling networks, we proposed the following hypothesis and aims:

1. P. gingivalis uses its protein serine phosphatase, SerB to selectively target specific host cell proteins and thus directly interfere with normal epithelial cell signaling to disrupt the host innate immune response.

2. The $P$. gingivalis tyrosine kinase Ptk1 is actively involved in the interspecies signaling between $P$. gingivalis and $S$. gordonii which underlies their dual species development.

Specific Aim 1: To determine if $P$. gingivalis SerB is affecting the secretion of Interleukin-8 (IL-8) via modulation of the NF-kB pathway.

Specific Aim 2: To investigate the presence and role of $P$. gingivalis Ptk1. 


\section{CHAPTER 3}

\section{MATERIALS AND METHODS}

\subsection{Bacterial Strains, Eukaryotic cells and Growth Conditions}

P. gingivalis strain ATCC 33277 wild-type (WT) (obtained from the American Type Culture Collection), its isogenic mutant $\Delta$ serB, serB::FLAG, Ltp1 C10S, all Ptk1 mutant strains ( $\Delta p t k 1 \mathrm{WT}, \Delta p t k 1 \mathrm{~W} 83, \Delta p t k 1+p p t k 1)$ and W83 were maintained as frozen stock cultures and cultured anaerobically in trypticase soy broth (TSB) supplemented with hemin $(5 \mu \mathrm{g} / \mathrm{ml})$, menadione $(1 \mu \mathrm{g} / \mathrm{ml})$ and yeast extract $(1 \mathrm{mg} / \mathrm{ml})$ at $37 \mathrm{C}$. Mutant strains were available in the laboratory. For solid media, TSB was supplemented with $5 \%$ sheep blood and $1.5 \%$ agar. The serB::FLAG strain expresses a three tandem FLAG-tag sequence inserted at the C-terminal end of the SerB protein. Overnight cultures were grown to mid exponential phase (OD600 nm; approx. 0.7). When necessary, erythromycin $(10 \mu \mathrm{g} / \mathrm{ml})$ and tetracycline $(1 \mu \mathrm{g} / \mathrm{ml})$ were added to the media. S. gordonii strain DL-1 was cultured in brain heart infusion $(\mathrm{BHI})$ broth which contained $0.5 \%$ yeast extract. E. coli strains were grown aerobically with shaking at $37 \mathrm{C}$ in LuriaBertani Broth containing either kanamycin $(50 \mu \mathrm{g} / \mathrm{ml})$ or ampicillin $(100 \mu \mathrm{g} / \mathrm{ml})$ as needed. Our model cell line, telomerase immortalized gingival epithelial cells (TIGKs), were maintained in keratinocyte-SFM (K-SFM, serum free media) (Invitrogen) supplemented with $5 \mathrm{ng} / \mathrm{ml}$ of human recombinant epidermal growth factor and $50 \mu \mathrm{g} / \mathrm{ml}$ of bovine pituitary extract. For passage cells were washed twice with phosphate buffered saline (PBS) and then incubated with $0.05 \%$ Trypsin/0.53mM EDTA at $37 \mathrm{C}$ for $5-10$ min, at which point cells separated from the surface of the flask. K-SFM was added to cell suspensions to inhibit activity of Trypsin. Cells were centrifuged at $1000 \mathrm{rpm}$ for 5 min. Supernatant was then removed and the cell pellet was re-suspended in K-SFM and 
then reseeded at $1.0 \times 10^{6}$ cells/flask. Once $80 \%$ confluence was obtained, cells were used for experimentation.

\subsection{P. gingivalis-S. gordonii Communities}

S. gordonii $\left(2 \times 10^{8}\right.$ cells $)$ were stained with the nucleic acid staining compound, hexidium iodide $(15 \mu \mathrm{g} / \mathrm{ml})$ and then incubated on glass coverslips for $16 \mathrm{~h}$ in anaerobic conditions at 37 C. $P$. gingivalis cells were stained with $(5,6)$-carboxyfluorescein succinimidyl ester (FITC; Invitrogen). Approximately $2 \times 10^{7} \mathrm{P}$. gingivalis cells were reacted with $S$. gordonii labeled cells for $18 \mathrm{~h}$ in pre-reduced PBS in an anaerobic environment at $37 \mathrm{C}$ with rocking. The resulting heterotypic biofilm community was washed in PBS and then analyzed via confocal scanning laser microscopy using an Olympus FV500 confocal microscope. Digital reconstruction of the $\mathrm{X}, \mathrm{Y}$, and $\mathrm{Z}$ stacks was accomplished using the Volocity analysis program (Perkin Elmer). In order to quantify the volume of $P$. gingivalis present in the mixed biofilm communities, the Find Objects Algorithm in the Volocity program was used. Similarly, the Find Objects algorithm also allowed analysis of the microcolony formation from the $3 \mathrm{D}$ digital confocal images. A threshold for $3 \mathrm{D}$ objects greater than $30 \mu \mathrm{m}^{3}$ was set.

\subsection{Expression/Purification of Recombinant Proteins}

The C-terminal region of Ptk1, spanning amino acids 541-821, was amplified by using the primers, 1524pet200F and 1524pet200R (Table 2), to generate a product $850 \mathrm{bp}$ in length. This $850 \mathrm{bp}$ product was cloned into the expression vector pET200 (Invitrogen) to create pET200-Fptk1, which was then transformed into E. coli TOP10 cells (Invitrogen). Successful transformants were analyzed by colony PCR, and the correct 
insert was confirmed by sequencing. For protein purification, pET200-Fptk1 was transformed into the BL21 Star (Invitrogen) expression strain. N-dodecylphosphocholine detergent was used for solubilization and paramagnetic precharged nickel particles were used to isolate the histidine-tagged protein. The final purity of FPtk1 was determined by SDS-PAGE and Coomassie staining. Generation of recombinant Ltp1:C10S was accomplished by PCR amplification of the coding region of the catalytically inactive mutant Ltp1:C10S from the vector pTCOW-Ltp1:C10S [135] using the primers Ltp1C10SF and Ltp1C10SR (listed in Table 2). This recombinant protein was then cloned into the expression vector pET200. After sequencing, the expression vector containing Ltp1:C10S was transformed into BL21 Star and protein was purified with MagneHIS particles as described above. The purity of the resulting protein was determined by SDS-PAGE and Coomassie staining. The recombinant proteins Ltp1, PGN_0224, PGN_0613, and PGN_0261 were generated by PCR amplification of the total coding region from a $P$. gingivalis 33277 genomic template. Recombinant proteins were then cloned into the pET200 expression vector. Soluble protein was obtained as described above.

\subsection{Kinase Assay}

The Beacon Tyrosine kinase assay (Molecular Probes) was used to measure kinase activity. The catalytically active cytoplasmic fragment Ptk1:541-821 [55] was incubated with $0.5 \mathrm{mmol} / \mathrm{L}$ ATP and polyGlu:Tyr (4:1 ratio; $200 \mu \mathrm{g} / \mathrm{mL})$ for $15 \mathrm{~min}$. Following incubation, the level of fluorescence intensity was measured using a Victor X1 plate reader. 


\subsection{Immunoblotting}

TIGK cells were lysed, centrifuged, separated by SDS-PAGE, and transferred onto nitrocellulose membranes by electroblotting. Membranes were blocked with TBS containing Tween 20 (0.1\%), 1\% skim milk and 10\% bovine serum albumin (BSA) for $1 \mathrm{~h}$ at room temperature. Membranes were incubated for $1 \mathrm{~h}$ at room temperature with primary antibodies. All primary antibodies were first diluted in PBST (PBS + Tween 20). These membranes were then washed three times with PBST followed by a second incubation with a 1:5000 dilution of HRP-conjugated secondary antibodies in PBST for 1 $\mathrm{h}$ at room temperature. After this second round of incubation, the membranes were again washed three times in PBST. Pierce Enhanced Chemiluminescence (ECL) Western Blotting Substrate (Thermo Scientific) and the ChemiDoc XRS Plus (Bio-Rad) were used to detect the presence of immunoreactive bands. All images were acquired using Image Lab Software version 3.0 from Bio-Rad.

\subsection{Dephosphorylation Assay}

Both Ltp1 and the catalytically inactive mutant, Ltp1:C10S $(5 \mu \mathrm{g})$ [135]) were each preincubated with $5 \mu \mathrm{g}$ of the catalytically active fragment, Ptk1:541-821for $1 \mathrm{~h}$; after which standard immunoblotting procedures were carried out as described above. Membranes were blocked for $16 \mathrm{~h}$ with TBS containing $0.1 \%$ Tween-20 (TBST) and 10\% BSA. Membranes were then probed with phosphotyrosine antibodies (Clone PY20; SigmaAldrich; 1:1000 dilution) for $2 \mathrm{~h}$. The ChemiDoc XRS Plus imaging system (BioRad) was used to detect immunoreactive bands on the membranes. 


\subsection{Autophosphorylation Assay}

Five micrograms of the catalytically active fragment, Ptk1:541-821, were treated with 20 units of calf intestinal alkaline phosphatase in buffer for $1 \mathrm{~h}$ at $37 \mathrm{C} .0 .1 \mathrm{mmol} / \mathrm{L}$ ATP plus a phosphatase inhibitor cocktail (Sigma-Aldrich) were both added to the reaction for an additional 15 min prior to reactions being stopped. Reactions were quenched using equal volumes of 2x SDS-PAGE buffer and boiling for $10 \mathrm{~min}$. Immunoblotting of protein samples was carried out as described previously. Phosphotyrosine antibodies were reacted with membranes. The ChemiDoc XRS imaging system (BioRad) was used to detect levels of phosphorylation.

\subsection{Substrate Phosphorylation Assay}

Five micrograms of the catalytically active fragment, Ptk1:541-821, were incubated with $10 \mu \mathrm{g}$ of recombinant substrate. Similar to the autophosphorylation assay, ATP (5 mmols) and $0.5 \mu \mathrm{L}$ of phosphatase inhibitor cocktail were both added to the reaction mixture and incubated for $30 \mathrm{~min}$ at $37 \mathrm{C}$. Addition of 2x SDS-PAGE buffer and boiling for $10 \mathrm{~min}$ halted the reaction. Protein samples were analyzed by Western immunoblotting as described above.

\subsection{Antibodies \& Reagents for epithelial cell analysis}

Mouse monoclonal anti-Myc and mouse monoclonal anti- $\beta$ actin were obtained from Sigma-Aldrich. The following antibodies were obtained from Cell Signaling Technology: rabbit monoclonal anti-phospho-NFkB p65 S536, rabbit monoclonal anti-phospho-NFkB p105 S933, rabbit monoclonal anti-NFkB p105/p50, rabbit monoclonal anti-NF-kB p65 
S468, mouse monoclonal anti-NF-kB p65, and rabbit monoclonal anti-calnexin. Rabbit monoclonal anti- $\beta$ tubulin was obtained from Imgenex. The following antibodies were obtained from Invitrogen: mouse monoclonal anti-FLAG, Rhodamine Red-X-conjugated secondary antibody (goat anti-mouse lgG), Alexa Fluor 488-conjugated secondary antibody (goat anti-rabbit lgG). Rabbit polyclonal anti-NF-kB p65 S276 was obtained from Abcam. Horseradish Peroxidase (HRP)-conjugated secondary antibodies were obtained from Cell Signaling Technology. TNF was obtained from Pepro Tech and used for cell stimulation experiments. FITC-conjugated phalloidin obtained from SigmaAldrich was used for actin staining in fluorescent microscopy. $P$. gingivalis whole cell antibody and SerB antibodies were previously generated in the laboratory as described in Moffatt et al. (2012) and Hasegawa et al. (2008).

\subsection{Transient Transfection}

Plasmid constructs were available in the Lamont laboratory. In brief, PCR amplified serB from $P$. gingivalis was cloned into the vector pCMV-Myc (Clontech) using exogenously added EcoRI sites to generate a chimeric construct of Myc-SerB. GFPtagged NF-kB p65 was created from TIGK cDNA and inserted into the pAcGFP1-C1 vector (Clontech) using exogenously added Kpnl sites. A point mutation of GFP-tagged NF-kB p65 to S536D was introduced by overlapping fusion PCR. Again using TIGK cDNA, GFP-tagged NF-kB p105 was generated and inserted into the pAcGFP1-C1 vector using exogenously added EcoRI sites. GFP-tagged NF-kB p50 was constructed from amino acids 1 to 438 of NF-kB p105 and then subsequently cloned into the pAcGFP1-C1 vector. The plL-8 kB-Luc reporter plasmid was constructed according to the published sequence [134]. The enhancer sequence of IL-8 was cloned into the pGL4.23 vector (luc2/minP) (Promega) using exogenously added Kpnl and Nhel sites. 
All PCR products and mutations were confirmed by sequencing. For all transient transfections of TIGK cells, the FuGENE 6 Transfection Reagent was employed (Promega).

Primer sequences used in this study are listed in Table 1 below.

Table 1. Selected Primers used for SerB experiments

\begin{tabular}{ll}
\multicolumn{1}{c}{ Name } & \multicolumn{1}{c}{ Sequence } \\
\hline SerB-F & 5'-CCGGAATTCTTATGAGTACAACACGA-3' \\
SerB-R & 5'-CCGGAATTCCTATAATTTTTCCGTAAGCA- \\
NF-kB p65-F & 5'-CGGGGTACCATGGACGAACTGTTC-3' \\
NF-kB p65-R & 5'-CGGGGTACCTTAGGAGCTGATCTGACTC-3' \\
NF-kB p65 S536D-F5'-AGACTTCTCCGACATTGCGGACAT-3' \\
NF-kB p65 S536D-R5'-ATGTCCGCAATGTCGGAGAAGTCT-3' \\
NF-kB p105-F & 5'-CCGGAATTCTTATGGCAGAAGATGATCC- \\
3' NF-kB p105-R & 5'-CCGGAATTCCTAAATTTTGCCTTCTAGAGG- \\
3' NF-kB p50-R & 5'-CCGGAATTCAGTGTCCATGGTTCC-3' \\
IL-8 kB-F & 5'-CGGGGTACC(TGTGGAATTTCCGC)4GCTAGCTAG-3' \\
IL-8 kB-R & 5'-CTAGCTAGC(GCGGAAATTCCACA)4GGTACCCCG-3' \\
\hline
\end{tabular}

\subsection{Confocal Microscopy of TIGK cells}

TIGK cells were fixed with $3 \%$ paraformaldehyde in PBS for 30 min at room temperature. Cells were permeabilized with $0.1 \%$ Triton $\mathrm{X}-100$ in PBS for 5 min at room temperature and blocked with $0.1 \%$ gelatin in PBS for $20 \mathrm{~min}$ at room temperature. All primary antibodies and the Rhodamine Red-X-conjugated secondary antibodies were diluted 1:400 in PBS. For labeling of DNA, cells were mounted onto glass slides using Vectashield Mounting Medium with DAPI (obtained from Vector laboratories). Cells 
were examined using laser scanning confocal microscopy (Olympus FV500) and analyzed with FluoView Software.

\subsection{NF-кB Nuclear Translocation}

TIGK cells were transfected with either GFP-tagged NF-kB p65 or GFP-tagged phosphomimic-p65 S536D. This phosphomimic is a constitutively active construct mimicking the phosphorylated state and cannot be dephosphorylated. TIGKs were cotransfected with Myc-SerB. TIGKs underwent transient transfection for $36 \mathrm{~h}$ and were stimulated with TNF $(5 \mathrm{ng} / \mathrm{ml})$ for 30 min (unless otherwise indicated). All cells were collected and stained with DAPI and anti-Myc labels. Confocal microscopy was used to detect GFP and Myc tags. $>/=90$ GFP/Myc positive cells were counted in each condition.

\subsection{Crosslinking}

TIGK cells were cross linked with dithiobis $(0.25 \mathrm{mM}$; Thermo Scientific) in PBS for 5 min at room temperature. Cells were then rinsed with a quenching buffer composed of $1 \mathrm{M}$ glycine in PBS at a pH 7.4. Cells were washed in the quenching buffer 4 times after which the cell proteins were extracted using lysis buffer. An anti-c-Myc immunoprecipitation kit (Sigma-Aldrich) was used in pull down reactions using cell lysates, following the manufacturer's protocol. All proteins that bound to the anti-c-Myc agarose were analyzed by immunoblotting. 


\subsection{Luciferase Reporter Assay}

TIGK cells were transfected with pIL-8 kB-Luc, pRL-CMV Vector (Promega), along with other combinations of expression plasmids. The total plasmid amounts for each transfection were normalized. TIGK cells were first lysed and then reporter activity was measured using the Dual-Glo Luciferase Assay System (Promega). Firefly luciferase activity was normalized to Renilla luciferase activity in the same extracts.

\subsection{Enzyme-linked Immunosorbent Assay (ELISA)}

A sandwich ELISA was used to measure Interleukin-8 (IL-8) concentrations in TIGK cell culture supernatants. The Quantikine Human CXCL/IL-8 kit by R\&D Systems was used according to the manufacturer's protocol.

\subsection{Quantitative Gene Expression}

P. gingivalis cells were reacted with $S$. gordonii or with PBS under anaerobic conditions for $1 \mathrm{~h}$. Total RNA was extracted using Trizol (Invitrogen). Extracted RNA from each of the samples was treated with DNase I. RNA template (20 ng) was converted to cDNA using the high capacity reverse transcription Kit from Applied Biosystems. Quantitative RT-PCR was performed on the StepOne Plus Real Time PCR system from Applied Biosystems. Power SYBR green PCR master mix along with $250 \mathrm{nmol} / \mathrm{L}$ of the following primers were used (Table 2 below). 


\section{Table 2. Primers used for Ptk1 experiments}

\begin{tabular}{|c|c|c|}
\hline Name & Primer sequence $\left(5^{\prime}-3^{\prime}\right)$ & Function \\
\hline $\begin{array}{l}\text { A1524usF } \\
\text { B1524usR }\end{array}$ & GGAAGCTATCGGGGGTACCTTCAATTAAGTTCATCTTTC & $\begin{array}{l}\text { Generating fragment } \\
\text { upstream of PGN_1524 for } \\
\text { use with allelic exchange } \\
\text { mutation }\end{array}$ \\
\hline $\mathrm{C} 1524 \mathrm{dsF}$ & $\begin{array}{l}\text { TGTCCCTGAAAAATTTCATCCATAGGATGTTTTCTATTTTCAAG } \\
\text { CTGTATTATAAAAACGATCGA }\end{array}$ & $\begin{array}{l}\text { Generating fragment } \\
\text { upstream of PGN_1524 for } \\
\text { use with allelic exchange } \\
\text { mutation }\end{array}$ \\
\hline A436usF & TTGAGAAGGACGATGTGCTG & $\begin{array}{c}\text { Generating fragment } \\
\text { upstream of PG436 for use } \\
\text { with allelic exchange mutation }\end{array}$ \\
\hline B436usR & GGAAGCTATCGGGGGTACCGGCCAATACACTCGCTACAA & \\
\hline C436dsF & TGTCCCTGAAAAATTTCATCCGCCCCATGAAGAAGAGCTAA & $\begin{array}{l}\text { Generating fragment } \\
\text { upstream of PG436 for use }\end{array}$ \\
\hline D436dsR & ATTCGGAACCAGCCCTTATC & with allelic exchange mutation \\
\hline $\begin{array}{l}\text { ERMf } \\
\text { ERMr }\end{array}$ & $\begin{array}{l}\text { GGTACCCCCGATAGCTTCC } \\
\text { GGATGAAATTTTTCAGGGACA }\end{array}$ & $\begin{array}{l}\text { Erythromycin gene for fusion } \\
\text { with upstream and } \\
\text { downstream products above }\end{array}$ \\
\hline ptcow1524F & ATGAACTTAATTGAAGATTCAAAAAACAC & $\begin{array}{l}\text { For cloning full length } \\
\text { PGN_1524 into pTCOW }\end{array}$ \\
\hline Itp1C10SF & ATGAAGCCACATAAAATC & $\begin{array}{l}\text { Generation of recombinant } \\
\text { Ltp1 C10S }\end{array}$ \\
\hline
\end{tabular}

Using the SYBR green channel from 60-95 C, melting curves were obtained. Relative quantities of mRNA were normalized to $16 \mathrm{~s}$ rRNA using the $\Delta \Delta \mathrm{Ct}$ method. A negative control of no RT was included in all experiments.

\subsection{Statistics}

All experiments were performed with at least 3 biological replicates and 2 technical replicates. Statistical analyses were performed using a two-tailed t-test for single 
comparisons and ANOVA with the Tukey correction for multiple analyses. P-values $<0.05$ were considered significant. 


\section{CHAPTER 4}

\section{P. GINGIVALIS SERINE PHOSPHATASE SERB: EXPERIMENTAL RESULTS}

\subsection{P. gingivalis SerB suppresses activation of the IL-8 Promoter}

It has been well documented that Interleukin-8 (IL-8) production is predominantly regulated by $\mathrm{p} 65$ homodimers of NF-kB [134]. Previous research has demonstrated that P. gingivalis can not only inhibit the accumulation of IL-8 from gingival epithelial cells but also inhibits the accumulation of IL-8 in response to other bacteria, a phenomenon coined local chemokine paralysis [40]. Later research revealed that secretion of $P$. gingivalis serine phosphatase, SerB, was a necessary step required for maximal inhibition of IL-8 production by gingival epithelial cells [136]. We first sought to determine if SerB-dependent inhibition of IL-8 occurred at the transcriptional level. TIGK cells were transfected with a luciferase reporter plasmid linked to the IL-8 promoter. Transfected TIGK cells were infected with $P$. gingivalis 33277 wild type (WT), or $P$. gingivalis $\Delta$ serB mutant strains, and stimulated with TNF to induce transcription of the IL8 gene. Plasmid pRL-CMV, in which Renilla luciferase is driven by the cytomegalovirus promoter, was a transfection control. Luciferase activity was then measured. The fold changes presented are relative to the activity level of the unstimulated control group. The IL-8 promoter activity increased by a measure of 5 -fold when stimulated with TNF, compared to the unstimulated control. When we infected with the $P$. gingivalis 33277 WT strain, the IL-8 promoter activity was significantly reduced (5-fold to 3.6 fold induction) compared to TNF stimulated, uninfected basal levels. Infection of TIGKs with $P$. gingivalis $\Delta$ serB mutant strain showed a marked inability to reduce TNF stimulated IL-8 promoter activity compared to the $P$. gingivalis WT strain (Figure 1). These results suggest that the ability of $P$. gingivalis SerB to inhibit IL-8 secretion by epithelial cells does occur at the transcriptional level. 


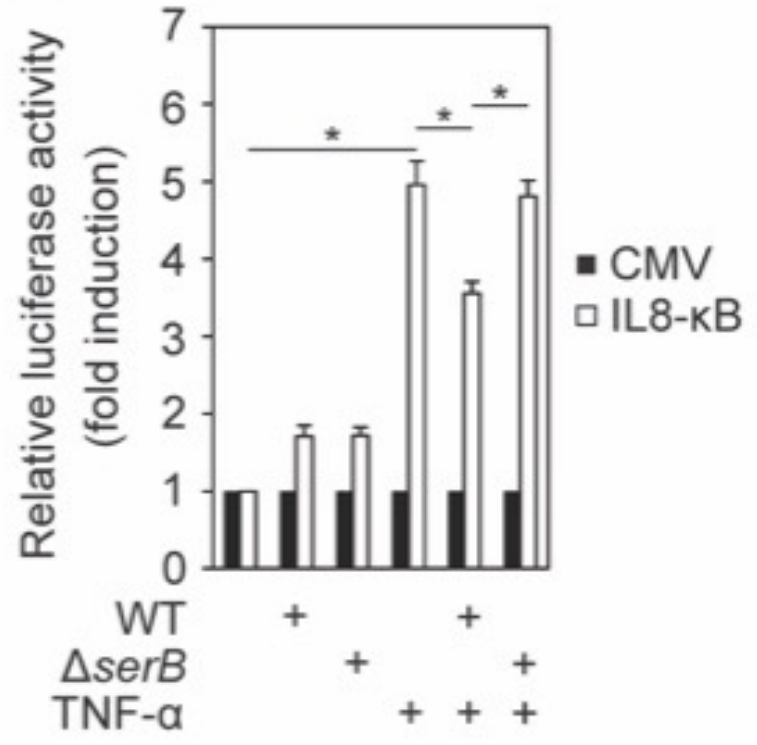

Figure 1. Infection of TIGK cells with $P$. gingivalis expressing SerB reduces IL-8 promoter activity. TIGKs were transiently transfected with pIL-8 kB-Luc luciferase reporter plasmid for IL-8 promoter activity, or pRL-CMV (CMV) where Renilla Luciferase driven by cytomegalovirus promoter, and infected with $P$. gingivalis. WT or $\Delta$ serB mutant (MOI=10). After $16 \mathrm{~h}$ infection, TIGKs stimulated with TNF (10 $\mathrm{ng} / \mathrm{mL}$ ) for $3 \mathrm{~h}$ or left unstimulated. Luciferase activity was measured and normalized to Renilla Luciferase. Results presented as fold relative to activity of unstimulated control. Values are mean +/- SD; $n=3$; ${ }^{*} p<0.05$. 


\subsection{P. gingivalis SerB dephosphorylates the NF-кB p65 subunit}

We next wanted to ascertain whether the ability of SerB to suppress IL-8 promoter activity was related to the phosphorylation status of the NF-kB p65 subunit. As mentioned earlier, it has been reported that IL-8 production is predominantly controlled by the p65 homodimers of NF-kB. Previous studies performed in Jurkat cells have demonstrated that phosphorylation of serine residue S536 of p65 induces IL-8 transcription [137]. This led us to hypothesize that this S536 residue in p65 is also the target for dephosphorylation by $P$. gingivalis SerB phosphatase. We infected TIGKs with either $P$. gingivalis 33277 WT or $P$. gingivalis $\Delta$ serB mutant strains for $16 \mathrm{~h}$. TIGKs were then stimulated with TNF or left unstimulated for 3 min or 10 min prior to cell lysis, and the phosphorylation status of S536 determined by immunoblotting. (Figure 2A). After 10 min of stimulation with TNF, the levels of phosphorylated (P)-S536 were significantly reduced when in the presence of $P$. gingivalis WT. In contrast we saw that the $\Delta$ serB mutant strain showed diminished ability to reduce phosphorylation levels of the S536 residue compared to the P.gingivalis WT strain (Figure 2A). For quantification of these results, we performed a densitometric analysis of the immunoblots (Figure 2B), which showed a $>4$-fold reduction of phosphorylation of S536 in $P$. gingivalis WT infected cells. We can conclude from these findings that NF-kB p65 S536 is in fact a target for dephosphorylation by $P$. gingivalis SerB. The importance of this finding is underscored by the fact that the phosphorylation status of this S536 residue is one factor that controls the dimerization and nuclear import of p65 into the nucleus. 


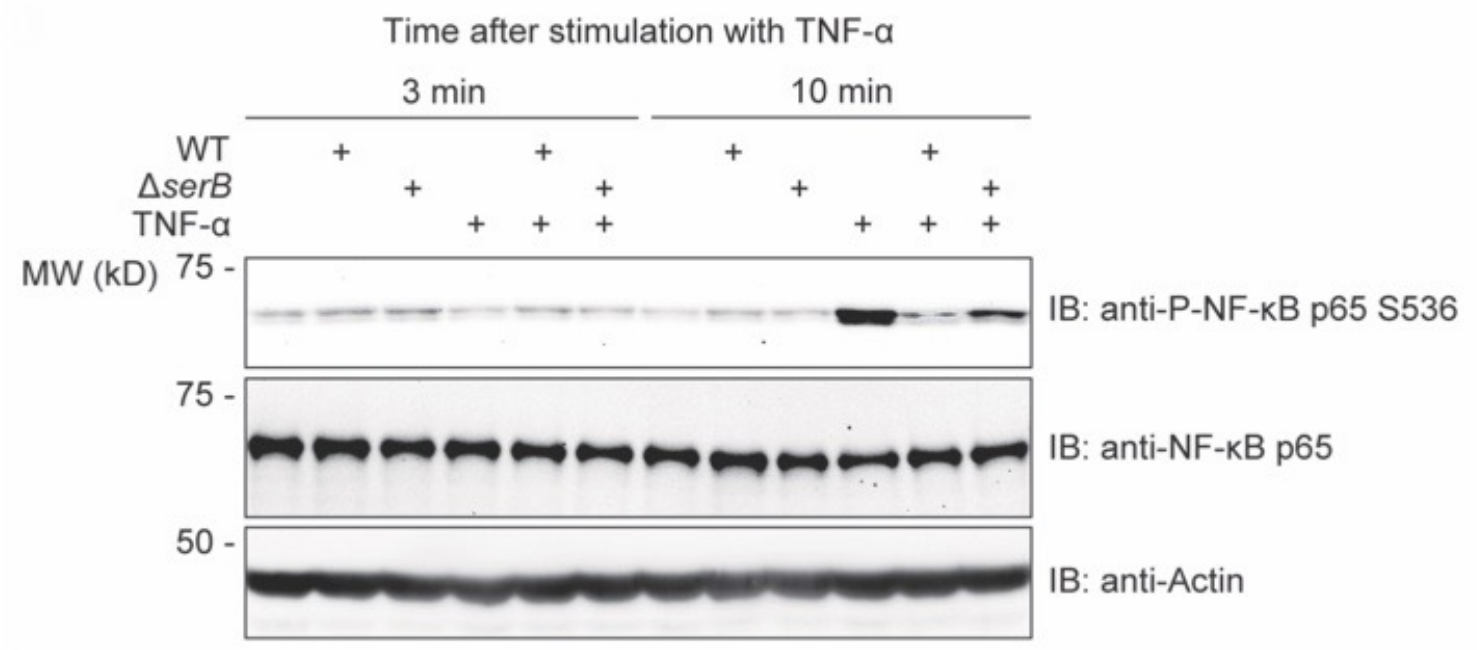

Figure 2A. Infection of TIGK cells with $P$. gingivalis expressing SerB diminishes phosphorylation of NF-kB p65. Immunoblots of cell lysates of TIGKs infected with $P$. gingivalis WT or $\Delta$ serB (MOI=10). $16 \mathrm{~h}$ after infection TIGKs were stimulated with TNF (10 $\mathrm{ng} / \mathrm{mL})$ or left unstimulated for indicated timepoints prior to cell lysis. Immunoblots probed with indicated antibodies. Anti-total p65 shows no difference in the level of the protein. Actin was used as a loading control. 


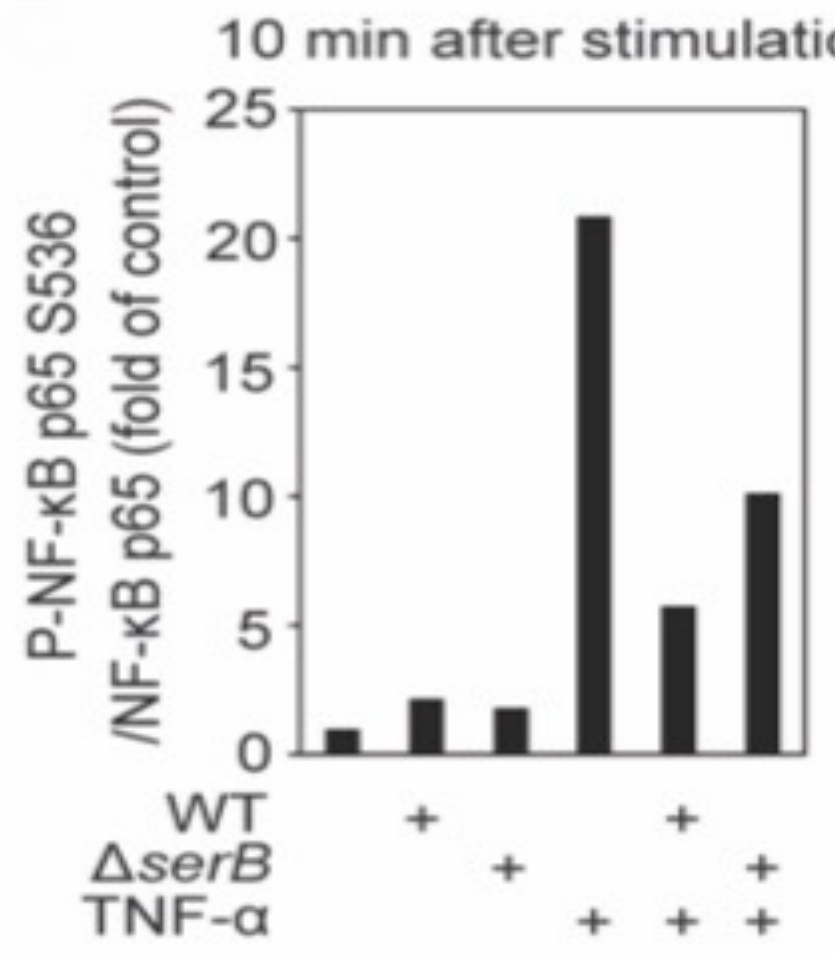

Figure 2B. Infection of TIGK cells with $P$. gingivalis expressing SerB diminishes phosphorylation of NF-kB p65. Scanning densitometry of immunoblots performed in A showing ratio of phosphorylated NF-kB p65 (S536) relative to total immunodetectable NF-kB p65. 
4.3 SerB is produced and secreted by intracellular $P$. gingivalis

Previous research has established that intracellular invasion of gingival epithelial cells by $P$. gingivalis is a pre-requisite for NF-kB suppression [40]. In an attempt to establish that SerB itself is secreted within epithelial cells by $P$. gingivalis and thus potentially working directly on host cell components to effectuate these results, we made a construct in $P$. gingivalis where SerB was tagged with a FLAG-epitope. We then infected our model cell line of TIGKs with this $P$. gingivalis construct expressing FLAG-SerB. Cells were stained with DAPI (cyan) to detect the nuclear and bacterial DNA, FITC-phalloidin (green) to detect the actin, and anti-FLAG (magenta) to detect SerB (Figures $3 A$ \& 3B). Preliminary experiments confirmed that the detection of infected bacteria using DAPI proved to be just as specific as was seen when using $P$. gingivalis antibodies. Utilizing confocal microscopy, SerB was detected within the cytoplasm of TIGK cells. Here we can conclude that SerB is secreted and accessible for direct host cell interactions following $P$. gingivalis infection. 

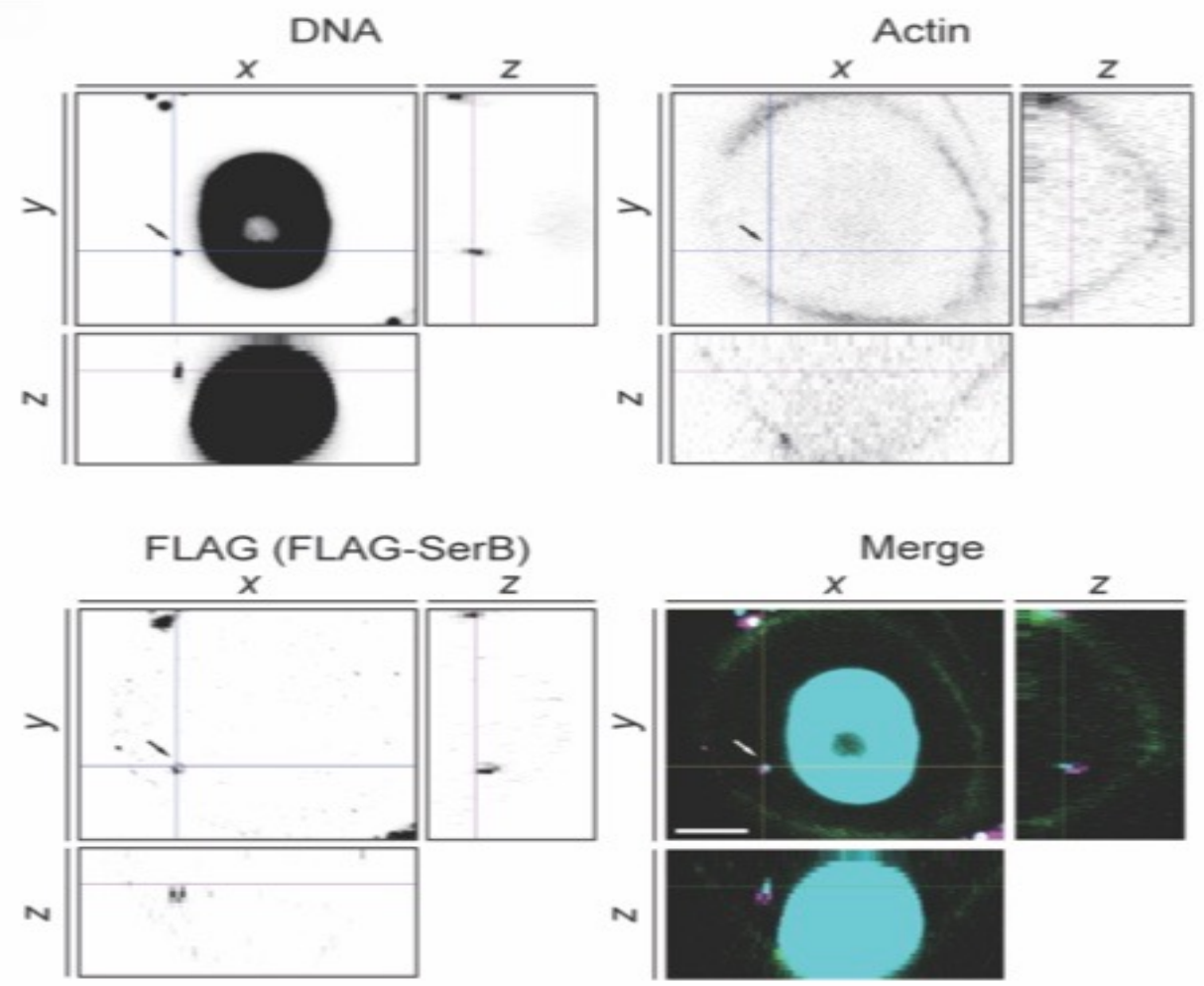

Figure 3A. TIGK cells infected with $P$. gingivalis expressing SerB show presence of SerB in cytoplasm of TIGKs. Confocal microscopy showing expression of SerB by intracellular $P$. gingivalis. TIGK cells were infected with $P$. gingivalis expressing FLAG-SerB (MOI=10) for $2 \mathrm{~h}$, stained with DAPI (cyan), FITC-phalloidin (green) or anti-FLAG (magenta). Bar=5 um. 


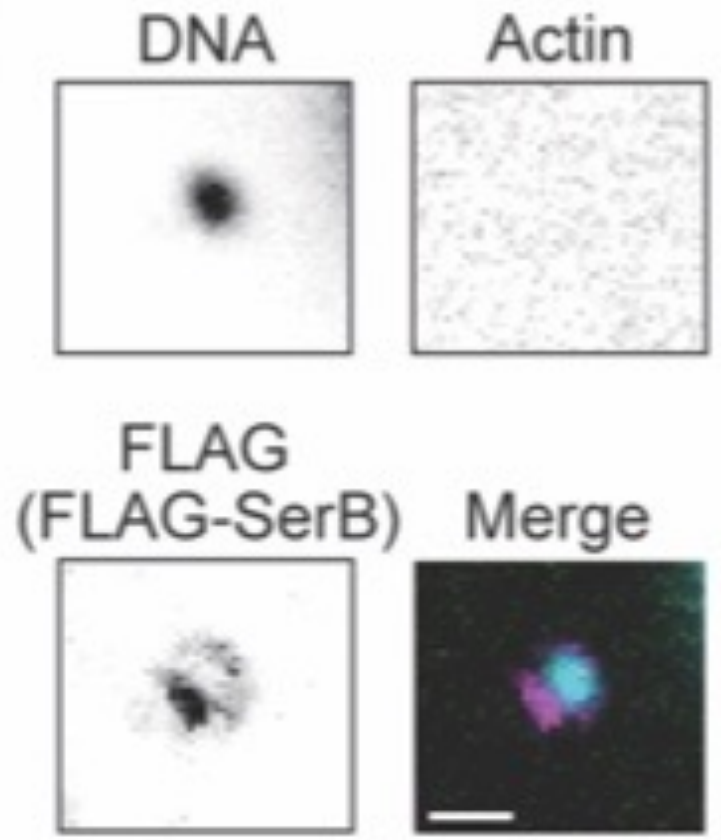

Figure 3B. TIGK cells infected with $P$. gingivalis expressing SerB show presence of SerB in cytoplasm of TIGKs. Higher magnification of $\boldsymbol{P}$. gingivalis indicated by arrow shown in 3A. Bar=1 um. 
4.4 SerB directly binds to and dephosphorylates NF-кB p65.

We wanted to investigate more thoroughly the precise function of SerB, independent of any other $P$. gingivalis effectors. First, we generated a mammalian expression vector, which expressed the fusion protein, Myc-SerB. TIGKs were transfected with an empty vector $(\mathrm{Myc})$ or Myc-SerB, and then stimulated with TNF. Cells were cross-linked with DSP to stabilize all enzyme-substrate interactions. Cell lysates were immunoprecipitated with anti-Myc antibody. We found that Myc-SerB coimmunoprecipitated with endogenous NF-kB p65, whereas this was not seen with the empty Myc vector alone (Figure 4A). For quantification purposes, we performed scanning densitometry analysis of the immunoblots from Figure $4 \mathrm{~A}$ showing the ratio of immunoprecipitated NF-kB p65 relative to immunoprecipitated Myc-SerB (Figure 4B). These findings suggest that $P$. gingivalis SerB can directly interact with p65. Yet it is also important to note that these results do not preclude the possibility that other $P$. gingivalis molecules might also possess the ability to interact with NF-kB components.

To further investigate the type of interaction between SerB and NF-kB p65 we used confocal microscopy to visualize the co-localization between SerB and p65 in TIGK cells. We constructed a GFP tagged NF-kB p65 (green) as well as a Myc expression vector, Myc-SerB (red), and transfected them into our model cell line of TIGKs. Transfected cells were then stimulated with TNF. Cells were fixed and stained with anti-Myc (red) and viewed with confocal microscopy (Figure 4C). Olympus FluoView software was used to measure the intensity of the fluorescent signals emitted from the GFP-NF-kB p65 (green), the Myc (Red, vector), and the Myc-SerB (red) (Figure 4D). Both Figures 4C and 4D clearly demonstrate that when Myc-SerB and GFP-NF-kB p65 are ectopically expressed in TIGK cells, Myc-SerB is found to co-localize with GFP-NF-kB p65 in the cytoplasmic region. 
In an attempt to confirm that the phosphorylation status of NF-kB p65 is a critical factor for SerB activity, we constructed a constitutively active phosphomimic p65 S536D mutant. This phosphomimic is a mutant version of p65 whereby serine was replaced by glutamate, which . mimics the phosphorylated state but cannot be dephosphorylated. TIGK cells were transfected with GFP-NF-kB p65 or GFP-NF-kB p65 S536D, as well as with Myc-SerB or empty vector (Myc). Cells were cross-linked with DSP to stabilize substrate-enzyme interactions. Cells were not stimulated with TNF so as to ensure the phosphorylation of p65 was maintained at basal levels. Cell lysates were then immunoprecipitated with anti-Myc antibody (Figure 4E). We then performed quantification analysis by scanning densitometry of the immunoblots shown in Figure 4E showing the ratio of immunoprecipitated GFP-NF-kB p65 or the p65 S536D mutant relative to the total immunoprecipitated Myc-SerB (Figure 4F). These immunoprecipitation experiments revealed that Myc-SerB co-immunoprecipitated with GFP-NF-kB p65 S536D phosphomimic mutant. In contrast, we were unable to detect co-immunoprecipitation of Myc-SerB with the unphosphorylated NF-kB p65. These results suggest that the phosphorylation status of NF-kB p65 S536 is, in fact, a crucial element involved in the binding of SerB to NF-kB p65. 


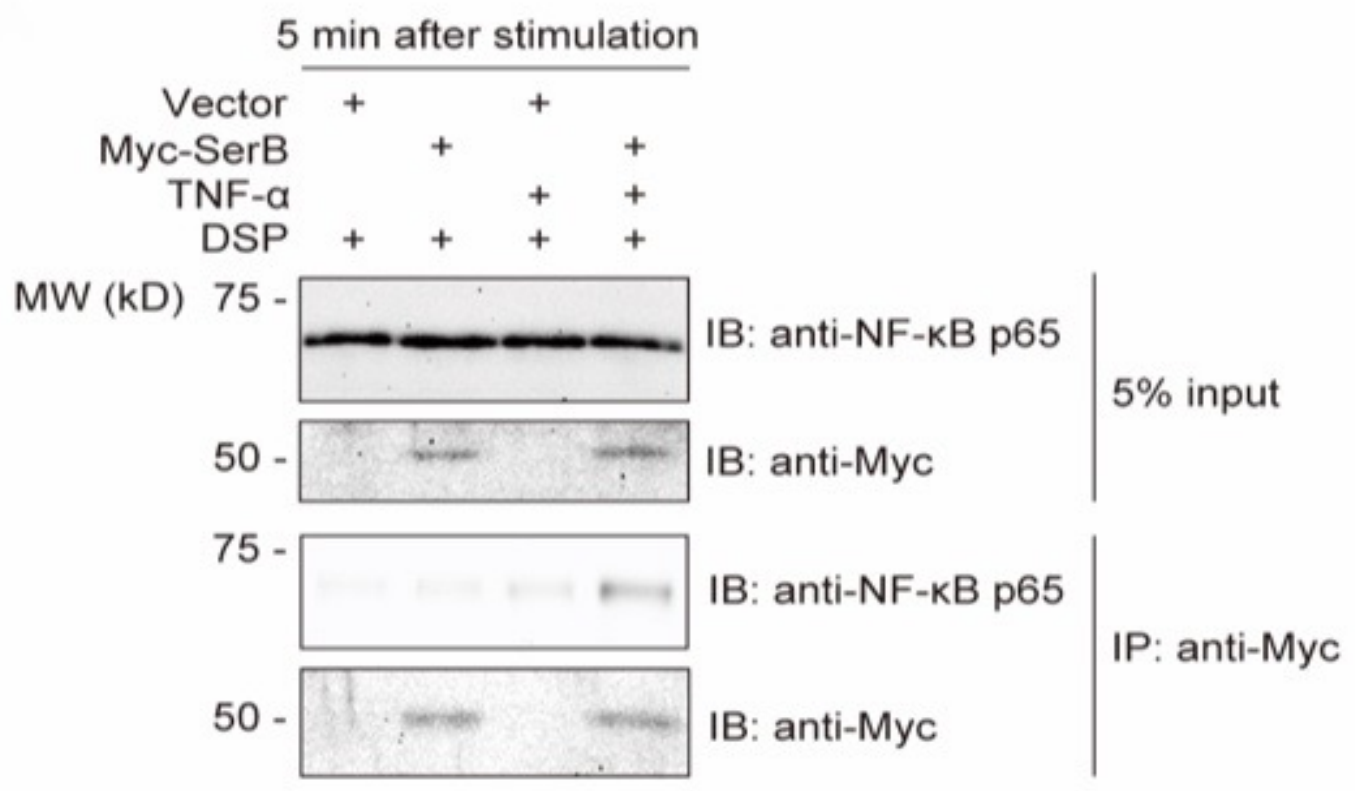

Figure 4A. Ectopically expressed SerB binds to and dephosphorylates NF-kB p65. TIGK cells were transfected with Myc-SerB or empty vector, stimulated with TNF (10 $\mathrm{ng} / \mathrm{mL}$ ) for $5 \mathrm{~min}$ or left unstimulated. TIGKs were cross-linked with DSP and cell lysates immunoprecipitated (IP) with anti-Myc antibody. Immunoblots show cell lysates prior to IP (5\% input) and immunoprecipitate with Myc antibodies. Results are representative of 3 biological replicates. 


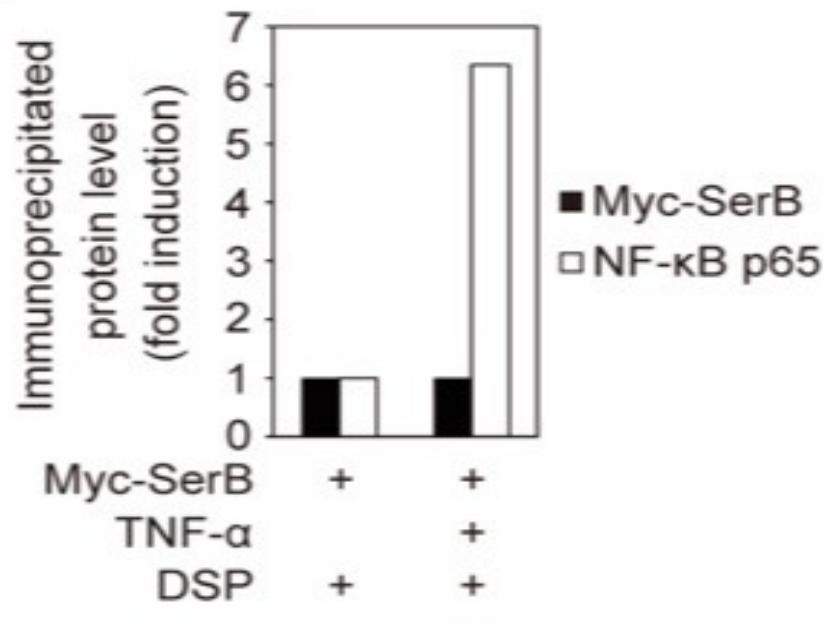

Figure 4B. Ectopically expressed SerB binds to and dephosphorylates NF-kB p65. Scanning Densitometry of immunoblot in (A) showing ratio of immunoprecipitated NF-kB p65 relative to immunoprecipitated Myc-SerB. 


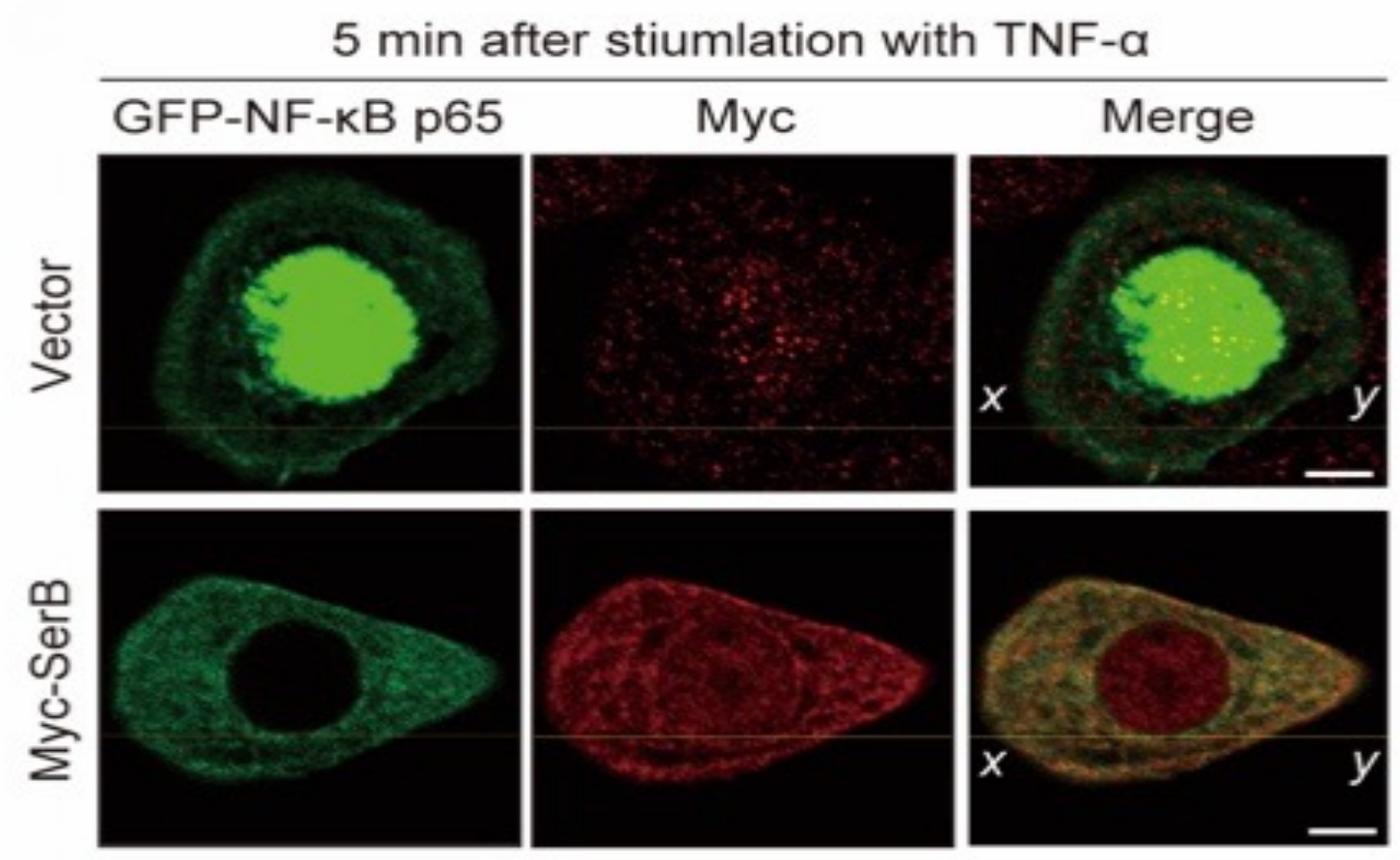

Figure 4C. Ectopically expressed SerB binds to and dephosphorylates NF-kB p65. Confocal microscopy of TIGKs expressing GFP-NF-kB p65 (green) and either Myc (vector) or Myc-SerB. $36 \mathrm{~h}$ after transfection, TIGKs were stimulated with TNF (10 $\mathrm{ng} / \mathrm{mL}$ ) for $5 \mathrm{~min}$ or left unstimulated. Cells were fixed and stained with anti-Myc (red). Bars $=5 \mu \mathrm{m}$. Results are representative of 3 biological replicates. 


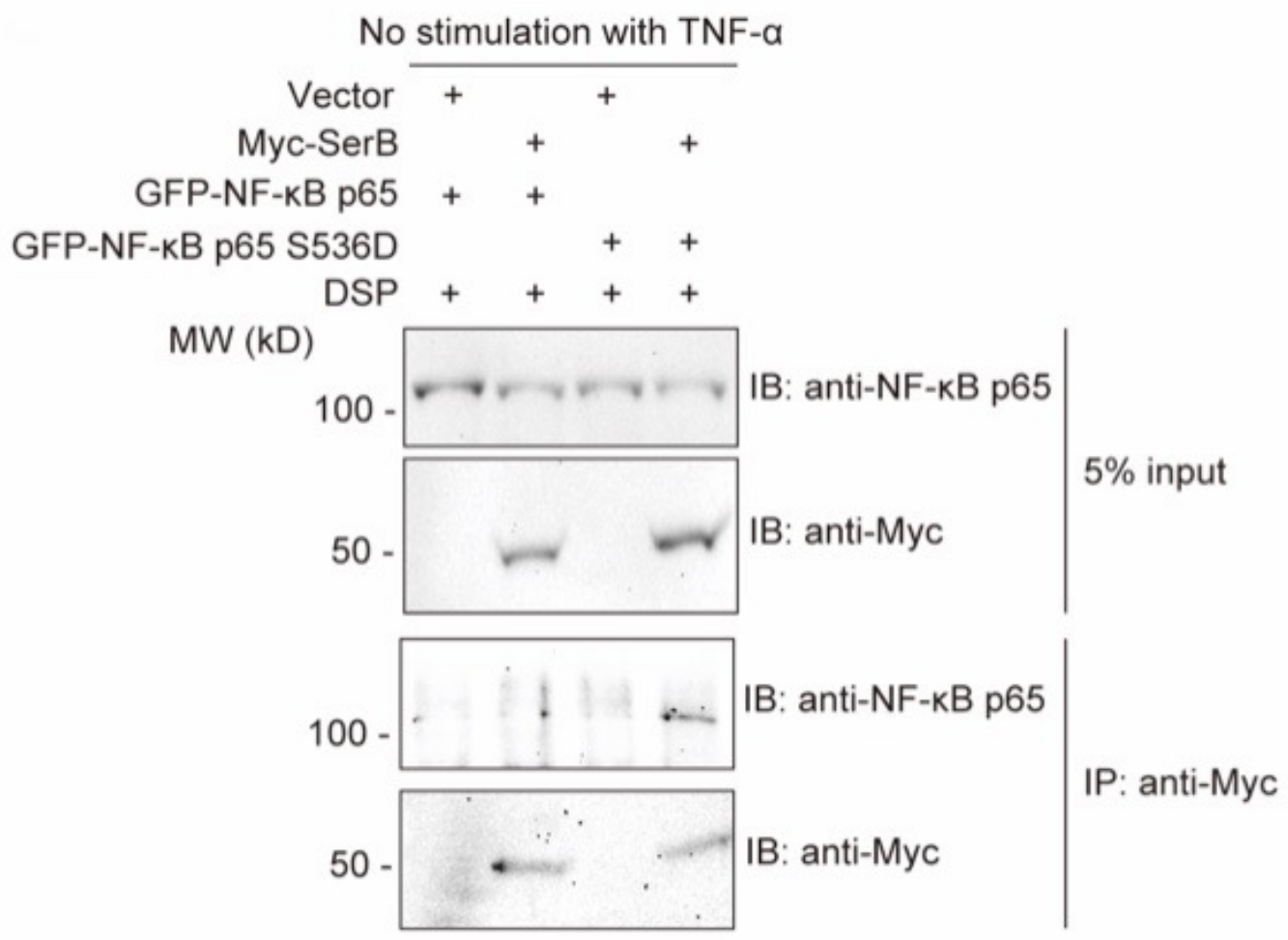

Figure 4D. Ectopically expressed SerB binds to and dephosphorylates NF-kB p65. TIGKs transfected with empty vector or Myc-SerB, and GFP-NF-kB p65 or GFP-NFkB p65 S536D. Cells were cross-linked with DSP and cell lysates immunoprecipitated with anti-Myc antibody. Immunoblots show cell lysates prior to IP (5\% input) and immunoprecipitate with Myc antibodies. Results are representative of 3 biological replicates. 


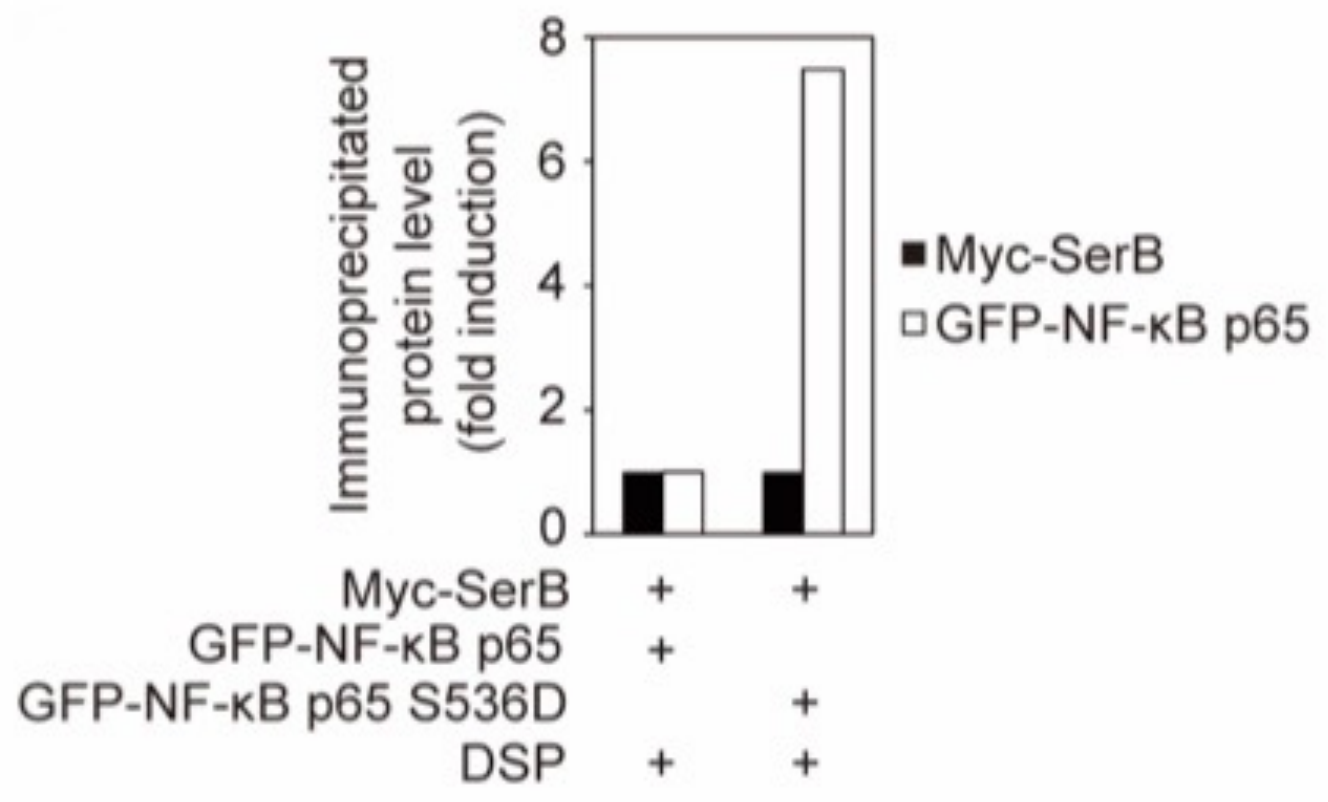

Figure 4E. Ectopically expressed SerB binds to and dephosphorylates NF-kB p65. Densitometry of immunoblots from (D) showing ratio of immunoprecipitated GFP. NF-kB p65 or p65 S536D relative to immunoprecipitated Myc-SerB. 
Our next area of focus was to determine whether the binding of SerB itself to p65 is the primary event that triggers the subsequent dephosphorylation of the S536 residue. TIGK cells were transfected with an empty vector (Myc) or Myc-SerB. TIGKs ectopically expressing Myc-SerB were then stimulated with TNF for 0, 5, 30, 60 and 120 min. For each time point, cell extracts were prepared and immunoblotted with specific antibodies to (P)hosphorylated-NF-kB p65 S536, unphosphorylated NF-kB p65, Myc vector alone or Myc-SerB (Figure 5A). We quantified these immunoblots from Figure 5A by scanning densitometry (Figure 5B) showing the proportion of (P)-NF-kB p65 (S536) relative to total detectable NF-kB p65. Our findings showed that TIGK cells expressing Myc-SerB exhibited a lower level of (P) -NF-kB p65 between the time periods of 5 to 30 min following TNF stimulation when compared to TIGKs transfected with the empty Myc vector. Interestingly, levels of phosphorylated NF-kB p65 dropped in cells expressing Myc vector alone as well as those expressing Myc-SerB after 60 min of TNF stimulation. This can be attributed to the transitory effect of TNF stimulation. These findings indicate that the S536 residue of NF-kB p65 subunit can be directly dephosphorylated by $P$. gingivalis SerB.

To further explore the specificity of SerB for the p65 subunit, we examined whether SerB could target other NF-kB subunits such as the p105 subunit, specifically the S933 residue of p105. TIGK cells were transfected with empty vector (Myc) or Myc-SerB. After transfection, TIGKs were stimulated with TNF for various time periods. Cell extracts were then immunoblotted with antibodies specific for phosphorylated p105 S933, p105, and p50 (Figure 5C). Quantitative analysis of all immunoblots was performed using scanning densitometry (Figures 5D and 5E). These results showed that SerB did not dephosphorylate the NF-kB p105 S933 residue (Figures 5C and 5D). Previous research has established that processing of the precursor p105, resulting in 
formation of the active subunit, p50, is also an important step in the activation of the NFkB transcription factor [138]. To further substantiate our findings from p105 data, we verified that the total amount of the active p50 subunit remained unchanged in our TIGK cells expressing Myc-SerB and stimulated with TNF. When compared to the empty Myc vector control group, we confirmed that the amount of p50 was unchanged (Figures 5C and $5 E)$.

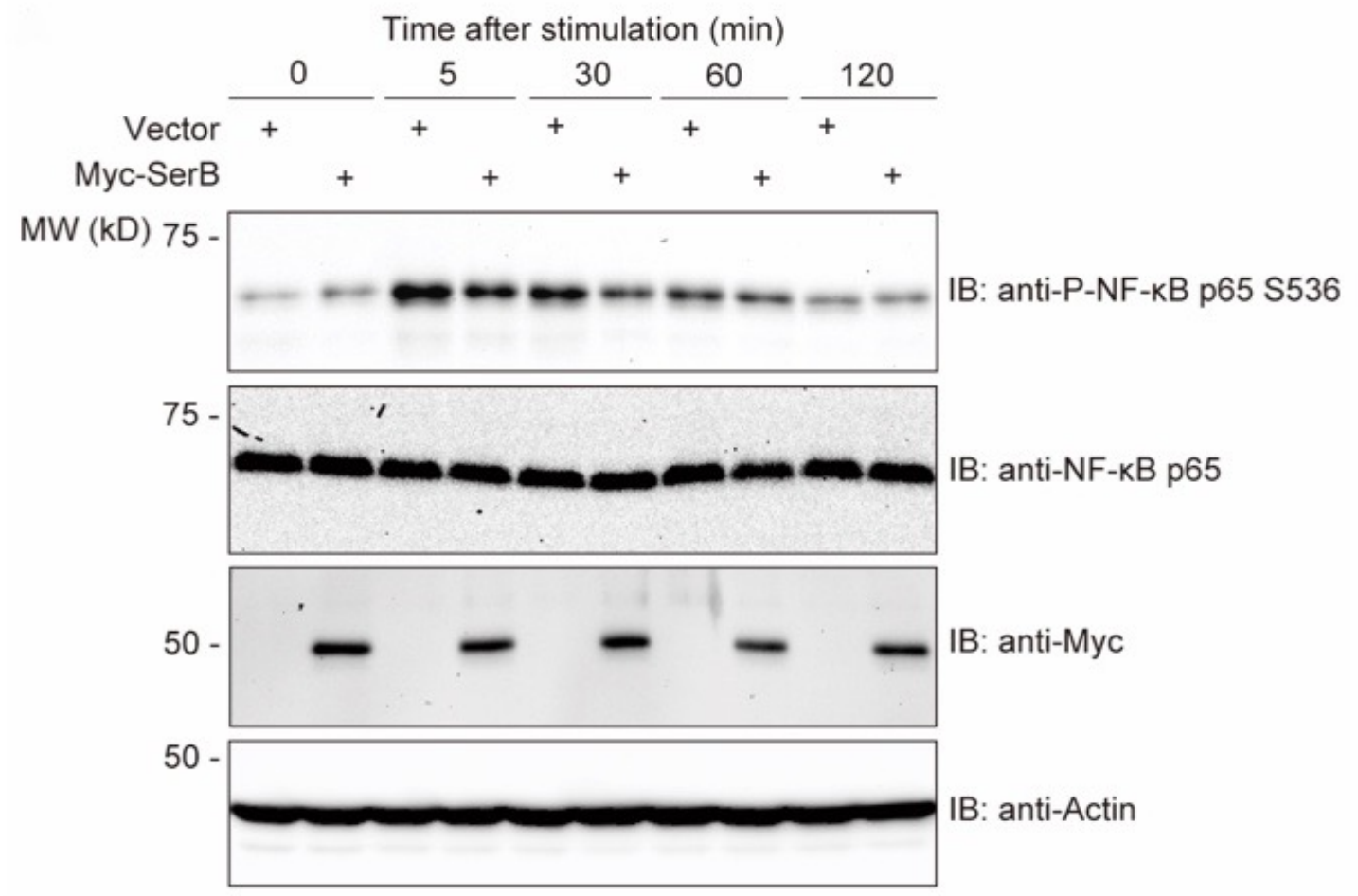

Figure 5A. P. gingivalis SerB dephosphorylates NF-kB p65 but not p105. TIGKs were transfected with empty Myc vector or Myc-SerB. $36 \mathrm{~h}$ after transfection, TIGKs were stimulated with TNF $(5 \mathrm{ng} / \mathrm{mL})$ and at time points shown cell extracts were prepared and immunoblotted with the antibodies indicated. Actin was used as the loading control. Results are representative of 3 biological replicates. 


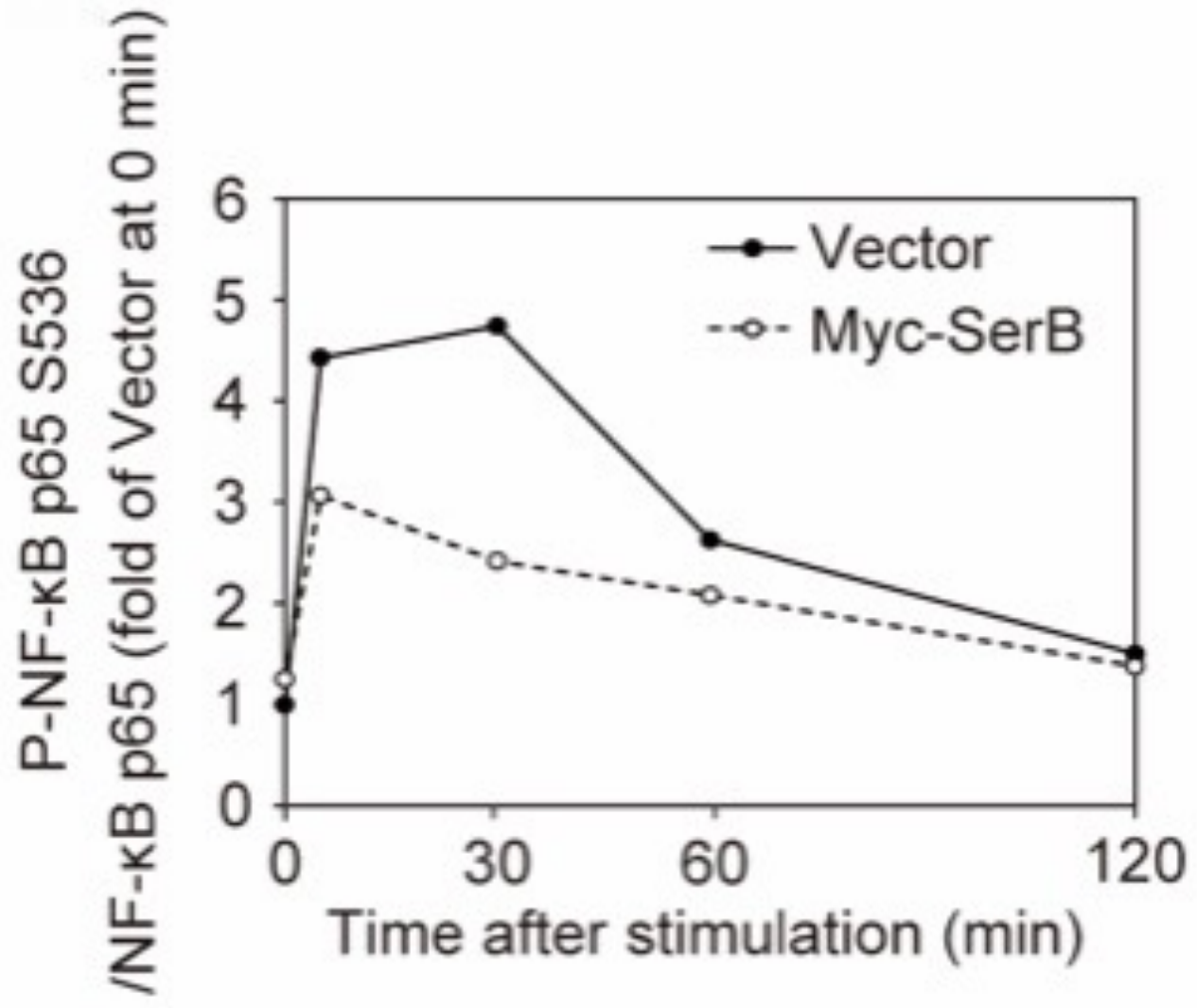

Figure 5B. P. gingivalis SerB dephosphorylates NF-kB p65 but not p105. Densitometry of the immunoblots shown in (A) showing ratio of phosphorylated NF-kB p65 (S536) relative to total immunodetectable NF-kB p65. 


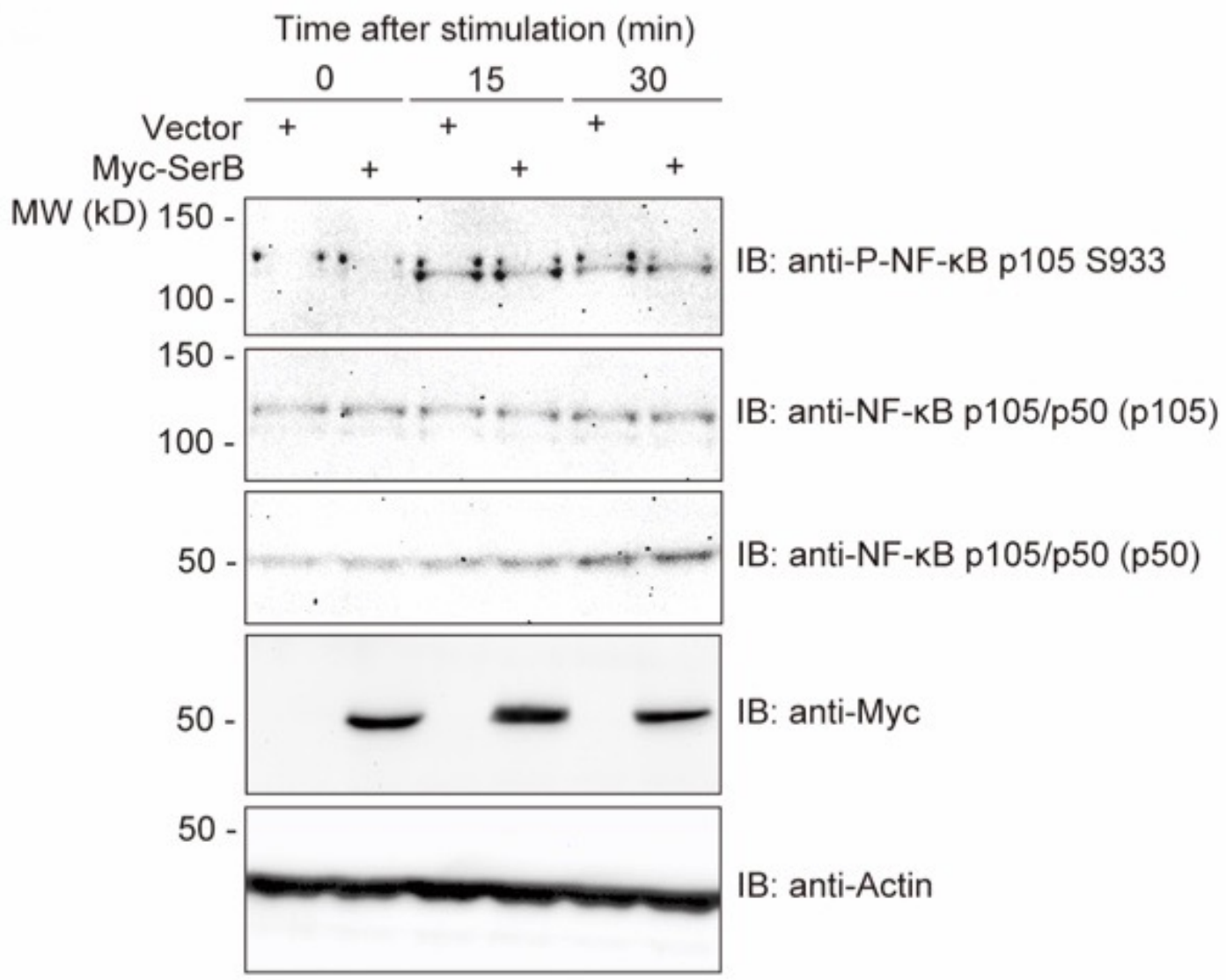

Figure 5C. P. gingivalis SerB dephosphorylates NF-kB p65 but not p105. TIGKs were transiently transfected with empty Myc vector or Myc-SerB. After $36 \mathrm{~h}$ transfection, TIGKs were stimulated with TNF $(5 \mathrm{ng} / \mathrm{mL})$ and at specified time points cell extracts were prepared and immunoblotted with the antibodies indicated. Results are representative of 3 biological replicates. 


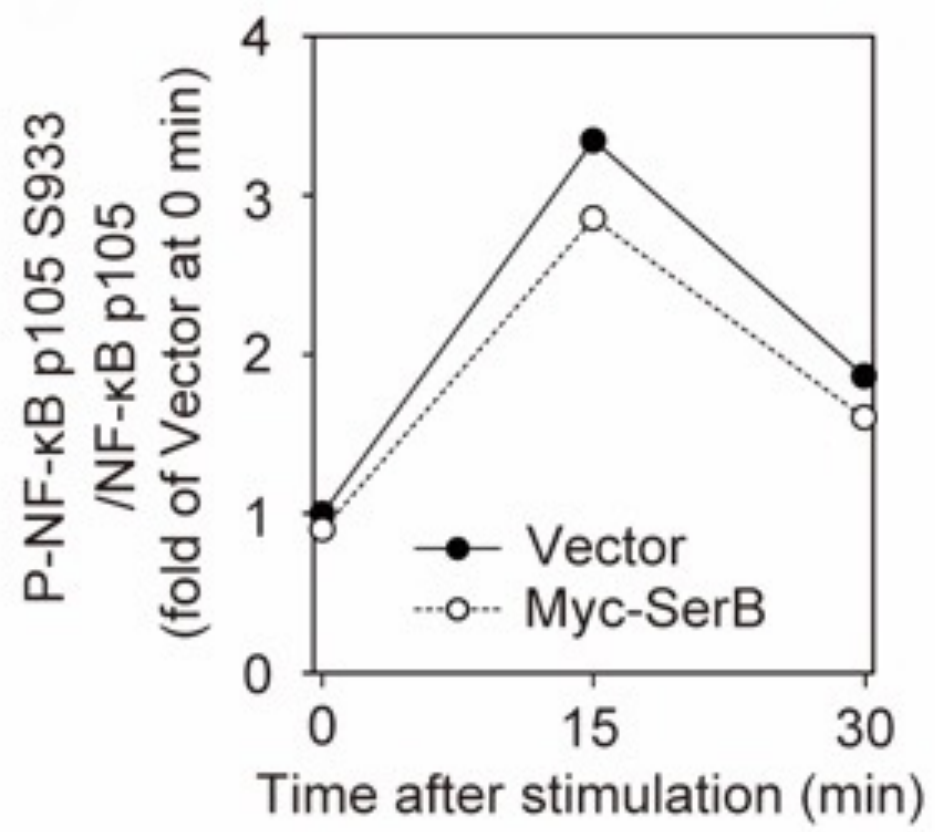

Figure 5D. $P$. gingivalis SerB dephosphorylates NF-kB p65 but not p105. Scanning densitometry of immunoblot from (C) showing ratio of phospho-NF-kB p105(S933) relative to total immunodetectable NF-kB p105. 


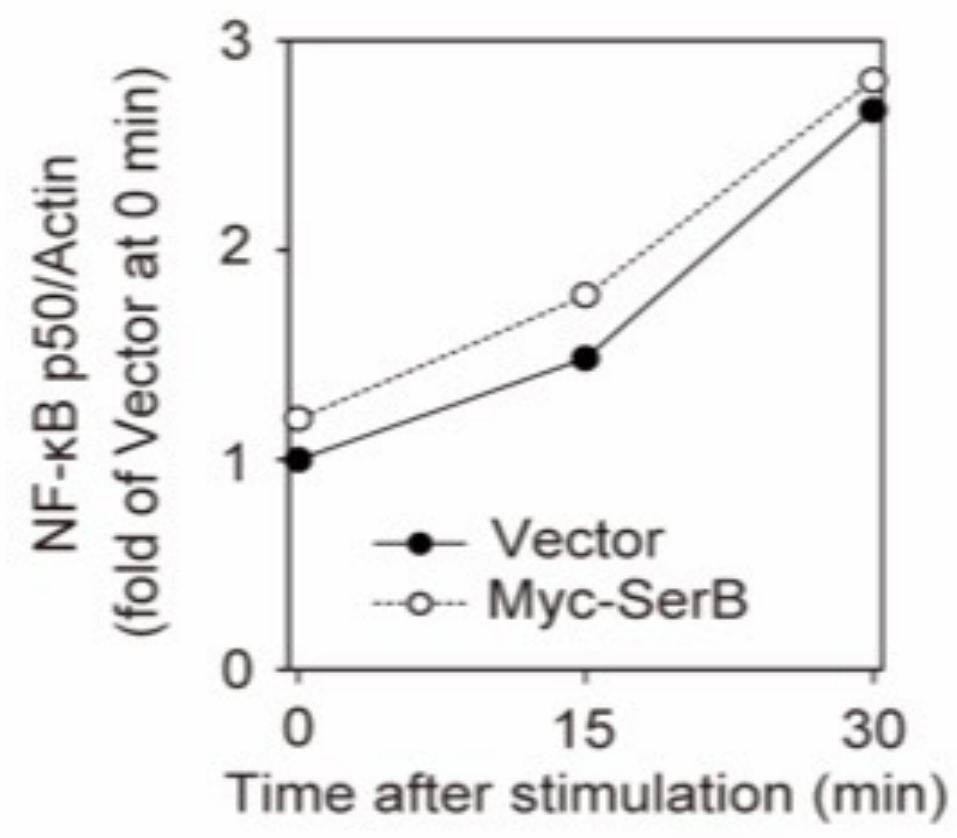

Figure 5E. P. gingivalis SerB dephosphorylates NF-kB p65 but not p105. Densitometry of immunoblot in (C) showing ratio of phosphor-NF-kB p50 relative to actin.

In order to fully address the specificity for dephosphorylation of p65 S536 residue by SerB, we examined whether this $P$. gingivalis enzyme could also dephosphorylate other serine residues, in particular, S276 and S468 (Figures 6 and 7). We transfected TIGK cells with empty Myc vector alone or Myc-SerB. TIGKs were then stimulated with TNF and cells lysates immunoblotted with phospho-specific antibodies (Figures 6A and 7A). For each experiment quantitative analysis of the immunoblots was performed using scanning densitometry to assess the ratios of (P)-NF-kB p65 S276 or S468 relative to 
total immunodetectable NF-kB p65 (Figures 6B and 7B). Our results showed that SerB failed to significantly decrease the levels of phosphorylated S276 or S468 naturally induced by TNF stimulation.

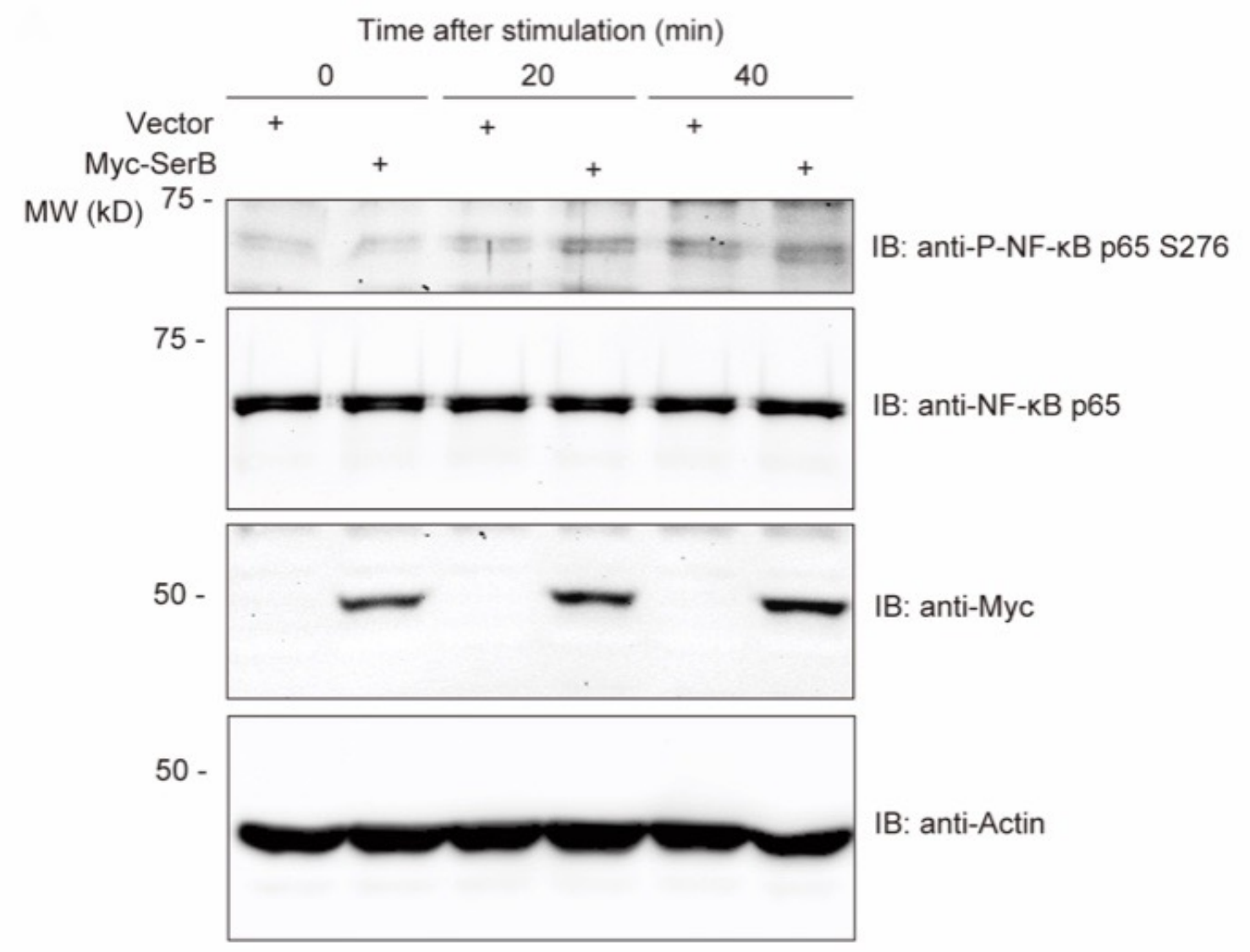

Figure 6A. Effects of ectopic expression of SerB on the phosphorylation of NF-kB p65 S276. TIGKs were transfected with empty vector or Myc-SerB. After $36 \mathrm{~h}$ transfection, cells were stimulated with TNF $(5 \mathrm{ng} / \mathrm{mL})$ for indicated time periods, then cell extracts were prepared and immunoblotted with the antibodies shown. Actin was used as the loading control. Results are representative of 2 biological replicates 


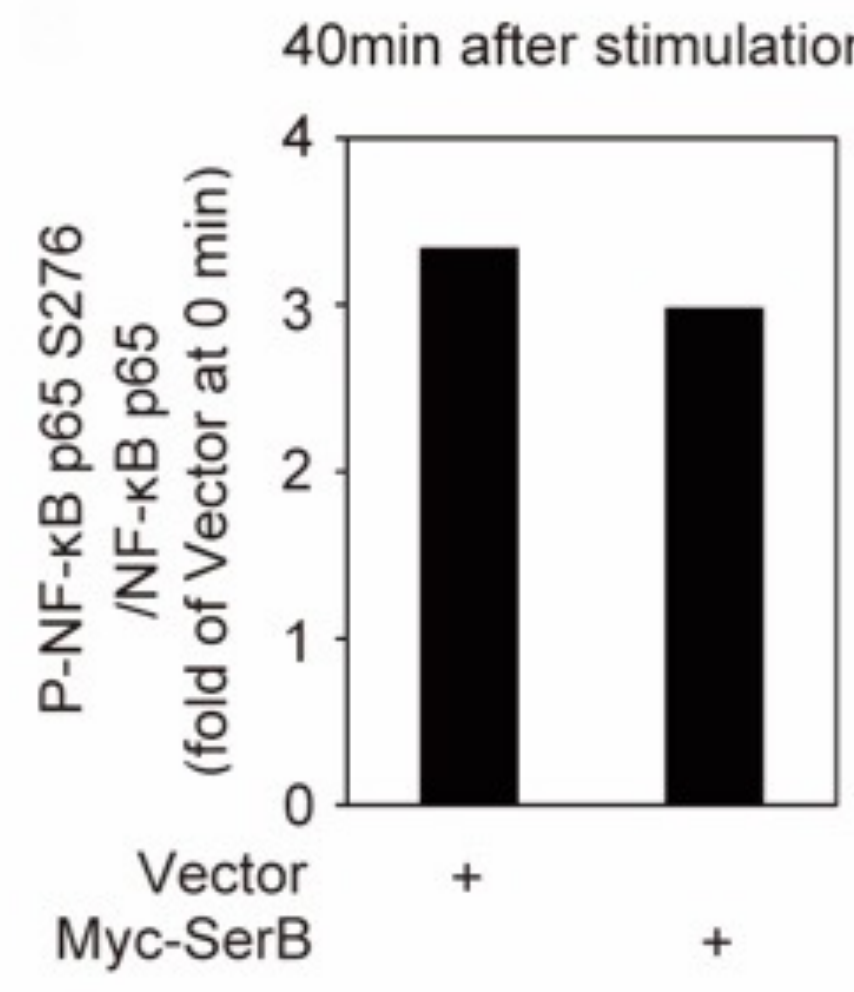

Figure 6B. Effects of ectopic expression of SerB on the phosphorylation of NF-kB p65 S276. Densitometry of immunoblots from (A) showing the ratio of phosphoNF-kB p65 (S276) relative to total immunodetectable NF-kB p65. 


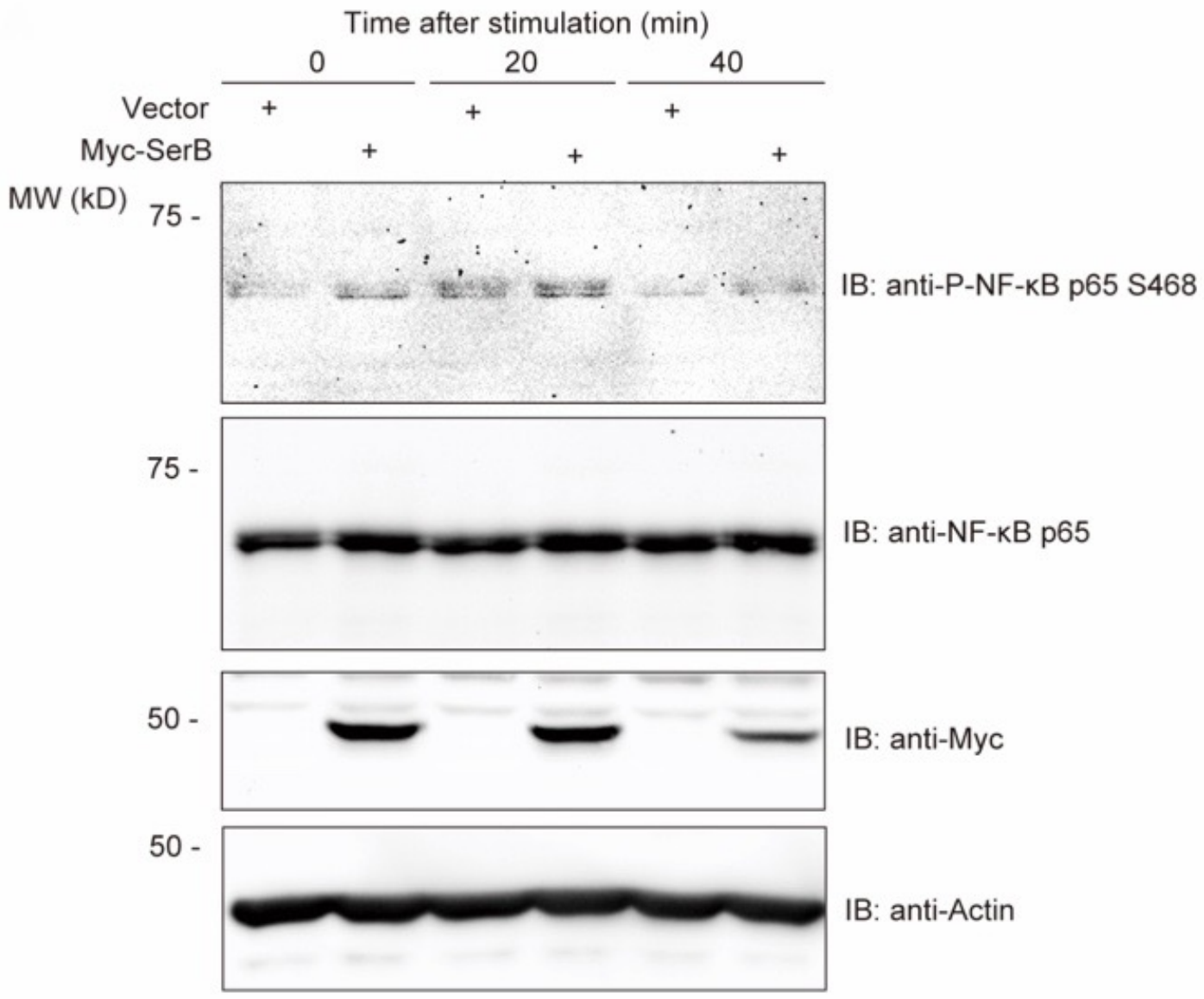

Figure 7A. Effects of ectopic expression of SerB on the phosphorylation of NF-kB p65 S468. TIGKs were transfected with empty vector or Myc-SerB. After $36 \mathrm{~h}$ transfection, cells were stimulated with TNF $(5 \mathrm{ng} / \mathrm{mL})$ for the indicated time periods. Cell extracts were then prepared and immunoblotted with the antibodies shown. Actin was used as a loading control. Results are representative of 2 biological replicates. 


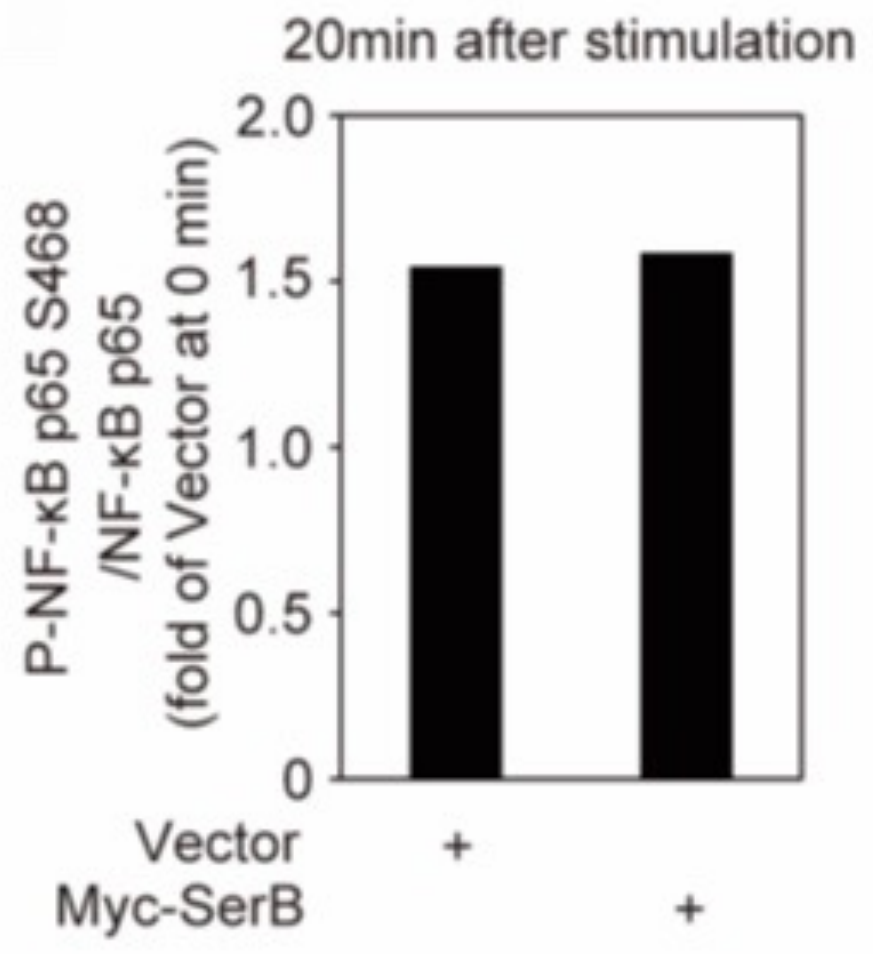

Figure 7B. Effects of ectopic expression of SerB on the phosphorylation of NF-kB p65 S468. Densitometry of immunoblots from (A) showing the ratio of phosphoNF-kB p65 (S468) relative to total immunodetectable NF-kB p65

Collectively, these findings illustrate that SerB does not directly target the phosphorylation status of either NF-kB p65 S468 or S276, nor does it impact NF-kB p105 S933. Furthermore, we can conclude that SerB does not affect the processing of phosphorylated p105 into the active form of NF-kB p50. Hence, the action of $P$. gingivalis SerB appears to be specific for the NF-kB p65 subunit, in particular the S536 residue. 


\subsection{P. gingivalis SerB prevents the nuclear translocation of NF-KB p65}

Previous studies performed in Jurkat cells have shown that the kinetics of NF-kB p65 nuclear import can be controlled by the phosphorylation status of p65 S536 residue [139]. This led us to postulate that the phosphorylation status of p65 S536 would exhibit this same control over the nuclear import of p65 in gingival epithelial cells, and hence SerB-mediated dephosphorylation of p65 S536 would have biological relevance. We hypothesized that SerB could block the nuclear translocation of p65 in TNF-stimulated TIGK cells. To test our hypothesis, we first transfected TIGK cells with GFP-tagged NFkB p65 or with GFP-tagged phosphomimic NF-kB p65 S536D mutant. This mutant p65 strain is constitutively active and therefore cannot be dephosphorylated by SerB. TIGK cells were then co-transfected with Myc vector alone or Myc-SerB. All cells were either stimulated with TNF or left unstimulated. Lastly, cells were fixed and stained with DAPI and anti-Myc and the location of the GFP-tagged NF-kB p65 was determined by confocal microscopy (Figure 8A). In Figure 8B we present quantification analysis of nuclear translocation of the cells shown in Figure 8A. In TIGK cells expressing Myc-SerB and GFP-NF-kB p65 and stimulated with TNF, we found $26 \%$ of counted cells to be positive for GFP-NF-kB p65 in the nucleus. Conversely, in stimulated TIGKs expressing Myc-SerB and GFP-tagged phosphomimic NF-kB p65 S536D, we found that the number of counted cells positive for nuclear p65 was in fact very similar to the levels seen in TIGKs not expressing SerB. Thus, we can infer that SerB-mediated dephosphorylation of S536 does inhibit nuclear translocation of NF-kB p65.

To further validate our findings that the action of SerB is specific for the NF-kB p65 subunit, thereby ruling out the possibility that SerB might also be targeting other NF-kB complexes we examined the effect of SerB on the nuclear translocation of the p50 and p105 subunits. TIGK cells were transfected with GFP-tagged NF-kB p50 or GFP-NF-kB 
p105 fusions and then co-transfected with Myc vector or Myc-SerB. TIGKs were then left unstimulated or stimulated with TNF. Confocal microscopy was used to visualize the nuclear translocation of both the p50 and p105 subunits. As expected, the results from these experiments showed that the presence of SerB did not impact the nuclear translocation of either the p50 or p105 subunits (Figures $8 \mathrm{C}$ and $8 \mathrm{D}$ ). Once again, corroborating our previous findings indicating that the action of this $P$. gingivalis serine phosphatase is specific for the NF-kB p65 subunit.

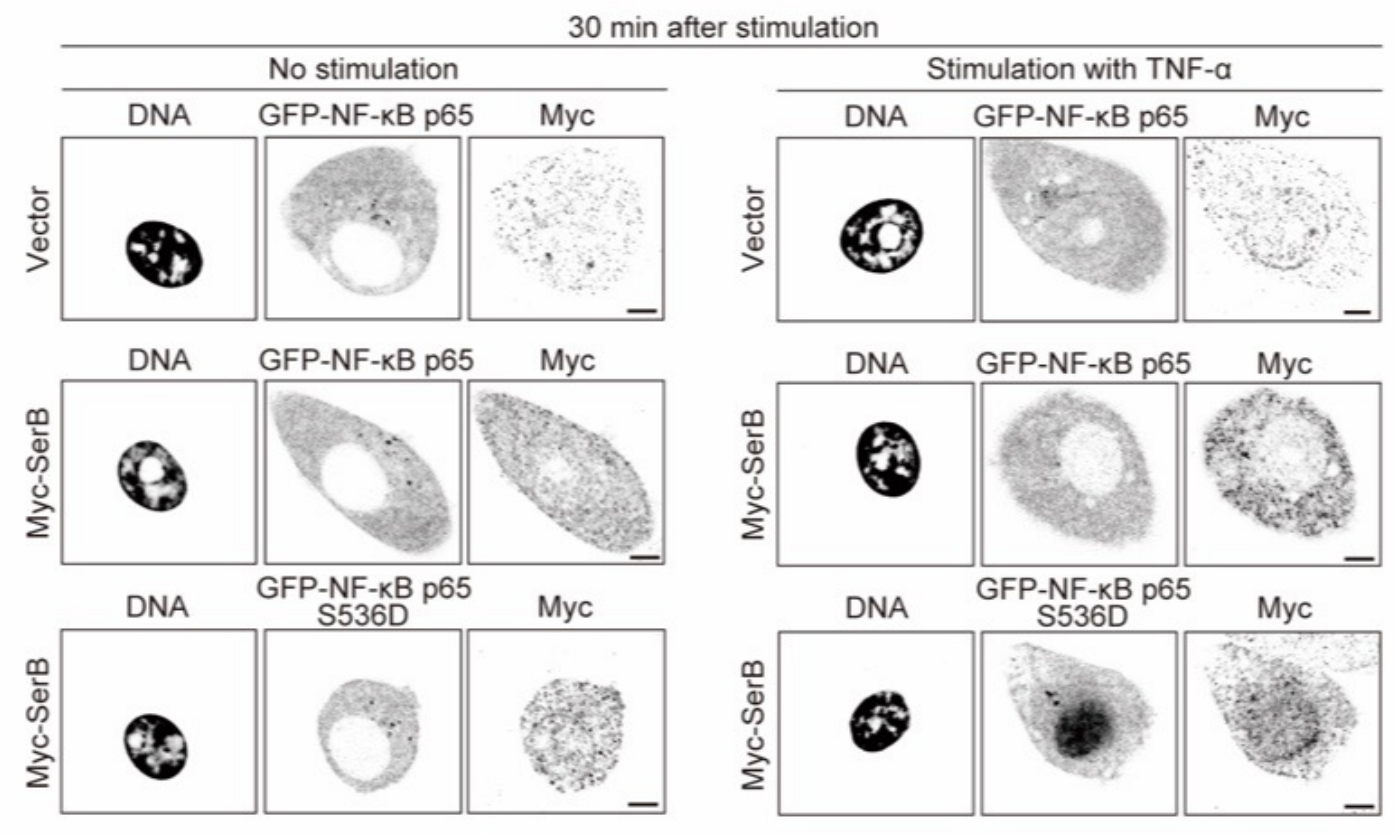

Figure 8A. P. gingivalis SerB inhibits nuclear translocation of NF-kB p65 but not p105/p50. Confocal microscopy of TIGKs co-transfected with empty Myc (vector) or Myc-SerB along with GFP-NF-kB p65 or GFP-NF-kB p65 S536D and left unstimulated or stimulated with TNF $(5 \mathrm{ng} / \mathrm{mL})$ for $30 \mathrm{~min}$. Cells were fixed and stained with DAPI and anti-Myc. Bars=5 $\mu \mathrm{m}$. Results are representative of 3 biological replicates. 


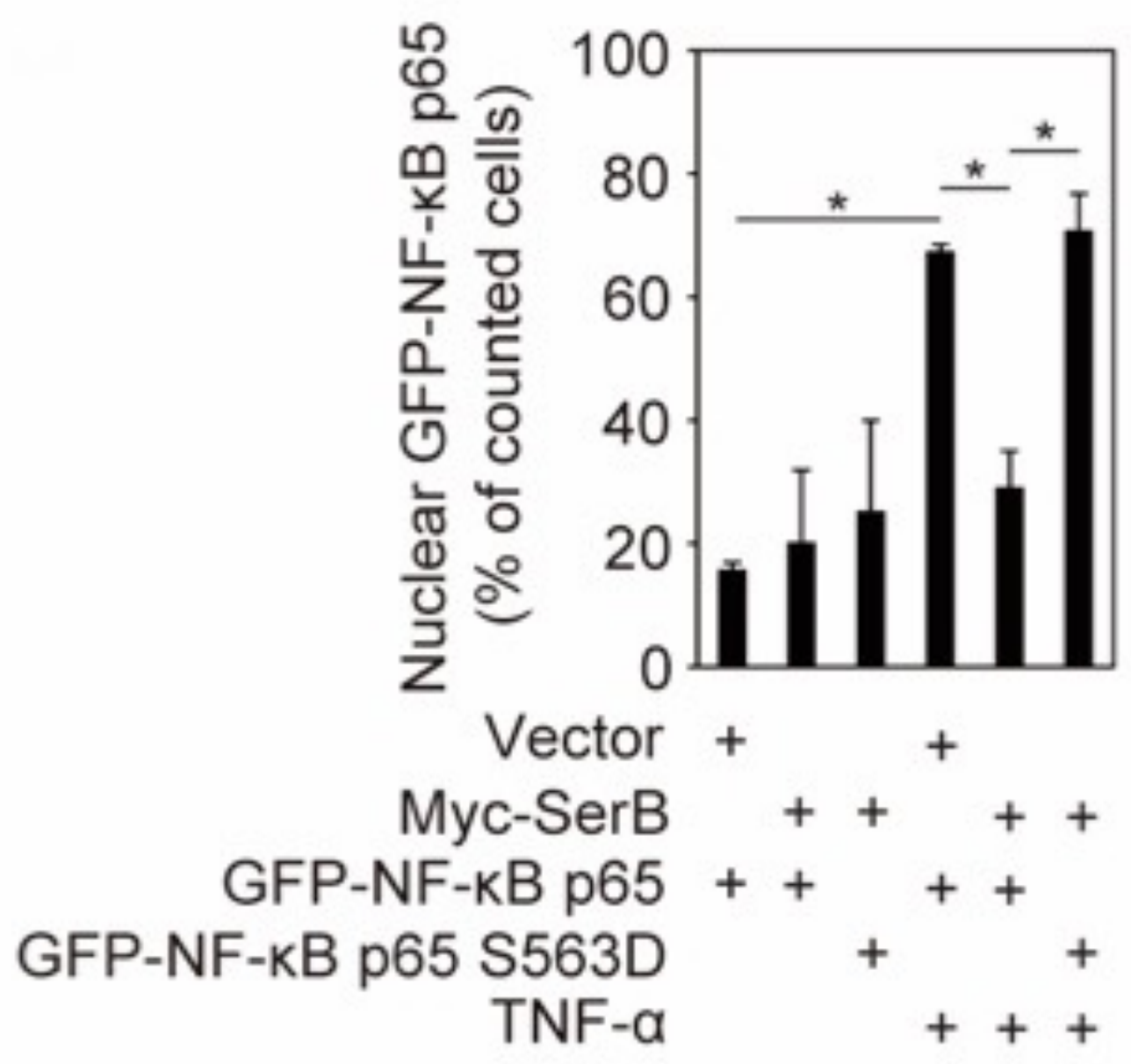

Figure 8B. P. gingivalis SerB inhibits nuclear translocation of NF-kB p65 but not p105/p50. Quantification of nuclear translocation seen in cells from (A). Results are expressed as the percentage of Myc positive cells with nuclear GFP-NF-kB p65 and are the mean with SEM of 3 independent experiments. $>/=90$ Myc/GFP positive cells were counted per test. ${ }^{*} p<0.05$. 
30 min after stimulation
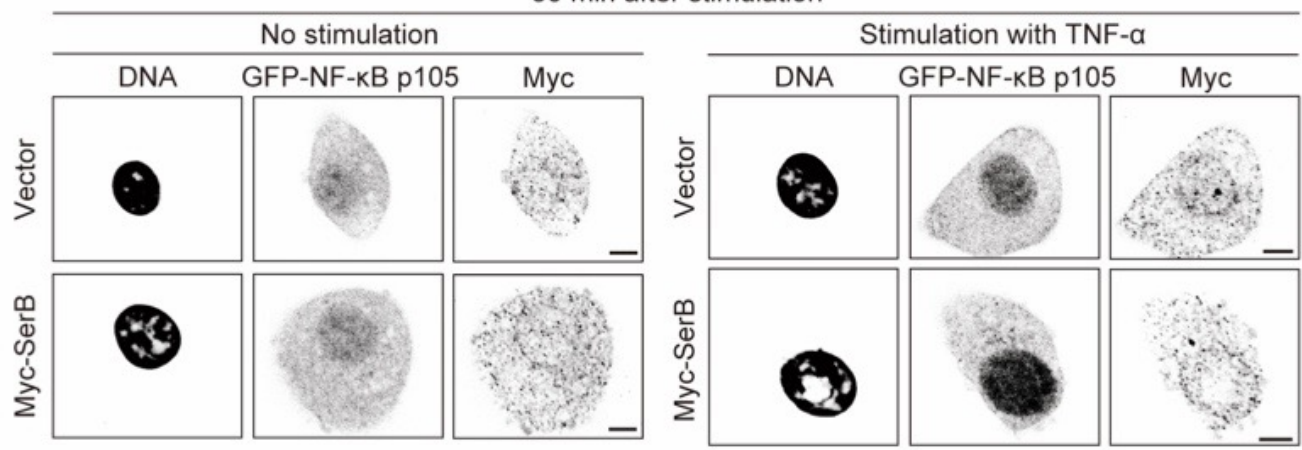

Figure 8C. P. gingivalis SerB inhibits nuclear translocation of NF-kB p65 but not p105/p50. Confocal microscopy of TIGKs co-transfected with Myc (vector) or MycSerB along with GFP-NF-kB p105 and left unstimulated or stimulated with TNF (5 $\mathrm{ng} / \mathrm{mL}$ ) for $30 \mathrm{~min}$. Cells were fixed and stained with DAPI and anti-Myc. Bars=5 $\mu \mathrm{m}$. Results are representative of 3 biological replicates. 


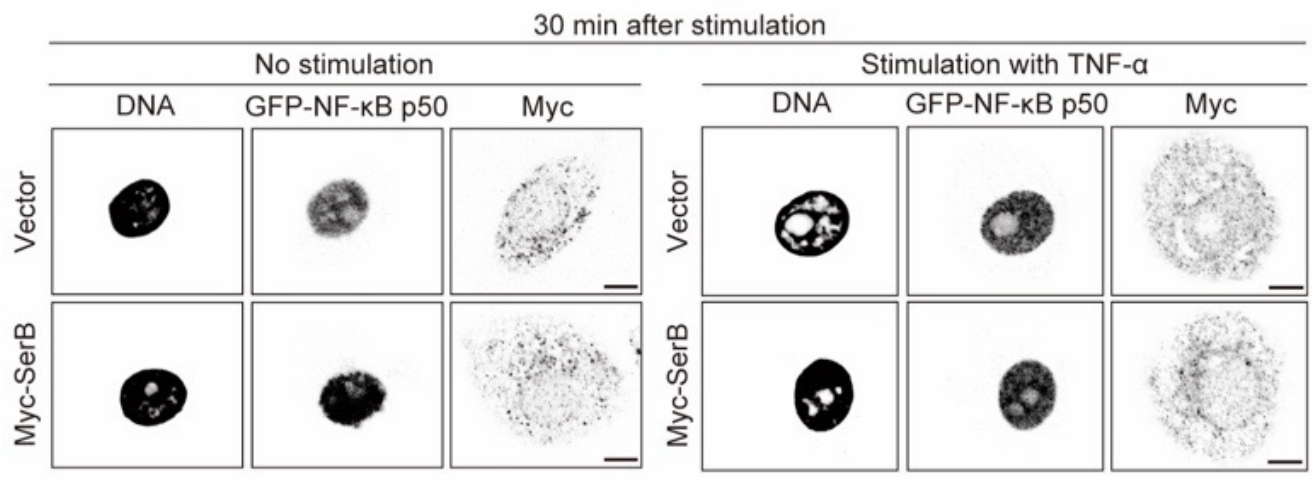

Figure 8D. $P$. gingivalis SerB inhibits nuclear translocation of NF-kB p65 but not p105/p50. Confocal microscopy of TIGKs co-transfected with Myc (vector) or MycSerB along with GFP-NF-kB p50 and left unstimulated or stimulated with TNF (5 $\mathrm{ng} / \mathrm{mL}$ ) for $30 \mathrm{~min}$. Cells were fixed and stained with DAPI and anti-Myc. Bars=5 $\mu \mathrm{m}$. 
4.6 P. gingivalis SerB inhibits the IL-8 promoter response regulated by NF- $\kappa B$ p65

Previous studies have reported the possibility of distinct groupings of p65, which can be distinguished based on their phosphorylation status at S536 residue and on their association with p50 [137]. Additionally, it has also been reported that p65 independent of the p50 subunit is not regulated by $\mathrm{kBB}$ proteins and appears to follow a non-canonical pathway. To briefly summarize, there are 2 signaling pathways that lead to the activation of $\mathrm{NF}-\kappa \mathrm{B}$, the canonical (classical) and non-canonical (alternative) pathways. The canonical pathway is activated by most physiological stimuli and is responsible for activating the NF-kB dimers comprising RelA, cRel, p50 and RelB. On the other hand, the non-canonical pathway is activated by only a very limited number of stimuli including lymphotoxin B and B cell activating factor. This non-canonical pathway is responsible for the activation of the p100/RelB complexes. These two pathways do, however, share a common regulatory step, and that is the activation of the IKB kinase (IKK) complex. One population of phosphorylated p65 subunits has been shown to translocate to the nucleus independently of p50 and can be recruited to the IL-8 promoter region following stimulation. We speculated that the action of SerB on the NF-kB p65 complex independent of any association with p50 was sufficient to block the recruitment of p65 as well as preventing its transcription of the IL-8 gene. To investigate this, we cotransfected TIGK cells with Myc vector or Myc-SerB, and also with either (1) GFP, (2) GFP-NF-kB p65, or (3) GFP-NF-kB p50. All cells were transfected with a Luciferase reporter plasmid, plL-8 kB-Luc, to measure IL-8 promoter activity. TIGKs were subsequently stimulated with TNF for $3 \mathrm{~h}$ at which point, cells were then measured for IL-8 promoter driven luciferase activity and normalized to Renilla Luciferase. Results shown in Figure 9A are presented as fold induction relative to luciferase activity of our unstimulated control group. We found that the luciferase activity of TIGKs expressing 
Myc-SerB was significantly reduced when stimulated with TNF when compared to TIGKs expressing empty Myc vector (Figure 9A). We also studied the effect of excess exogenous p65 or p50 on the IL-8 promoter activity. Accordingly, we found that the presence of exogenous p50 did not impact the SerB-mediated suppression of the IL-8 promoter activity. However, exogenous p65 introduced via GFP-NF-kB subunits into the TIGKs demonstrated the ability to relieve the suppression of the IL-8 reporter as evidenced by an increase in promoter activity from 0.76 to 55 -fold induction of the control level compared with TNF-stimulated TIGKs expressing Myc-SerB and GFP (Figure 9A). To validate the relevance of this interaction between SerB and NF-kB p65 in terms of IL-8 production we next examined the amount of IL-8 secreted into TIGK culture media. TIGKs were transfected with Myc vector or Myc-SerB and stimulated with TNF for various timepoints. At each time period the levels of IL-8 present in the culture supernatants were measured by ELISA (Figure 9B). We found that after $2 \mathrm{~h}$ of TNF stimulation, IL-8 levels decreased by $74 \%$ in TIGKs expressing Myc-SerB. Likewise, after 4 hrs of stimulation, a similar trend was seen as IL-8 levels had decreased by $65 \%$ in TIGKs expressing Myc-SerB (Figure 9B). To further corroborate these results we cotransfected TIGKs with either Myc vector alone or Myc-SerB, and with either (1) GFP, (2) GFP-NF-kB p65, or (3) GFP-NF-kB p50. TIGKs were stimulated with TNF and then the IL-8 levels in the supernatants were measured by ELISA (Figure 9C). Once again, in support of our previous findings, exogenous p65 did function to relieve the inhibition of TNF stimulated IL-8 secretion. This trend however was not observed in TIGKs that had been transfected with GFP-NF-kB p50 subunit. Altogether, these findings indicate that exogenous intracellular SerB is capable of preventing IL-8 production. And, most importantly, inhibition of p65 directly corresponds to lower levels of IL-8 production. 


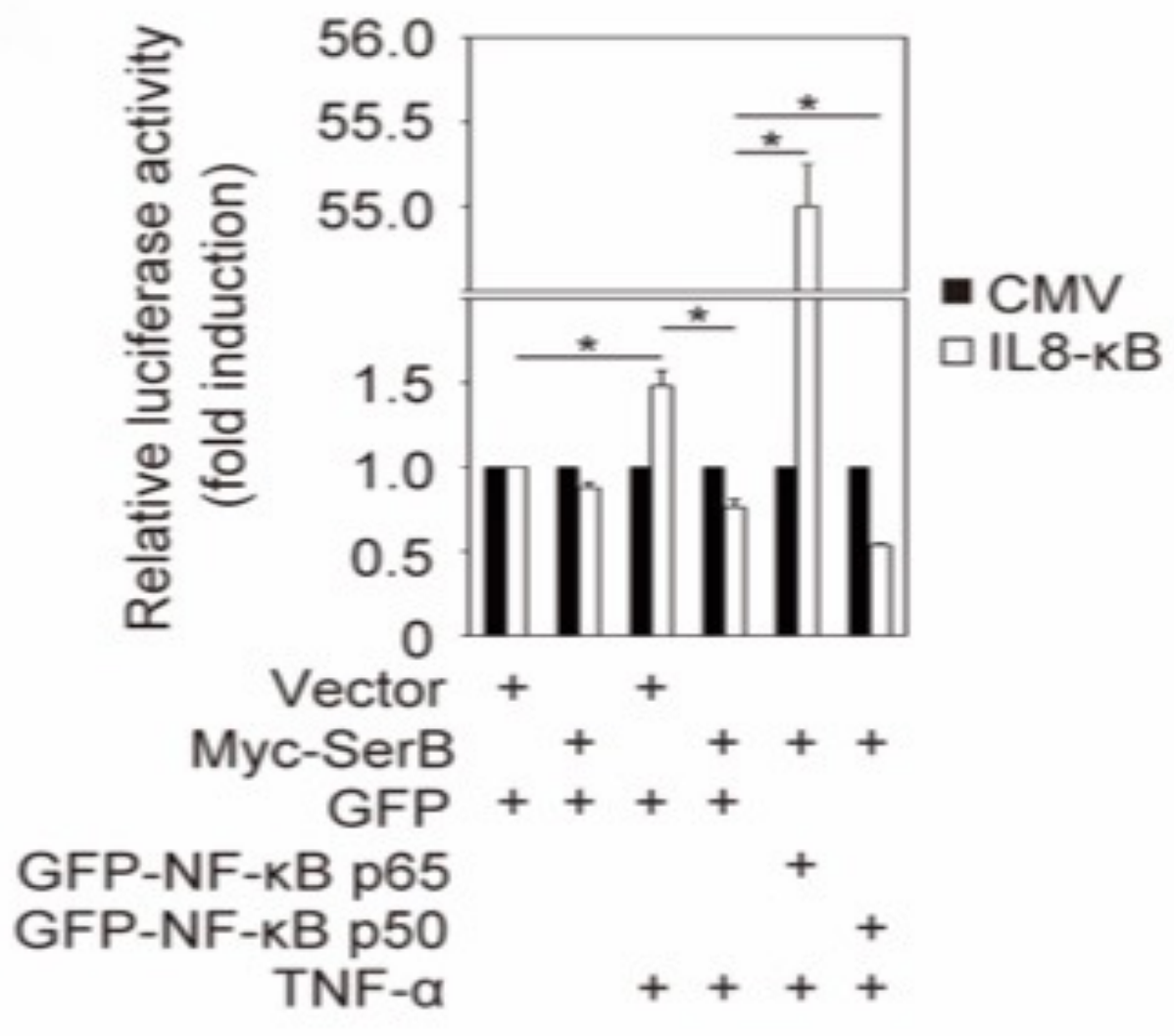

Figure 9A. SerB dephosphorylation of NF-kB p65 inhibits IL-8 promoter activity and IL-8 production. TIGK cells were co-transfected with Myc (vector) or MycSerB, and with either of GFP, GFP-NF-kB p65, GFP-NF-kB p50, along with pIL-8 kB-Luc luciferase reporter for IL-8 promoter activity or pRL-CMV Renilla Luciferase control. Cells were stimulated with TNF (40 $\mathrm{ng} / \mathrm{mL})$ as indicated and after $3 \mathrm{~h}$ stimulation, IL-8-kB luciferase activity was measured and normalized to Renilla luciferase. Results are presented as fold increase relative to the activity of the unstimulated control and are means $+/-S D$ of 6 biological replicates. ${ }^{*} p<0.05$. 


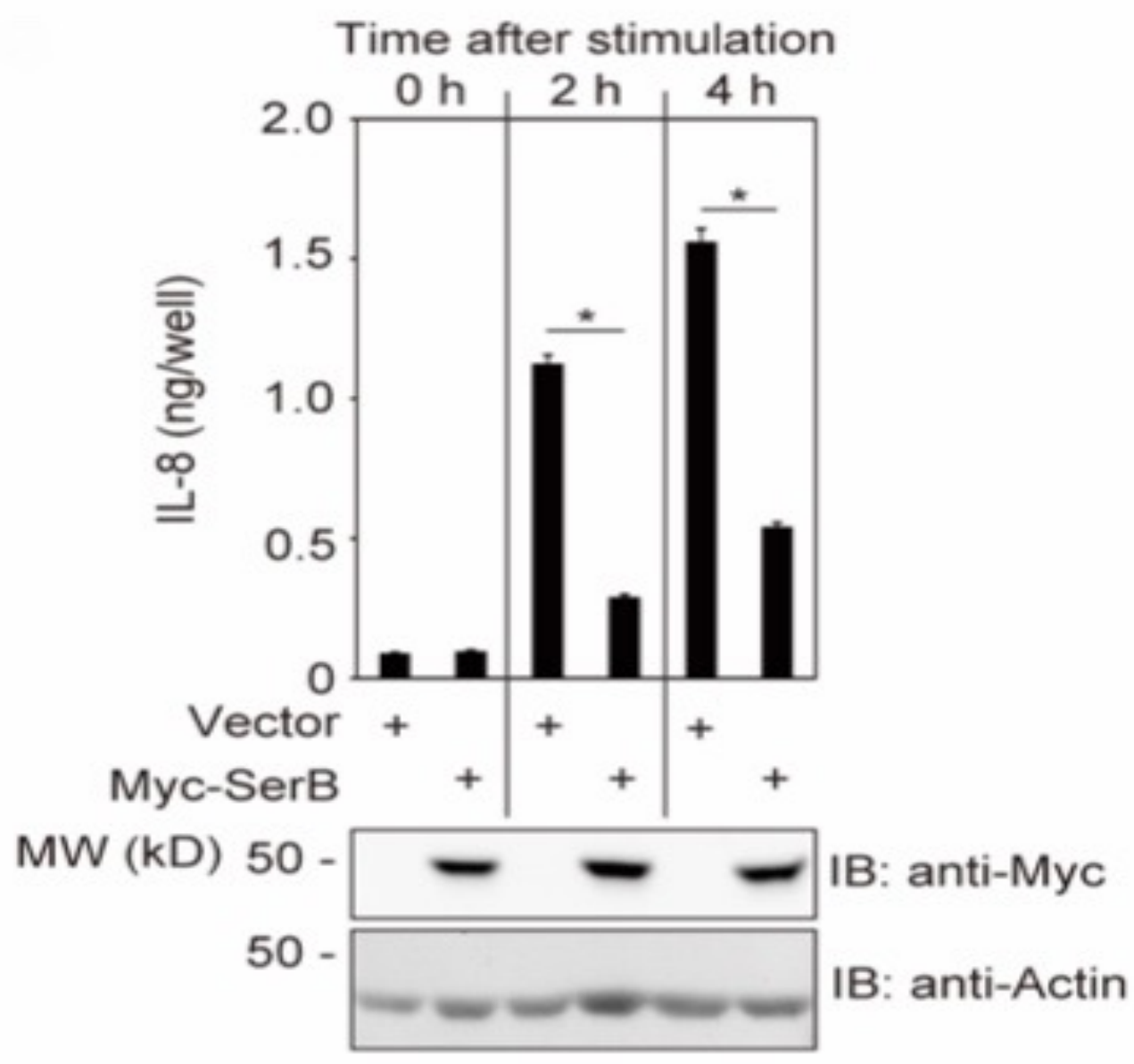

Figure 9B. SerB dephosphorylation of NF-kB p65 inhibits IL-8 promoter activity and IL-8 production. TIGKs were transfected with Myc (vector) or Myc-SerB and at $36 \mathrm{~h}$ after transfection cells were stimulated with TNF $(5 \mathrm{ng} / \mathrm{mL})$ for the indicated time periods. At each time point, the level of IL-8 in culture supernatants was measured by ELISA. Values are the mean +/-SD of 6 biological replicates. ${ }^{*} \mathrm{p}<0.05$. 


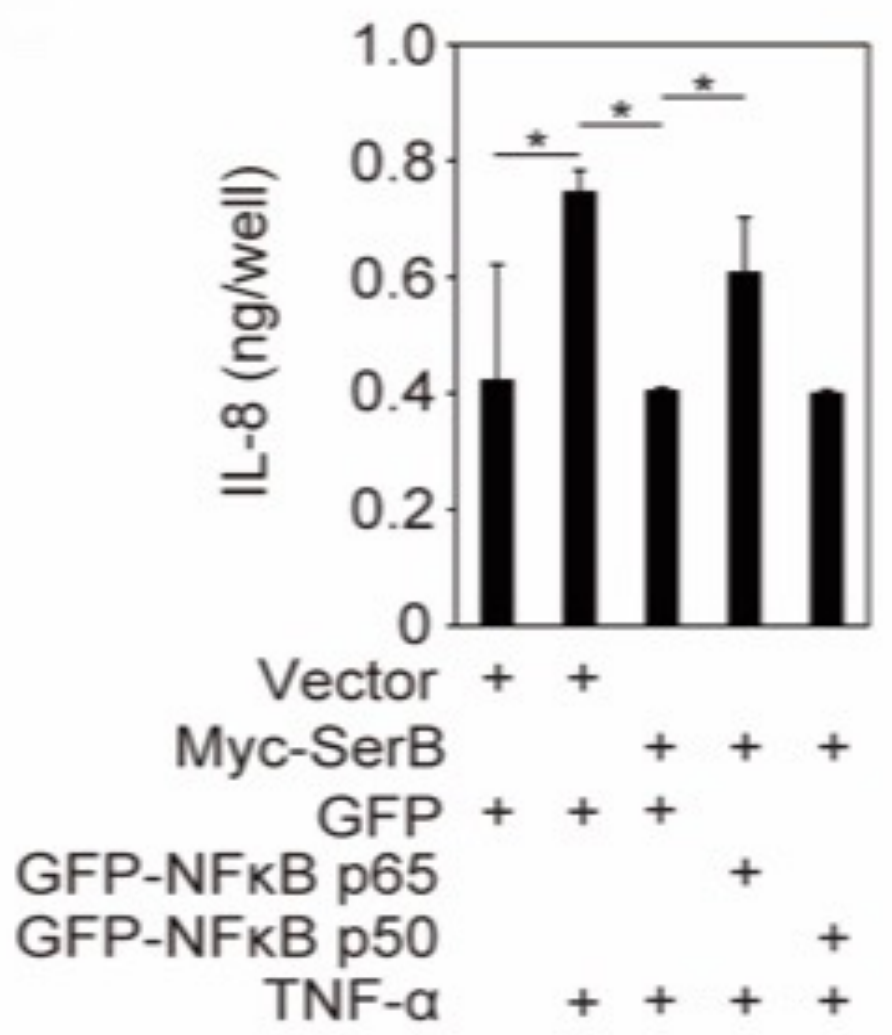

Figure 9C. SerB dephosphorylation of NF-kB p65 inhibits IL-8 promoter activity and IL-8 production. TIGKs co-transfected with Myc (vector) or Myc-SerB, and either of GFP, GFP-NF-kB p65, GFP-NF-kB p50. Cells were stimulated with TNF (5 $\mathrm{ng} / \mathrm{mL}$ ) as indicated and after $4 \mathrm{~h}$ the level of IL-8 in culture supernatants was measured by ELISA. Values are the mean +/-SD of 6 biological replicates. ${ }^{*} \mathrm{p}<0.05$. 
Consistent with all previous findings we have presented definitive evidence demonstrating that dephosphorylation of NF-kB p65 by $P$. gingivalis SerB serves to prevent its nuclear translocation which in turn inhibits activity of NF-kB p65 on the IL-8 promoter thereby resulting in reduced IL-8 secretion in TIGK cells. 


\section{CHAPTER 5}

\section{P. GINGIVALIS TYROSINE KINASE-1: EXPERIMENTAL RESULTS}

\subsection{PGN_1524 is a bacterial tyrosine (BY) kinase present in $P$. gingivalis}

Previous studies have shown that PGN_1524, originally identified as a hypothetical protein in $P$. gingivalis, was found to possess proteotypical features of a bacterial tyrosine (BY) kinase. This determination was made from in silico analysis of the genome of $P$. gingivalis 33277 [140]). These aforementioned proteotypical features are well conserved among prokaryotic BY kinases and include Walker A and B motifs, a transmembrane domain, as well as a C-terminal tyrosine-rich cluster $[109,141])$. Comparisons of the amino acid sequences between this hypothetical PGN_1524 protein and a previously identified BY kinase in E. coli, Wzc, showed a high degree of similarity. Given this information, our first course of action was to establish whether PGN_1524 possessed tyrosine kinase activity. Initially, we had difficulty attempting to express the full length recombinant PGN_1524 protein in E. coli due to toxicity issues. Previous studies have shown that the cytoplasmic domains of BY kinases often possess functional activity so we then decided to work with only recombinant cytoplasmic domain (aa residues 541-821) of PGN_1524, thus circumventing any toxicity issues. We tested this fragment for tyrosine kinase activity by performing a quantitative kinase assay. Our peptide cytoplasmic fragment (Ptk1: 541-821) was incubated with ATP and a poly:GluTyr substrate for $15 \mathrm{~min}$. Measurement of fluorescence intensity indicated the amount of tyrosine phosphorylation activity. The results showed that residues $541-821$ (labeled FPtk1 in Figure 10) possessed significant $(p<0.001)$ kinase activity when compared to the negative kinase control (Figure 10A). To further test whether this kinase activity was dose-dependent we carried out a subsequent concentrationdependent kinase assay for FPtk1 where we tested fluorescence intensity with varying 
amounts of FPtk1 (Figure 10B). Our negative control was kinase buffer. Here we found that tyrosine kinase activity was strongly dose-dependent (Figure 10B). Based on these initial findings we assigned PGN_1524 the name of Ptk1, $\underline{P}$. gingivalis tyrosine kinase 1. Autophosphorylation as well as substrate phosphorylation are key abilities exhibited by bacterial tyrosine kinases $[109,142]$. Thus, we explored the ability of FPtk1 to autophosphorylate. The recombinant purified protein fragment FPtk1: 541-821 was heavily phosphorylated so we first treated this fragment with alkaline phosphatase. We then added exogenous ATP along with a phosphatase inhibitor cocktail. Samples were collected and prepared for Western blot analysis. Immunoblots were probed with phosphotyrosine antibodies. Our findings showed that with the addition of ATP, FPtk1 was restored to its heavily phosphorylated state observed in the untreated control (Figure 10C). This provides us with two important pieces of information: (1) Ptk1 is capable of utilizing ATP to autophosphorylate and (2) this autophosphorylation activity of Ptk1 dwells within the cytoplasmic domain. This finding was corroborated later by research from our lab which showed that mutations in any of the Walker A, B, RK and YC domains present in Ptk1 all prevented autophosphorylation of Ptk1. The Walker A and $B$ motifs are responsible for nucleotide binding and hydrolysis [143]. The C-terminal YC domain is comprised of multiple closely spaced tyrosine residues which receive phosphate groups from the catalytic domain and, in turn, increase kinase activity [107]. The RK cluster, rich in arginine and lysine residues, contributes to catalytic activity [144]. 


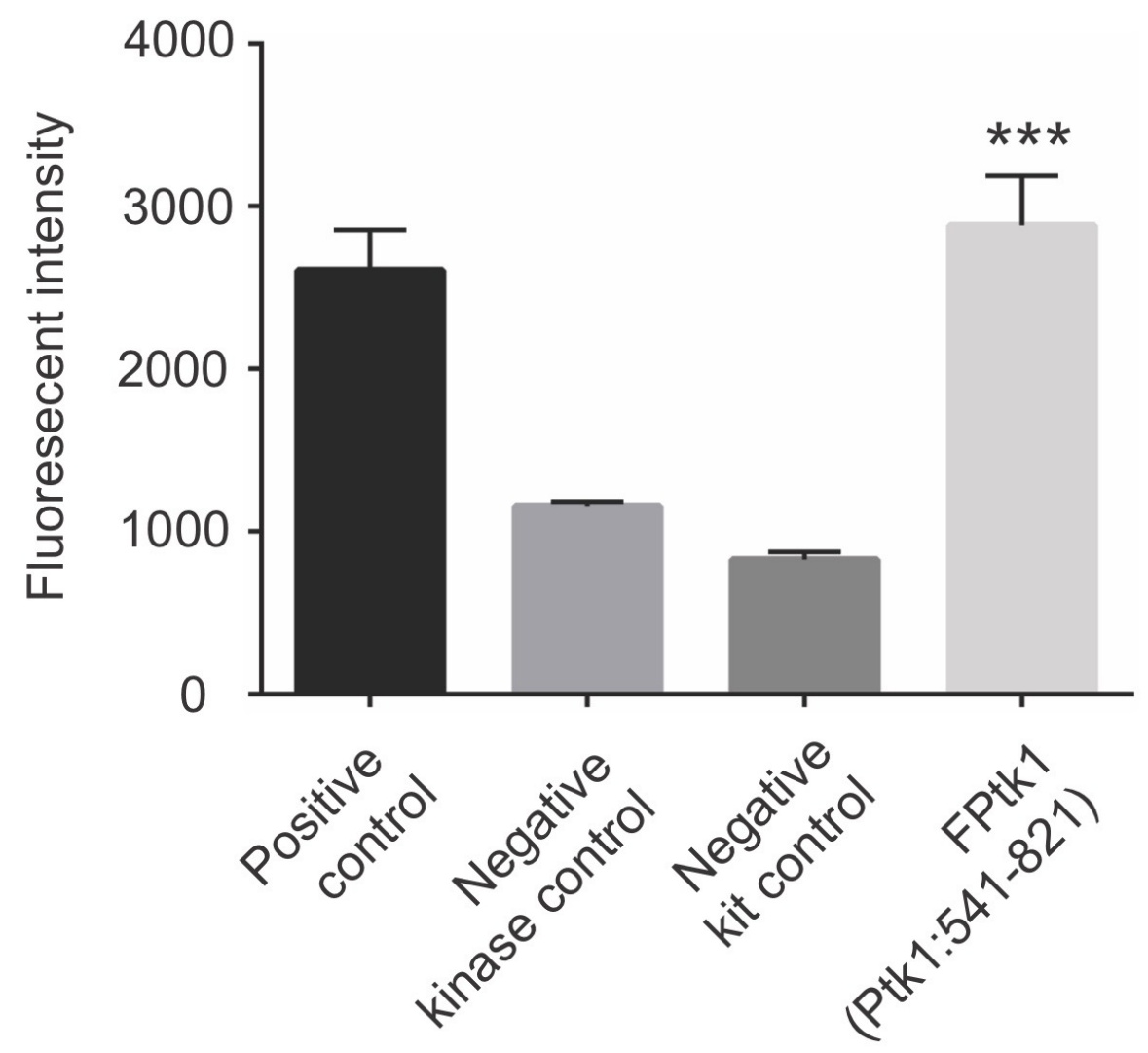

Figure 10A. Ptk1 demonstrates substrate- and auto- phosphorylation. Tyrosine kinase assay with the 541-821 C-terminal aa fragment of Ptk1 (FPtk1, $5 \mu \mathrm{g}$ ). Positive control and negative kit control supplied with the assay kit. Negative kinase control is buffer only. $\mathrm{N}=3 .{ }^{* * *} \mathrm{p}<0.001$ compared to kinase control. 


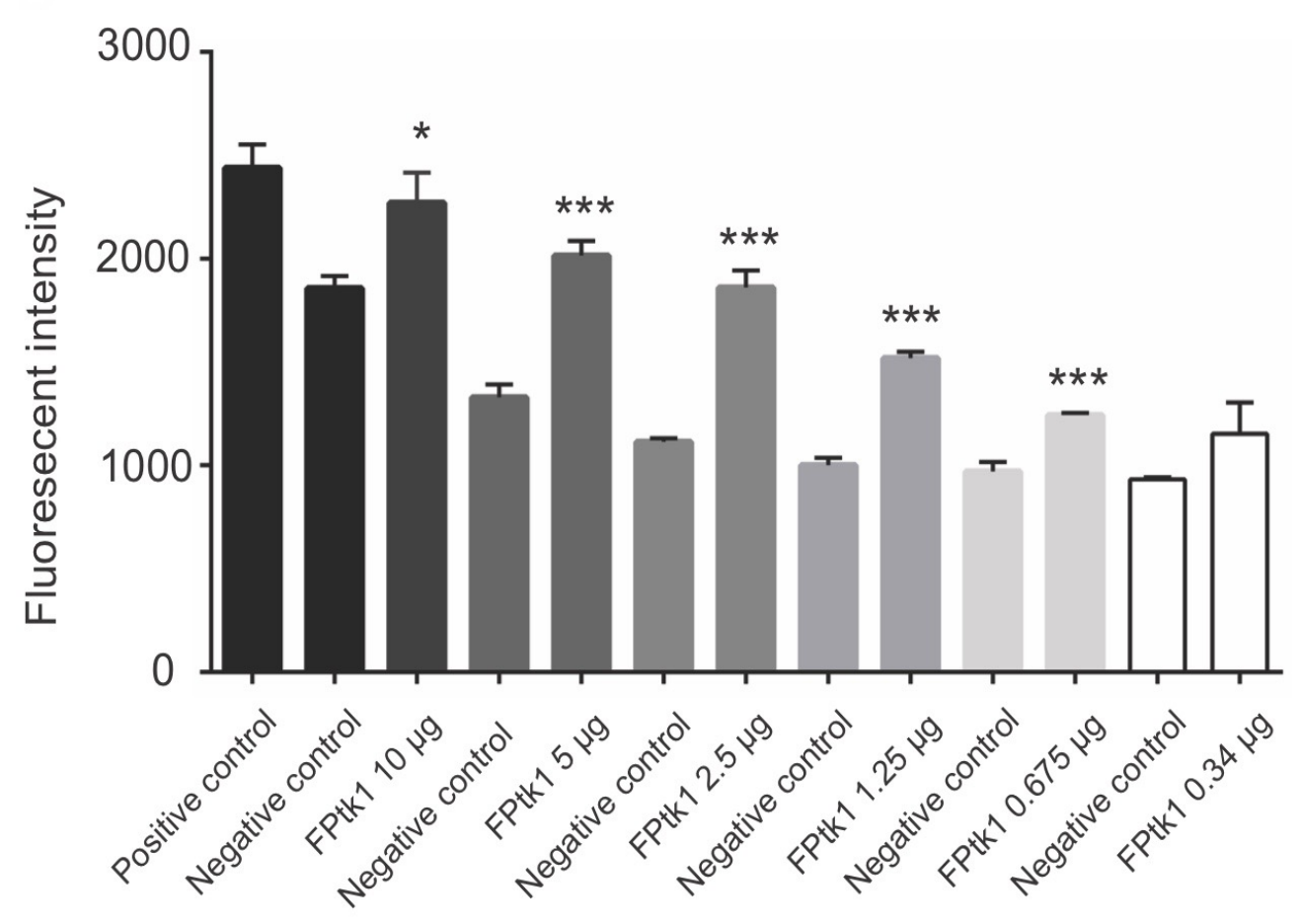

Figure 10B. Ptk1 demonstrates substrate- and auto- phosphorylation. Concentration-dependent kinase activity of FPtk1. Negative control is kinase buffer only. ${ }^{*} p<0.05 ;{ }^{* * *} p<0.001$ compared to negative control. 


\section{FPtk1}

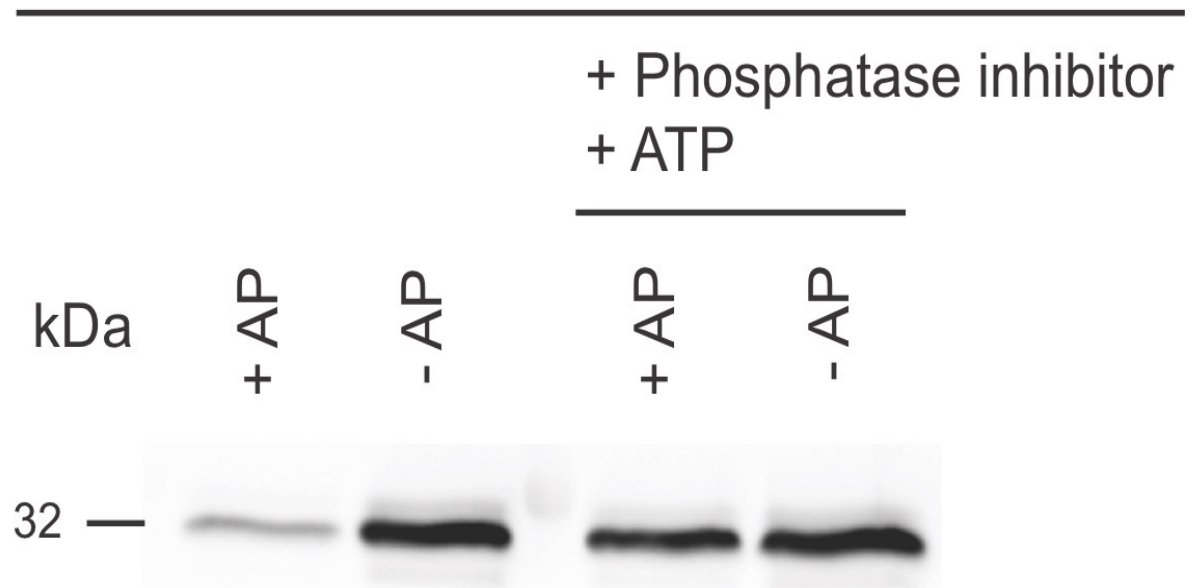

Figure 10C. Ptk1 demonstrates substrate- and auto- phosphorylation. Autophosphorylation of FPtk1. FPtk1 was dephosphorylated with alkaline phosphatase (AP) then treated with phosphatase inhibitor and ATP or left untreated as a control. Phosphorylated FPtk1 was visualized with Western Blots using phosphotyrosine antibodies. 
5.2 P. gingivalis tyrosine phosphatase, Ltp1, dephosphorylates Ptk1

Currently, the only annotated tyrosine phosphatase and tyrosine kinase enzymes identified within the $P$. gingivalis 33277 genome are Ltp1 and Ptk1, respectively [135, 140, 143]. Previous research from our lab elucidated the role of tyrosine phosphatase, Ltp1, in P. gingivalis-S. gordonii dual species community development $[126,135]$. We know that initial contact between $P$. gingivalis and $S$. gordonii cells initiates a streptococcal derived signal propagated through the minor Mfa1-component fimbriae, which activates Ltp1 and in turn, this transduces a signaling event that converges on the downstream transcriptional regulator, named Community Development and Hemin Regulator (CdhR). The main functions of $L t p 1$ and $C d h R$ are to constrain $P$. gingivalis accumulation within the context of $P$. gingivalis-S. gordonii communities. Furthermore, we know from studies of other systems that these types of phosphatases usually have a kinase cognate pair as has been reported in E. coli as well as S. pneumoniae. Given that Ptk1 is currently the only identified tyrosine kinase in the $P$. gingivalis 33277 genome this raised our suspicions that perhaps Ptk1 is the cognate kinase of Ltp1 and may also be involved in this signaling cascade regulating the community formation process between $P$. gingivalis and $S$. gordonii. Our first task was to perform an initial mRNA screening of Ptk1 to assess whether it is regulated early on in the interaction between $P$. gingivalis and $S$. gordonii, thereby indicating its importance and involvement. Figure 11 shows the reverse transcriptase PCR of Ptk1 mRNA performed over a period of time in $P$. gingivalis when it is in association with S. gordonii. This experiment showed an early transcriptional increase (red bars=upregulation) in Ptk1 mRNA and thus supports our hypothesis that this kinase is important early on during $P$. gingivalis-S. gordonii community development. 


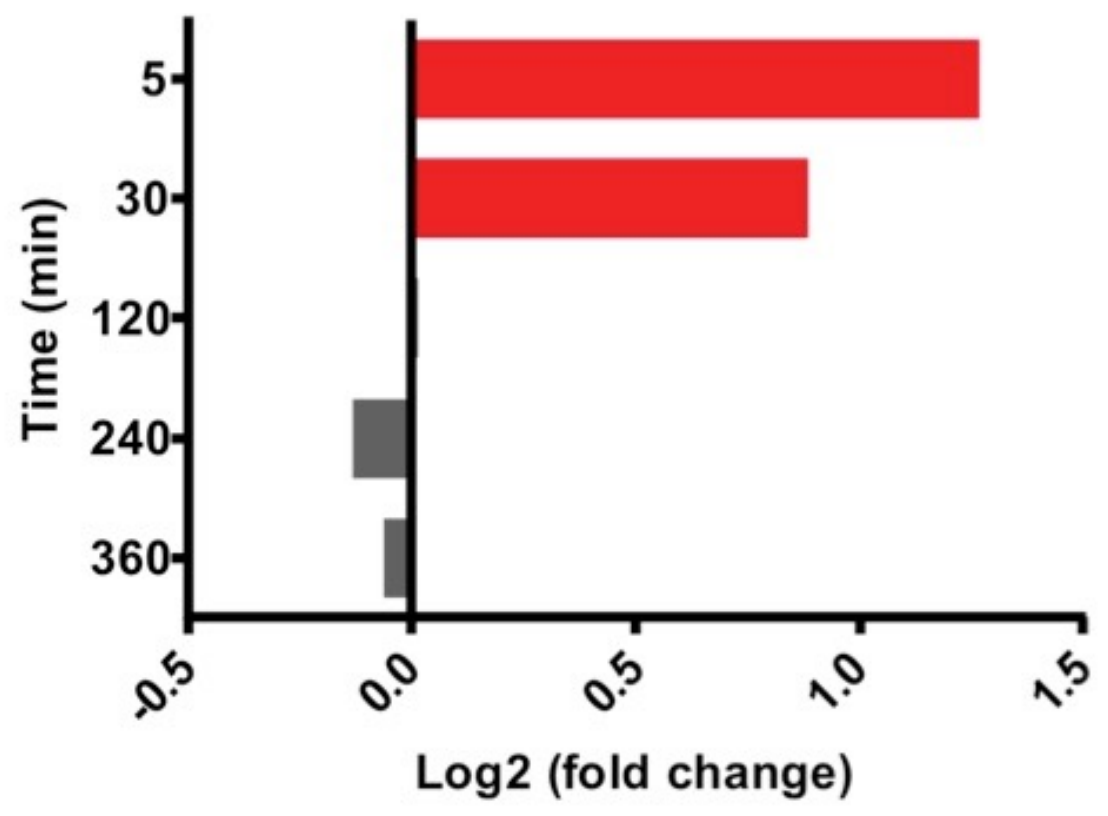

Figure 11. qRT-PCR of Ptk1 mRNA expression in P. gingivalis + S. gordonii compared to $\boldsymbol{P}$. gingivalis alone over time. Results are expressed as $\log _{2}$ fold change in $P$. gingivalis $-S$. gordonii compared to $P$. gingivalis alone at the times indicated. Statistically significant higher mRNA levels are represented by red bars. 
We then wanted to examine the ability of Ltp1 to dephosphorylate the Ptk1 kinase. We carried this out by performing another tyrosine kinase assay where we found that incubation of the catalytically active domain of Ptk1 (FPtk1: 541-821) with Ltp1 resulted in significantly diminished kinase activity when compared to the FPtk1 group by itself (Figure 12A). When we substituted a Ser for Cys residue in the active domain of Ltp1, rendering it inactive, we found that when the FPtk1 was incubated with this inactive Ltp1 C10S mutant the kinase activity was restored back to normal levels seen previously when only FPtk1 activity was measured (Figure 12A). Consistent with these findings, we also observed reduced tyrosine phosphorylation of FPtk1following reaction with active Ltp1 by western blot analysis, probing with specific phosphotyrosine antibodies (Figures $12 \mathrm{~B}$ and $12 \mathrm{C}$ ). Moreover, addition of a phosphatase inhibitor served to block the action of Ltp1 thereby restoring the normal phosphorylated state of FPtk1. These results demonstrate that the catalytically inactive Ltp1 C10S mutant is unable to dephosphorylate FPtk1. In contrast, Ltp1 can successfully dephosphorylate and thus reduce kinase activity of Ptk1. We can conclude that Ptk1 is one of the substrates for Ltp1 and it is the phosphatase activity of Ltp1 which directly affects the kinase activity of Ptk1. Thanks to additional research carried out by our lab, it was determined that Ptk1 could also directly phosphorylate Ltp1, thus suggesting that Ptk1 and Ltp1 can phosphorylate and dephosphorylate each other, providing further evidence to support the notion that they are a cognate kinase-phosphatase pair potentially involved in a feedback mechanism important in regulating various signaling networks [143]. 


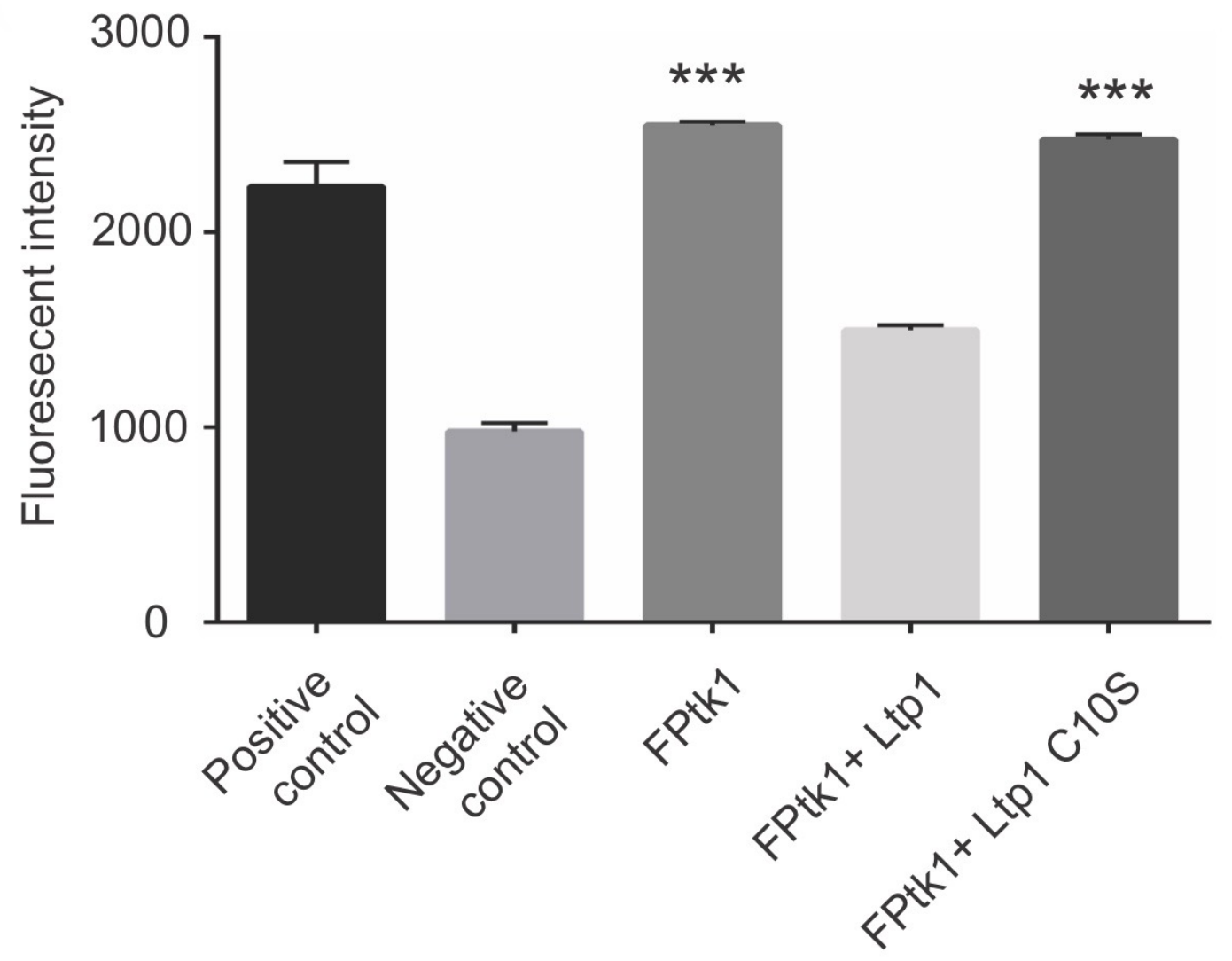

Figure 12A. Dephosphorylation of FPtk1 by Ltp1. Incubation of FPtk1 with Ltp1 results in dephosphorylation. ${ }^{* * *} \mathrm{p}<0.001$ compared to negative control. 


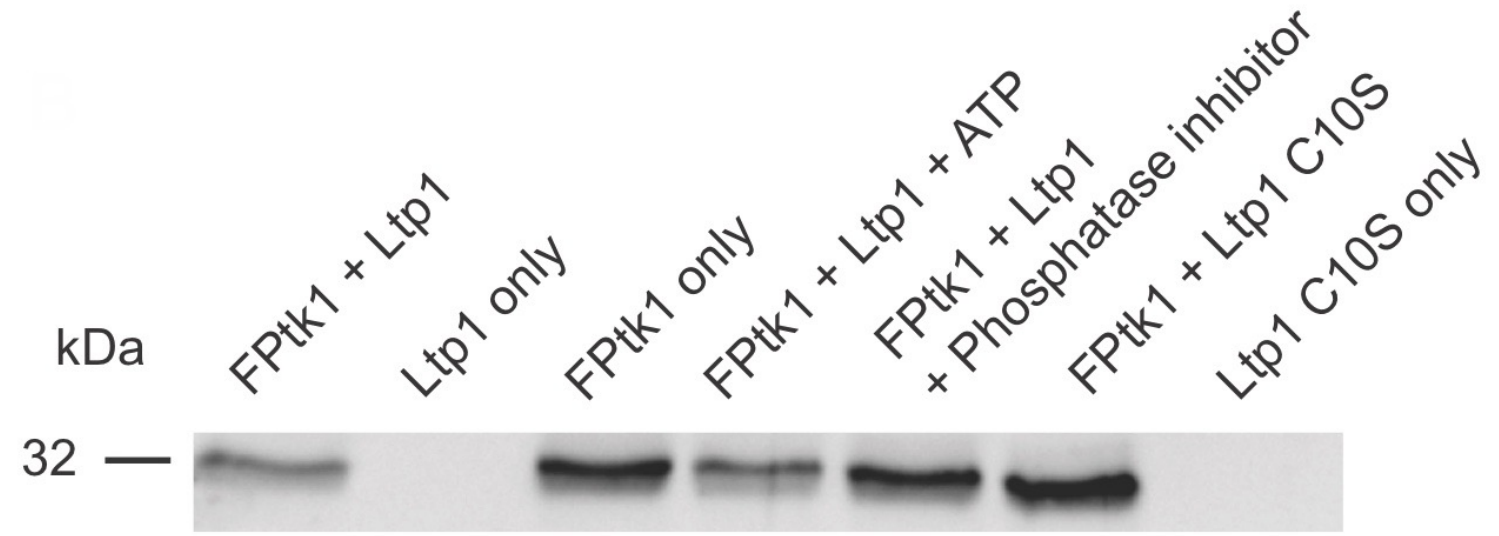

Figure 12B. Dephosphorylation of FPtk1 by Ltp1. Western immunoblot of FPtk1 incubated with Ltp1 or Ltp1 C10S, and with ATP or phosphatase inhibitor as indicated. Phosphorylation levels of FPtk1 determined by Western blots probed with phosphotyrosine antibodies as indicated. 


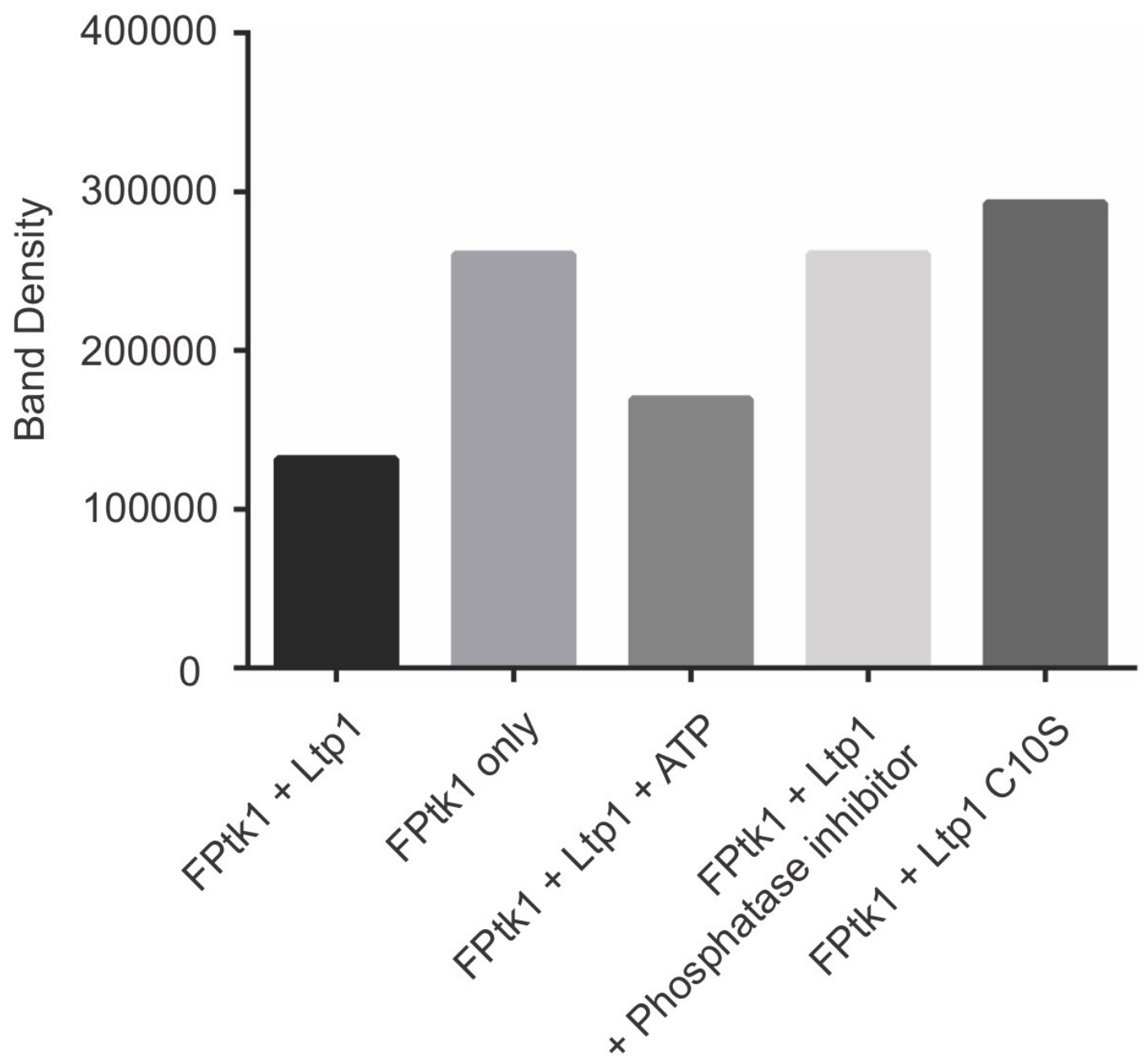

Figure 12C. Dephosphorylation of FPtk1 by Ltp1. Densitometry of immunoblots shown in (B) using ImageJ software. ${ }^{*} p<0.05 ;{ }^{* * *} p<0.001$ compared to FPtk1+Ltp1. 
5.3 Ptk1 is required for optimal $P$. gingivalis-S. gordonii community development

To further investigate the role of Ptk1 in $P$. gingivalis-S. gordonii community development we generated a mutant in the ptk1 gene and then complemented the mutant with the functional allele in trans. These strains were tested for their abilities to form communities with $S$. gordonii. Since we already know from previous research generated by our lab that Ltp1 phosphatase activity leads to reduced accumulation of $P$. gingivalis with S. gordonii [126]), we predicted that this Ptk1 kinase would yield an opposite effect and thereby promote $P$. gingivalis-S. gordonii community formation. The P. gingivalis strains, 33277 (WT), $\Delta p t k 1$, and $\Delta p t k 1+p p t k 1$ complemented mutant, were all labeled with FITC (green). The S. gordonii substrate was labeled with hexidium iodide (red). The $P$. gingivalis strains were then reacted with the $S$. gordonii substrate for $18 \mathrm{hrs}$ and these communities were visualized using confocal microscopy (Figure 13A). We found that with the $\Delta p t k 1$ mutant (no active Ptk1) there was significantly reduced accumulation of $P$. gingivalis on the $S$. gordonii substrate. However, when we complemented the ptk1 mutant, the levels of $P$. gingivalis accumulation were restored back to those seen when in the presence of $P$. gingivalis WT 33277 strain. We performed a quantitative image analysis of the results from Figure 13A in terms of $P$. gingivalis biovolume and microcolony counts (Figures 13B and 13C). Consistent with our previous findings, when comparing everything to our mutant ptk1 strain we again see that the presence of Ptk1 promotes $P$. gingivalis accumulation on a $S$. gordonii substrate. 

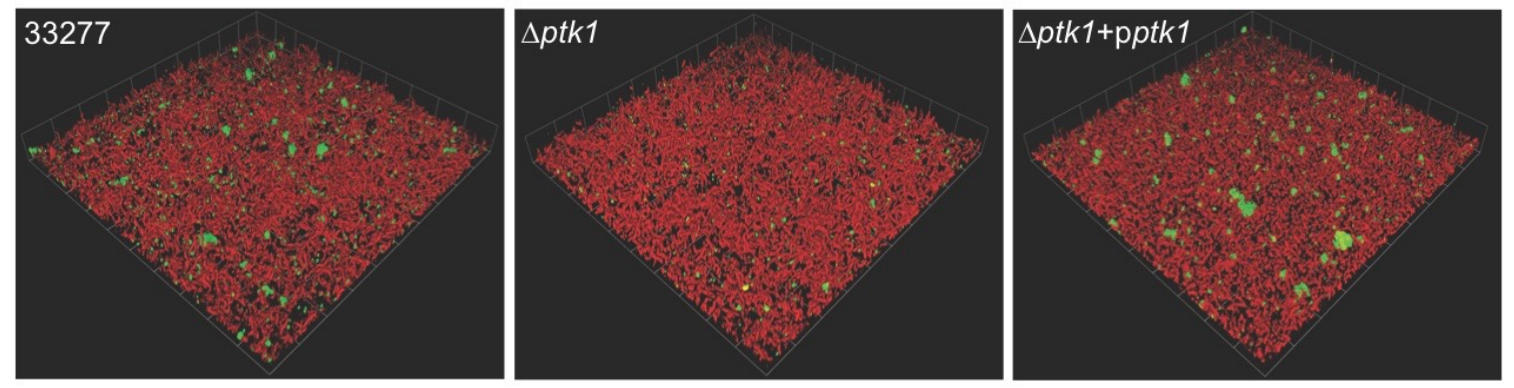

Figure 13A. ptk1 is required for maximal $P$. gingivalis-S. gordonii community development. Confocal microscopy of $P$. gingivalis $33277, \Delta$ ptk1, and $\Delta$ ptk1 + pptk1 (green) reacted with S. gordonii substrate (red) for $18 \mathrm{~h}$. 


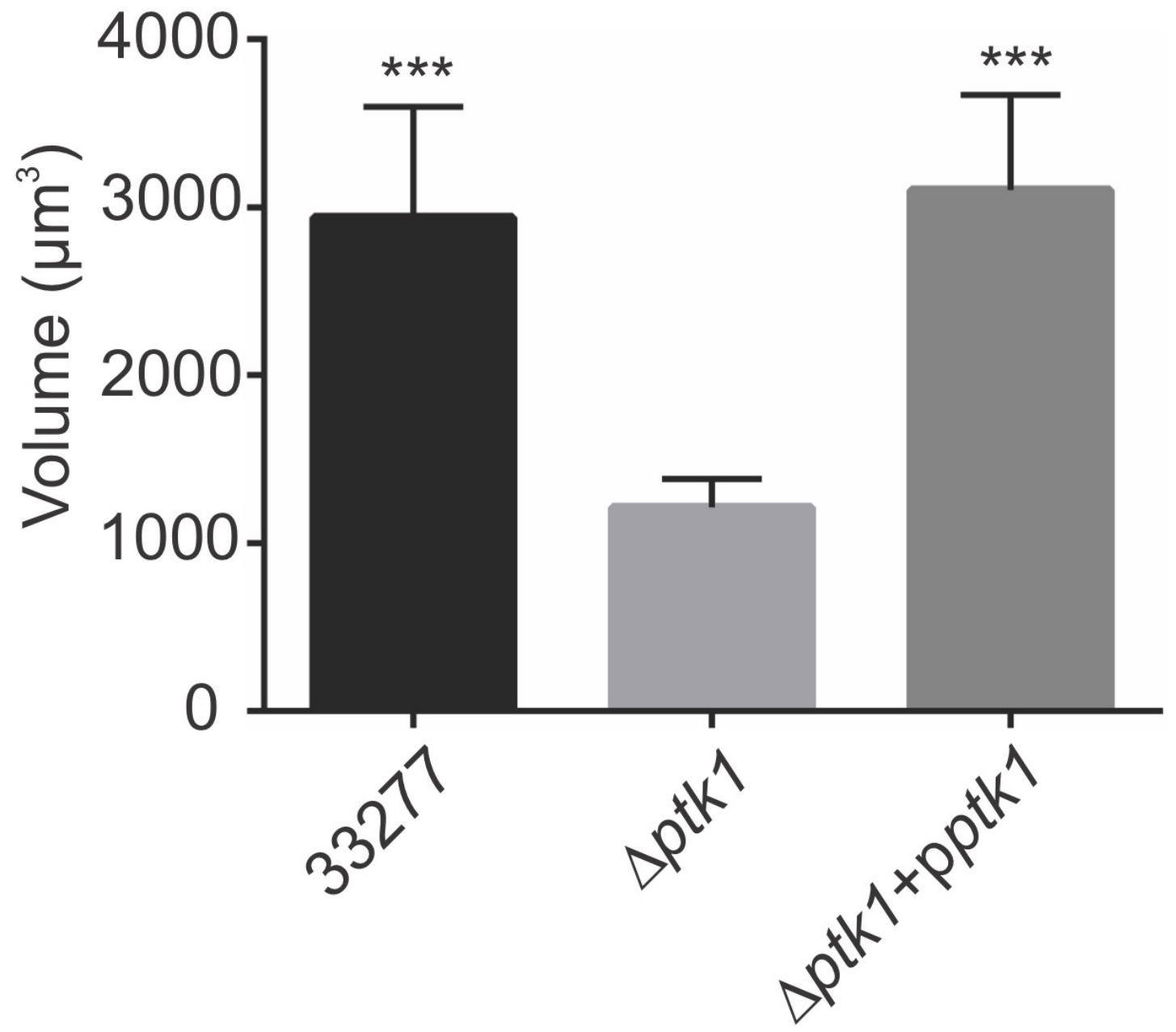

Figure 13B. ptk1 is required for maximal $P$. gingivalis-S. gordonii community development. Total $P$. gingivalis biovolume was obtained with the 3D Find Objects function of Volocity software. 


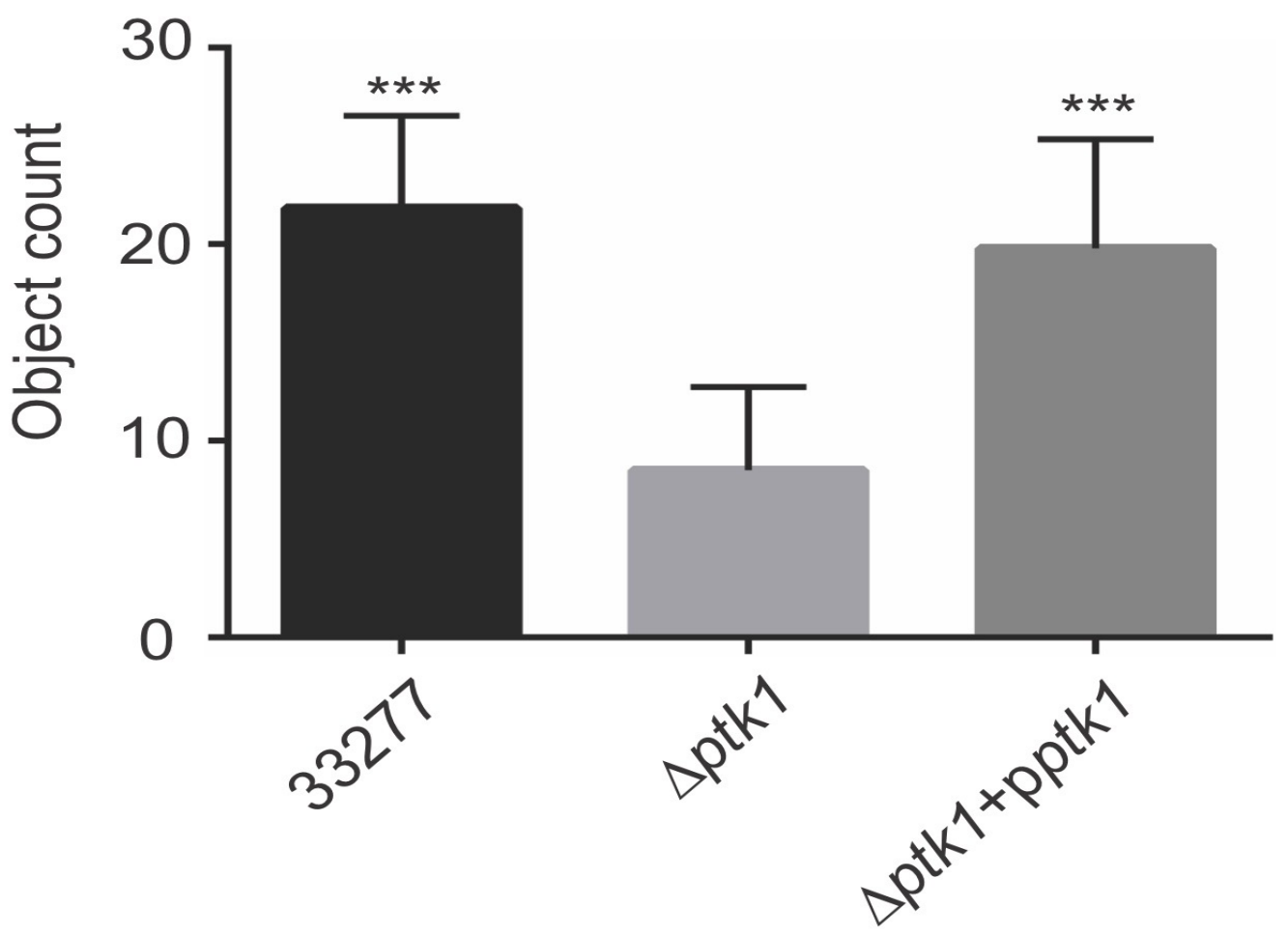

Figure 13C. ptk1 is required for maximal $P$. gingivalis-S. gordonii community development. Numbers of microcolonies of $P$. gingivalis using an object size cutoff algorithm of $>30 \mu \mathrm{m}$ for the total 3D volume for $P$. gingivalis fluorescence. Error bars represent SD. $\mathrm{N}=3 ;{ }^{* * *} \mathrm{p}<0.001$ compared to $\Delta p t k 1$. 


\section{CHAPTER 6}

\section{DISCUSSION}

The ability of microorganisms to communicate and co-ordinate their behavior provides the basis for community living, and confers advantages to the bacterial population as a whole. The mechanisms of biofilm initiation and development have been extensively reviewed $[145,146]$. These bacterial communities are comprised of multiple, physiologically diverse bacterial taxa [147]. Mixed microbial communities contain an endless number of inter- and trans-species signaling networks imparting on constituents the ability to collectively regulate activities including gene expression, nutrient acquisition, antibiotic resistance and DNA exchange. The physiology and potential pathogenicity of a mixed species community is contingent on the flow of information throughout the polymicrobial consortia. In a healthy state there is an equilibrium or homeostasis established between the community and the host. However, any significant populational shift towards higher numbers organisms with pathogenic potential, which can be a consequence of host or environmental influences, can lead to disease. Thus, in general, disease ensues when there is an ecological disruption in the normal hostmicrobe equilibrium. A vast amount of human diseases are caused by polymicrobial infections including periodontal disease, diabetic wound infections, osteomyelitis, urinary tract infections, and angular cheilitis [148]). Chronic periodontitis, the more severe form of periodontal disease, is a chronic inflammatory condition characterized by a continuous cycling between the induction and resolution phases of inflammation, thereby causing significant destruction of the hard and soft tissues of the periodontium. Periodontitis is a polymicrobial infection and one of the most strongly associated periodontopathogens implicated in the progression and severity of this disease is Porphyromonas gingivalis. 
Porphyromonas gingivalis, a Gram-negative anaerobe harbors many unique virulence factors and pathogenic mechanisms. $P$. gingivalis plays a central role in the initiation and progression of chronic periodontitis [63]. Some of the more well studied pathophysiological properties of $P$. gingivalis include its invasion of epithelial cells, intercellular spread, inhibition of apoptosis in gingival epithelial cells, and suppression of cytokine production such as Interleukin-8 $[40,49,81,149]$. In addition, $P$. gingivalis has an obligate requirement for iron in the form of hemin for growth, and possesses several hemin acquisition and storage systems with different activities and affinities [27]. The presence of early Gram-positive colonizers such as Streptococcus gordonii as well as other Gram-negative opportunistic bacterial species such as Fusobacterium nucleatum, favor further colonization by the more pathogenic species like $P$. gingivalis. $P$. gingivalis relies on these antecedent organisms for its attachment as well as for physiological support $[150,151]$. In fact, recent research has identified a potential treatment therapy for periodontal disease through the use of small molecule inhibitors of this attachment. In particular, 1,2,3-triazole based inhibitors were found to effectively block $P$. gingivalis adherence to oral streptococci and thus prevent biofilm formation [152].

$P$. gingivalis is best described as a host-adapted opportunistic pathogen which possesses the ability to raise the pathogenicity of the entire microbial community. Hence, $P$. gingivalis is often regarded as a "keystone" pathogen [153]. Despite its pathogenic potential, $P$. gingivalis is commonly found in healthy patients [154]. The ability of $P$. gingivalis to persist and thrive in overt disease as well as in the absence of disease indicates the existence of various mechanisms capable of enhancing or restraining $P$. gingivalis' pathogenic potential in the context of a community. One study analyzing the pathogenic potential of $P$. gingivalis when colonized in germ free mice found that while $P$. gingivalis was able to successfully colonize this host, it failed to elicit 
periodontal disease in the absence of an endogenous microbiota [155]. Thus, in addition to environmental parameters, $P$. gingivalis virulence is strongly influenced by its other accessory pathogens residing in the community. These other neighboring bacteria can establish the pathogenic potential of the entire community [156]. Furthermore, analysis of virulence gene expression in healthy versus diseased states shows the expression profile changes based on environmental cues and also between individuals [157].

The oral streptococci are a major component of both supra- and sub -gingival microbial communities. While some streptococci are antagonistic toward $P$. gingivalis, S. gordonii promotes $P$. gingivalis attachment and colonization. This is primarily due to the presence of a BAR motif found in streptococcal Ag I/II family adhesins that supports P. gingivalis attachment through its Mfa fimbriae [158, 159]. P. gingivalis-S. gordonii heterotypic community formation is initiated by the binding of the streptococcal SspA/B surface protein to the $P$. gingivalis Mfa1 fimbrial adhesin [159-161], and $P$. gingivalis exhibits mutualistic growth with S. gordonii in biofilm communities [162]. Interestingly, when $P$. gingivalis is exposed to tobacco smoke extract, it shows increased expression of FimA which enhances initial binding interactions and ultimately strengthens the Mfa1SspB binding which promotes community formation [163]. Thus, both theoretical and experimental frameworks exist for enhanced pathogenicity of $P$. gingivalis when in a heterotypic community with S. gordonii. In vivo support comes from experiments where mice infected with $S$. gordonii followed by $P$. gingivalis displayed significantly greater bone loss compared to mice infected with either organism alone [75].

Inflammatory cytokines play a pivotal role in the control of infection and the host innate immune response to pathogens. Cytokines are important chemical messengers that function as immunomodulating agents and are primarily produced by immune cells. 
Chemokines, a type of cytokine, are particularly important in that they can direct the chemotaxis of immune cells to respond to different environmental triggers or stimuli. Cytokines, both pro-inflammatory and anti-inflammatory, are largely responsible for regulating the host immune response to infection. The pro-inflammatory cytokines are necessary for controlling the initial infection. The acute inflammatory response is the initial protective response to bacterial pathogens, foreign stimuli or injury. This early stage is characterized by increased blood flow, vascular dilation, enhanced capillary permeability and increased recruitment of leukocytes into tissues. Some of the more commonly studied pro-inflammatory cytokines include TNF, IL-1 $\beta, I L-1 \alpha$, IL-6, IL-8, and IL-17. These stimulate systemic inflammation. The secretion of these chemokines directly recruits and activates polymorphonuclear leukocytes (e.g. neutrophils) and macrophages. Neutrophils are paramount here as they are the most common leukocyte recruited to periodontal pockets [30]. The second grouping of cytokines, the antiinflammatory cytokines, help to prevent any undesirable or harmful side effects of an exaggerated inflammatory reaction [164]. In general, the pro-inflammatory mediators are often associated with tissue damage and destruction; while the anti-inflammatory mediators have the ability to counteract this pro-inflammatory effect and ultimately arrest disease progression. Anti-inflammatory cytokines work to resolve the inflammation by suppression of inflammation. The net effect of these cytokines is to direct and coordinate the host immune response in a balanced way. Anti-inflammatory cytokines are often identified as "pro-resolving mediators" in the literature, as they can effectively halt disease progression through restricting leukocyte trafficking to inflamed sites, coordinating the clearance of expended leukocytes, and reversal of the signs of inflammation [12]. This balancing act between anti- and pro-inflammatory cytokines is a crucial element in regulating the overall inflammatory response because an overabundance of pro-inflammatory secretion can lead to severe tissue damage. The 
disease progression and tissue destruction evident in periodontal disease is due to the periodontitis associated bacteria that exploit the normal secretion of inflammatory cytokines. Periodontal inflammation is not only a means by which host tissues are destroyed, rather it also functions as a means by which the periodontal bacteria can derive a wealth of nutrients important for their survival and persistence. It is this type of damage that culminates in the periodontitis phenotype characterized by a heightened and chronic inflammatory response that remains unresolved [165].

We know that the presence of bacteria alone is not sufficient for the progression and severity of periodontitis; rather it takes an immunologically susceptible host as well. The prolonged and persistent dysregulated host immune response to the polymicrobial biofilm communities is likely the primary cause of the tissue damage. This overwhelming and chronic inflammatory response by the host helps the persistence of periodontal bacteria as it inadvertently generates a continuous flow of nutrients supplied to the offending bacteria and this allows them to flourish and thrive. $P$. gingivalis has evolved to exploit this heightened inflammatory response to serve its own nutritional needs. It is the persistent host inflammatory response targeting pathogens that results in the irreversible destruction. Yet, by prolonging inflammatory reactions in the host, pathogens such as $P$. gingivalis ensure a continuous supply of host derived nutrients. In periodontally healthy subjects, both the innate and adaptive branches of immunity are functioning optimally, operating simultaneously in harmony. This establishes a neutral relationship between the human host and the microbiota. While the histopathogenesis of periodontal disease involves responses by the innate and adaptive branches of the immune system, it is the innate immunity that provides the first line of defense against any type of microbial challenge or insult. Even in the absence of disease, the host maintains control over commensal microbial inhabitants through its continuous and 
coordinated gradient of various cytokines/chemokines and cell adhesion molecules throughout the epithelial cell layers.

The primary resident cells involved in the host innate immune response include epithelial cells, periodontal ligament fibroblasts, osteoblasts, and dendritic cells [166]. In gingival epithelial cells (GECs), P. gingivalis inhibits the production of Interleukin (IL)-8, a member of the CXC (Cysteine X Cysteine) family of chemokines and neutrophil chemokine, along with the T-cell chemokines IL-10, IL-9, and IL-11 [40, 167], a phenomenon known as Localized Chemokine Paralysis. Conversely, P. gingivalis induces increased levels of secretion of IL-1 $\beta$ and IL-6 in GECs [168], and thus has both 'stealth-like' and pro-inflammatory properties depending on context. Recent research indicates that $P$. gingivalis gingipains play a role in modulating the innate immune response. Tada et al. found that $P$. gingivalis increased the expression of IL-33 mRNA and protein in GECs in a gingipain-dependent manner [169]. IL-33 is an important cytokine because it is also involved in regulating the inflammatory responses. In particular, IL-33 enhances Th2 cytokine mediated inflammation. Yet another recent study concluded that $P$. gingivalis (W83 strain) was a strong inducer of IL-6 secretion in monocytes only when all gingipain activity was entirely absent [170]. In fact, this study found that active gingipains degraded cytokines, as the accumulation of IL-6 was inversely dependent on the presence of active gingipains. The remarkable ability of $P$. gingivalis to differentially regulate the expression of various cytokines, helps to facilitate the dysregulation of the innate immune response. Despite its broad impact on a wide range of cytokines, $P$. gingivalis can also employ a much more targeted and selective approach when regulating individual cytokines, such as IL-8, produced by macrophages, epithelial cells, and endothelial cells among others. When epithelial cells secrete IL-8, this results in the recruitment of neutrophils and an increase in monocyte adhesion in 
blood vessels. Neutrophils are continually being recruited into the subgingival area, and thus are very important for constraining the microbial challenge. This continuous gradient of neutrophils effectively helps to keep the bacterial community under control as they are responsible for inducing the secretion of many pro-inflammatory cytokines.

Considering the central role NF-KB plays in innate immune responses and regulation, it is not surprising that many different human pathogens have evolved a plethora of mechanisms to interfere with NF-kB activity and use this to their advantage [171]. For example, one common target of the NF-kB pathway is the $1 \kappa B$ kinase complex (IKK), which is involved in the initial activation of NF-кB. Listeria monocytogenes, an intracellular pathogen capable of infecting both human and animal hosts, specifically targets this IKK complex to modulate innate immune responses. Listeria monocytogenes secretes the InIC protein intracellularly which directly interacts with a subunit of the IKK complex, IKK $\alpha$. The interaction of InIC with IKK $\alpha$ blocks phosphorylation of IKK $\alpha$, thereby restricting nuclear translocation of NF-KB and thus preventing transcription of genes [172]. The pathogen Yersinia pseudotuberculosis secretes an effector protein, YopJ which binds and acetylates the IKK $\beta$ inhibitory proteins. This prevents phosphorylation and degradation of the IKK complex thereby resulting in inhibition of NF-kB activation [173]. Enteropathogenic E. coli (EPEC) secrete effector proteins, NleH1 and $\mathrm{NleH} 2$, which attenuate the degradation of the IkB $\alpha$ subunit

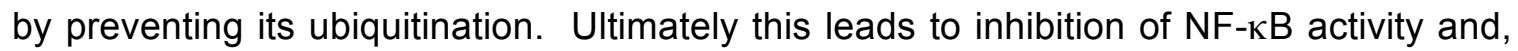
in turn, a down regulation of pro-inflammatory cytokine secretion [93].

Bacterial effectors can also target components of the NF-kB signaling pathway both upstream and downstream of the IKK complex. While many of the mammalian NF$\kappa B$ subunits are Rel proteins, other studies have identified a non-Rel subunit of NF- $\mathrm{B}$ 
complexes, ribosomal protein S3 (RPS3), which is responsible for regulating NF-кB specificity for certain target genes [174]. The EPEC effector protein NleH1 can bind to this RPS3 subunit and prevent its phosphorylation [175]. This strategy allows EPEC to selectively inhibit the transcription of downstream RPS3-dependent target genes, amongst which include IL-8 and TNF. The novelty of this strategy is that the regulation or inhibition of those select target genes can be accomplished while at the same time no other NF-кB dependent gene expression is influenced. Shigella flexneri uses a Type 3 secretion system to secrete the effector protein OspG which is a kinase that binds ubiquitin substrates, thereby preventing degradation of phosphorylated inhibitory proteins such as $\mathrm{lkB} \alpha$. In doing this, activation of NF-kB is inhibited [176].

The serine phosphatase SerB protein of $P$. gingivalis plays a vital role in the entry and survival of $P$. gingivalis within GECs [127]. $P$. gingivalis SerB belongs to the haloacid dehalogenase (HAD) superfamily of hydrolytic dehalogenases [127]. SerB is required for optimal invasion of gingival epithelial cells, as well as IL-8 inhibition $[42,127$, 136]. The results presented here have provided a much closer look into the role of $P$. gingivalis SerB in IL-8 suppression. Our data generated several layers of evidence supporting the concept that SerB antagonizes IL-8 production by dephosphorylating the serine-536 residue of the p65 subunit of NF-кB. Firstly, infection of epithelial cells with a $\Delta$ serB mutant resulted in lower levels of dephosphorylation of NF-kB p65 S536 as compared to the levels of dephosphorylation seen with infection by the $P$. gingivalis WT (33277) strain. Further, infection with the $\Delta$ serB mutant resulted in increased levels of IL-8 promoter activity when compared to the parental $P$. gingivalis strain. When expressed ectopically, SerB successfully bound to and dephosphorylated the NF-кB p65 subunit in epithelial cells that were stimulated with TNF. Exogenous SerB did, in fact, thwart the nuclear translocation of p65. And lastly, SerB was found to suppress IL-8 
promoter activity and blocked IL-8 secretion from epithelial cells. These results describe for the first time a novel NF-кB subversion tactic employed by a periodontopathogen. $P$. gingivalis SerB can specifically dephosphorylate the p65 subunit at serine residue 536, thereby preventing its nuclear translocation. Previous studies have shown that phosphorylation of the p65 subunit at the serine 536 residue led to increased nuclear translocation and activity of NF-KB in monocytes and macrophages stimulated with lipopolysaccharide (LPS) [177]. Of course there is still ongoing research to better understand the full extent to which this phosphorylated serine residue in p65 broadly influences NF-kB regulation. It is believed that the full effect of serine phosphorylation of p65 on NF-кB transcription may vary depending on cell types; in addition, the exact mechanism of phosphorylation may also change (i.e. site-specific phosphorylation) [178]. Phosphorylation of serine residues is just one of many post-translational modifications that can happen to NF-KB and can result in distinct functional and biological consequences. Inhibition of IL-8 accumulation by $P$. gingivalis at sites of bacterial accumulation could have a devastating effect on innate host defense in the periodontium, where bacterial exposure is constant. The host may no longer be able to detect the presence of bacteria and direct leukocytes for their removal. The ability of $P$. gingivalis to selectively target p65 may also generate precision in terms of inhibiting IL-8 without impacting other functions controlled by NF-kB, as the IL-8 promoter is predominantly controlled by the p65 homodimers [134]. Our findings on $P$. gingivalis SerB represent the only current example of a bacterial HAD family phosphatase capable of reshaping innate immune responses by selective dephosphorylation of specific host signaling molecules. Furthermore, these results have provided the molecular mechanisms responsible for the localized chemokine paralysis induced by $P$. gingivalis 
at mucosal surfaces; this being the selective targeting of IL-8 transcription carried out via dephosphorylation of p65 by SerB.

In order to fully investigate all aspects of $P$. gingivalis pathogenicity, the second major focus of my research was to evaluate $P$. gingivalis pathogenicity in the context of multispecies biofilms. In particular, the aspects of $P$. gingivalis pathogenicity when in a heterotypic community with the oral commensal Streptococcus gordonii. An overwhelming amount of literature pertains to monospecies biofilms and the molecular mechanisms underlying the development of these structures. However, there is substantially less research available on the complexities of multispecies biofilms as they relate to human disease and pathogenesis. However, a burgeoning interest in the complex mechanisms underlying multispecies bacterial biofilm communities has generated a surge in research on their implications for human disease. Many microorganisms have evolved to coexist within these diverse communities and often exhibit a harmonious, mutualistic relationship [179, 180]. Evidence for synergistic pathogenicity is emerging. For example, co-culture with $S$. gordonii elevates the pathogenic potential of $A$. actinomycetemcomitans) [181]. This increased pathogenic potential of $A$. actinomycetemcomitans-S. gordonii communities has been observed in vivo [179].

Early initiating organisms in the development of multispecies biofilm communities on tooth surfaces are the mitis group streptococci (MGS), that includes S. gordonii, S. oralis, S. sanguinis and related species [182]. P. gingivalis and S. gordonii, in particular, have a unique interaction and relationship when taking residence alongside each other. Interspecies binding is effectuated by two sets of interacting adhesins involving streptococcal surface proteins and the major and minor fimbriae of $P$. gingivalis. Interaction of the Ssp and Mfa proteins is required for the subsequent accumulation of $S$. 
gordonii and $P$. gingivalis into heterotypic communities [60].

S. gordonii can also provide metabolic support to $P$. gingivalis, and $P$. gingivalis exhibits mutualistic growth with S. gordonii in biofilm communities [162]. While the full nature of the interspecies cross talk remains to be established, mutation of a large number of $S$. gordonii genes abolishes the ability of the organism to support a heterotypic community with $P$. gingivalis [183].

In community-associated $P$. gingivalis, there is upregulation of Itp 1 , a gene encoding a cytoplasmic eukaryotic-type Low Molecular Weight Tyrosine Phosphatase [125]. Ltp1 is responsible for restricting community development of $P$. gingivalis with $S$. gordonii by upregulating and activating the transcription factor CdhR (Community Development and Hemin Regulator), an orphan LuxR family transcriptional regulator $[126,135]$. Once activated, CdhR negatively regulates expression of the mfa1 gene encoding the Mfa1 co-adhesin [126]. Deletion of the Itp1 gene, or loss of tyrosine phosphatase activity through expression of a catalytically inactive mutant, increases the level of $P$. gingivalis accumulation with $S$. gordonii [135]. Constraint of community development by Ltp1 may serve to maintain an optimal area:volume ratio [184], or to prevent the community from expanding into microenvironments that are more oxygenated and damaging to the obligately anaerobic $P$. gingivalis.

Preliminary work in the lab using RNA sequencing had shown that a putative tyrosine kinase (PGN_1524, Ptk1) was upregulated early on in the interaction of $P$. gingivalis with S. gordonii, immediately before the Ltp1 tyrosine phosphatase was upregulated. The enzymatic activity of this protein was confirmed through its ability to autophosphorylate and to phosphorylate both a small peptide and a $P$. gingivalis protein substrate. This is the first bacterial tyrosine kinase to be identified in $P$. gingivalis. Our findings are also the first to demonstrate the importance of a bacterial tyrosine (BY) 
kinase in the signaling pathways that regulate the cooperative interactions in the context of a heterotypic biofilm community. The results showed that deletion of the ptk1 gene caused a decrease in the levels of dual species $P$. gingivalis-S. gordonii community formation. As expected, restoration of active ptk1 in the $\Delta$ ptk1 mutant, promoted $P$. gingivalis accumulation on a S. gordonii substrate. This finding corroborated our initial prediction that Ptk1 would yield an opposing effect and serve to promote community formation, whereas the Ltp1 phosphatase inhibited $P$. gingivalis accumulation. Given the dynamic and opposing interaction between Ltp1 and Ptk1 it appears that these two proteins are involved in a signaling rheostat in the context of community development. We know from previous studies that phosphatases often have a cognate kinase that displays opposing effects. For example, in E. coli the BY kinases, Wzc and Etk are modulated by the cognate phosphatases, Web and Etp. These phosphatases are responsible for the cycling of the kinases between heavily phosphorylated and reduced phosphorylated states $[185,186]$. Having a phosphatase-kinase cognate pair can confer many advantages to an organism in terms of its ability to selectively fine-tune its activities based on the fluctuating and dynamic changes/needs of its particular microenvironment.

It has been well established that the addition and/or removal of phosphoryl groups from Ser/Thr/Tyr residues is a common mechanism to carry out post-translational protein modifications. These changes serve to control a variety of important cellular functions in both eukaryotes and prokaryotes [112]. In terms of control of heterotypic $P$. gingivalis-S. gordonii community development, the studies reported here, along with subsequent work in the lab have led to the following model (Figure 14). Following initial contact of $P$. gingivalis with the $S$. gordonii surface, a streptococcal signal is propagated through the minor fimbria structural protein of $P$. gingivalis, Mfa1. This leads to the 
activation of Ltp1 which results in subsequent dephosphorylation and inactivation of Ptk1. One substrate of Ptk1 is the transcriptional regulator CdhR (Community Development and Hemin Regulator), a negative regulator of mfa1 transcription [126]. Phosphorylation of $\mathrm{CdhR}$ by Ptk1 diminishes activity and relieves repression of mfa1 expression. Increased levels of Mfa1 then will be predicted to enhance interspecies binding and community development. In this manner the activation states of Ltp1 and Ptk1 constitute a signaling hub that controls community development. Recent research by the Lamont lab has also identified a specific metabolite produced by $S$. gordonii, para-amino benzoic acid (PABA) which is produced by the cbe gene. When $P$. gingivalis is in close proximity to $S$. gordonii, it can sense the release of this PABA metabolite and in fact takes up this PABA and feeds it into its folate metabolism. The presence of PABA serves to inactivate Ltp1 which means that Ptk1 is no longer inhibited. This increase in Ptk1 activity results in increased expression of Mfa1 since active Ptk1 inhibits CdhR. FimA expression is also increased as active Ptk1 normally induces FimA expression. The end result of $P$. gingivalis' sensing and uptake of PABA results in more attachment and thereby more community development [187]. The cumulative effect of PABA seems to function as a way of priming the $P$. gingivalis cell for physical attachment to the $S$. gordonii cells. Then over time $P$. gingivalis physically engages the $S$. gordonii cell through complementary fit between the Mfa1 and SspA/B proteins. Once $P$. gingivalis is physically attached to $S$. gordonii, this action suppresses the cbe gene that makes PABA and this priming effect is turned off and Ltp1 returns to its normal state of activation (refer to Figure 14 below). 


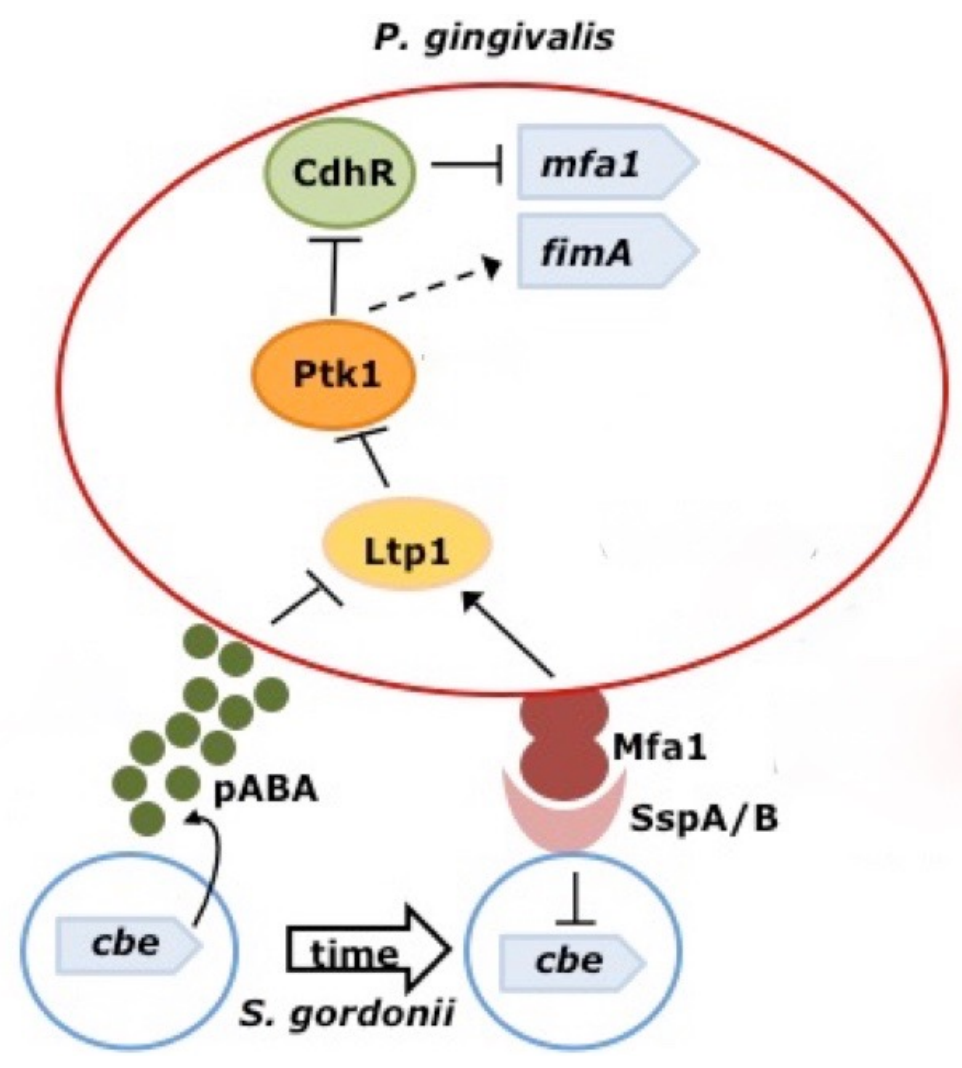

Figure 14. Partial rudimentary model of $P$. gingivalis-S. gordonii signaling related to community development and community pathogenicity 
This work has implications for future strategies designed to prevent or treat periodontal infections. Targeting pathways responsible for the development of heterotypic communities may prevent an increase in the number of $P$. gingivalis and maintain the microbial community in a homeostatic state. Another potentially effective measure could involve targeted modulation of signaling pathways within epithelial cells that are subverted by $P$. gingivalis and fuel dysbiosis, such as chemokine paralysis. For example, blocking the action of SerB intracellularly could prevent antagonism of IL-8 production and maintain immune surveillance along with periodontal tissue homeostasis. 


\section{REFERENCES}

1. Kassebaum, N.J., et al., Global burden of severe periodontitis in 1990-2010: a systematic review and meta-regression. J Dent Res, 2014. 93(11): p. 1045-53.

2. Kuboniwa, M., et al., Insights into the virulence of oral biofilms: discoveries from proteomics. Expert Rev Proteomics, 2012. 9(3): p. 311-23.

3. Aas, J.A., et al., Defining the normal bacterial flora of the oral cavity. J Clin Microbiol, 2005. 43(11): p. 5721-32.

4. Lamont, R.J. and G. Hajishengallis, Polymicrobial synergy and dysbiosis in inflammatory disease. Trends Mol Med, 2015. 21(3): p. 172-83.

5. Winning, L. and G.J. Linden, Periodontitis and Systemic Disease: Association or Causality? Curr Oral Health Rep, 2017. 4(1): p. 1-7.

6. Casanova, L., F.J. Hughes, and P.M. Preshaw, Diabetes and periodontal disease: a twoway relationship. Br Dent J, 2014. 217(8): p. 433-7.

7. Humphrey, L.L., et al., Periodontal disease and coronary heart disease incidence: $a$ systematic review and meta-analysis. J Gen Intern Med, 2008. 23(12): p. 2079-86.

8. Ide, M. and P.N. Papapanou, Epidemiology of association between maternal periodontal disease and adverse pregnancy outcomes--systematic review. J Clin Periodontol, 2013. 40 Suppl 14: p. S181-94.

9. Fitzpatrick, S.G. and J. Katz, The association between periodontal disease and cancer: a review of the literature. J Dent, 2010. 38(2): p. 83-95.

10. Cekici, A., et al., Inflammatory and immune pathways in the pathogenesis of periodontal disease. Periodontol 2000, 2014. 64(1): p. 57-80.

11. Darveau, R.P., Periodontitis: a polymicrobial disruption of host homeostasis. Nat Rev Microbiol, 2010. 8(7): p. 481-90.

12. Hasturk, H. and A. Kantarci, Activation and resolution of periodontal inflammation and its systemic impact. Periodontol 2000, 2015. 69(1): p. 255-73.

13. Abbayya, K., et al., Association between Periodontitis and Alzheimer's Disease. N Am J Med Sci, 2015. 7(6): p. 241-6.

14. Whitmore, S.E. and R.J. Lamont, Oral bacteria and cancer. PLoS Pathog, 2014. 10(3): p. e1003933.

15. Inaba, H., et al., Porphyromonas gingivalis promotes invasion of oral squamous cell carcinoma through induction of proMMP9 and its activation. Cell Microbiol, 2014. 16(1): p. 131-45.

16. Michaud, D.S., Role of bacterial infections in pancreatic cancer. Carcinogenesis, 2013.

17. Michaud, D.S., et al., Periodontal Disease, Tooth Loss, and Cancer Risk. Epidemiol Rev, 2017. 39(1): p. 49-58.

18. Nagy, K.N., et al., The microflora associated with human oral carcinomas. Oral Oncol, 1998. 34(4): p. 304-8.

19. Katz, J., et al., Presence of Porphyromonas gingivalis in gingival squamous cell carcinoma. Int J Oral Sci, 2011. 3(4): p. 209-15.

20. Kuboniwa, M., et al., P. gingivalis accelerates gingival epithelial cell progression through the cell cycle. Microbes Infect, 2008. 10(2): p. 122-8.

21. Zhou, Y., et al., Noncanonical activation of beta-catenin by Porphyromonas gingivalis. Infect Immun, 2015. 83(8): p. 3195-203.

22. Sztukowska, M.N., et al., Porphyromonas gingivalis initiates a mesenchymal-like transition through ZEB1 in gingival epithelial cells. Cell Microbiol, 2016. 18(6): p. 844-58. 
23. Wegner, N., et al., Peptidylarginine deiminase from Porphyromonas gingivalis citrullinates human fibrinogen and alpha-enolase: implications for autoimmunity in rheumatoid arthritis. Arthritis Rheum, 2010. 62(9): p. 2662-72.

24. Janssen, K.M.J., et al., Autoantibodies against citrullinated histone $\mathrm{H} 3$ in rheumatoid arthritis and periodontitis patients. J Clin Periodontol, 2017. 44(6): p. 577-584.

25. Kaur, T., A. Uppoor, and D. Naik, Parkinson's disease and periodontitis - the missing link? A review. Gerodontology, 2016. 33(4): p. 434-438.

26. Persson, G.R., Dental geriatrics and periodontitis. Periodontol 2000, 2017. 74(1): p. 102115.

27. Lewis, J.P., Metal uptake in host-pathogen interactions: role of iron in Porphyromonas gingivalis interactions with host organisms. Periodontol 2000, 2010. 52(1): p. 94-116.

28. Hendrickson, E.L., et al., Insights into Dynamic Polymicrobial Synergy Revealed by TimeCoursed RNA-Seq. Front Microbiol, 2017. 8: p. 261.

29. Ardila, C.M. and I.C. Guzman, Association of Porphyromonas gingivalis with high levels of stress-induced hormone cortisol in chronic periodontitis patients. J Investig Clin Dent, 2016. 7(4): p. 361-367.

30. Hajishengallis, G. and R.J. Lamont, Dancing with the Stars: How Choreographed Bacterial Interactions Dictate Nososymbiocity and Give Rise to Keystone Pathogens, Accessory Pathogens, and Pathobionts. Trends Microbiol, 2016. 24(6): p. 477-89.

31. Darveau, R.P., G. Hajishengallis, and M.A. Curtis, Porphyromonas gingivalis as a potential community activist for disease. J Dent Res, 2012. 91(9): p. 816-20.

32. Hajishengallis, G., Periodontitis: from microbial immune subversion to systemic inflammation. Nat Rev Immunol, 2015. 15(1): p. 30-44.

33. How, K.Y., K.P. Song, and K.G. Chan, Porphyromonas gingivalis: An Overview of Periodontopathic Pathogen below the Gum Line. Front Microbiol, 2016. 7: p. 53.

34. Stathopoulou, P.G., et al., Porphyromonas gingivalis induce apoptosis in human gingival epithelial cells through a gingipain-dependent mechanism. BMC Microbiol, 2009. 9: $p$. 107.

35. Belton, C.M., et al., Fluorescence image analysis of the association between Porphyromonas gingivalis and gingival epithelial cells. Cell Microbiol, 1999. 1(3): p. 21523.

36. Yilmaz, O., et al., Intercellular spreading of Porphyromonas gingivalis infection in primary gingival epithelial cells. Infect Immun, 2006. 74(1): p. 703-10.

37. Yilmaz, O., K. Watanabe, and R.J. Lamont, Involvement of integrins in fimbriae-mediated binding and invasion by Porphyromonas gingivalis. Cell Microbiol, 2002. 4(5): p. 305-14.

38. Kerr, J.E., et al., Genetic exchange of fimbrial alleles exemplifies the adaptive virulence strategy of Porphyromonas gingivalis. PLoS One, 2014. 9(3): p. e91696.

39. Watanabe, K., et al., Association of mitogen-activated protein kinase pathways with gingival epithelial cell responses to Porphyromonas gingivalis infection. Infect Immun, 2001. 69(11): p. 6731-7.

40. Darveau, R.P., et al., Local chemokine paralysis, a novel pathogenic mechanism for Porphyromonas gingivalis. Infect Immun, 1998. 66(4): p. 1660-5.

41. Hajishengallis, G. and R.J. Lamont, Breaking bad: manipulation of the host response by Porphyromonas gingivalis. Eur J Immunol, 2014. 44(2): p. 328-38.

42. Moffatt, C.E., et al., Porphyromonas gingivalis SerB-mediated dephosphorylation of host cell cofilin modulates invasion efficiency. Cell Microbiol, 2012. 14(4): p. 577-88. 
43. Takeuchi, H., et al., The serine phosphatase SerB of Porphyromonas gingivalis suppresses IL-8 production by dephosphorylation of NF-kappaB RelA/p65. PLoS Pathog, 2013. 9(4): p. e1003326.

44. Richards, A.M., et al., Cellular microbiology and molecular ecology of Legionella-amoeba interaction. Virulence, 2013. 4(4): p. 307-14.

45. Price, C.T., et al., Amoeba host-Legionella synchronization of amino acid auxotrophy and its role in bacterial adaptation and pathogenic evolution. Environ Microbiol, 2014. 16(2): p. 350-8.

46. Ensminger, A.W., Legionella pneumophila, armed to the hilt: justifying the largest arsenal of effectors in the bacterial world. Curr Opin Microbiol, 2016. 29: p. 74-80.

47. LaRock, D.L., A. Chaudhary, and S.I. Miller, Salmonellae interactions with host processes. Nat Rev Microbiol, 2015. 13(4): p. 191-205.

48. Nakhjiri, S.F., et al., Inhibition of epithelial cell apoptosis by Porphyromonas gingivalis. FEMS Microbiol Lett, 2001. 200(2): p. 145-9.

49. Mao, S., et al., Intrinsic apoptotic pathways of gingival epithelial cells modulated by Porphyromonas gingivalis. Cell Microbiol, 2007. 9(8): p. 1997-2007.

50. Yilmaz, O., et al., ATP scavenging by the intracellular pathogen Porphyromonas gingivalis inhibits P2X7-mediated host-cell apoptosis. Cell Microbiol, 2008. 10(4): p. 863-75.

51. Yilmaz, O., et al., Activation of the phosphatidylinositol 3-kinase/Akt pathway contributes to survival of primary epithelial cells infected with the periodontal pathogen Porphyromonas gingivalis. Infect Immun, 2004. 72(7): p. 3743-51.

52. Yao, L., et al., Porphyromonas gingivalis infection sequesters pro-apoptotic Bad through Akt in primary gingival epithelial cells. Mol Oral Microbiol, 2010. 25(2): p. 89-101.

53. Moffatt, C.E. and R.J. Lamont, Porphyromonas gingivalis induction of microRNA-203 expression controls suppressor of cytokine signaling 3 in gingival epithelial cells. Infect Immun, 2011. 79(7): p. 2632-7.

54. Enersen, M., K. Nakano, and A. Amano, Porphyromonas gingivalis fimbriae. J Oral Microbiol, 2013. 5.

55. Wright, C.J., et al., Characterization of a bacterial tyrosine kinase in Porphyromonas gingivalis involved in polymicrobial synergy. Microbiologyopen, 2014. 3(3): p. 383-94.

56. Umemoto, T. and N. Hamada, Characterization of biologically active cell surface components of a periodontal pathogen. The roles of major and minor fimbriae of Porphyromonas gingivalis. J Periodontol, 2003. 74(1): p. 119-22.

57. Kuboniwa, M., et al., Distinct roles of long/short fimbriae and gingipains in homotypic biofilm development by Porphyromonas gingivalis. BMC Microbiol, 2009. 9: p. 105.

58. Arjunan, P., et al., High-throughput sequencing reveals key genes and immune homeostatic pathways activated in myeloid dendritic cells by Porphyromonas gingivalis 381 and its fimbrial mutants. Mol Oral Microbiol, 2016. 31(1): p. 78-93.

59. Maeda, K., et al., Oral streptococcal glyceraldehyde-3-phosphate dehydrogenase mediates interaction with Porphyromonas gingivalis fimbriae. Microbes Infect, 2004. 6(13): p. 1163-70.

60. Lamont, R.J., et al., Role of the Streptococcus gordonii SspB protein in the development of Porphyromonas gingivalis biofilms on streptococcal substrates. Microbiology, 2002. 148(Pt 6): p. 1627-36.

61. Hajishengallis, G., M. Wang, and S. Liang, Induction of distinct TLR2-mediated proinflammatory and proadhesive signaling pathways in response to Porphyromonas gingivalis fimbriae. J Immunol, 2009. 182(11): p. 6690-6. 
62. Chiang, C.Y., et al., Interleukin-1 and tumor necrosis factor activities partially account for calvarial bone resorption induced by local injection of lipopolysaccharide. Infect Immun, 1999. 67(8): p. 4231-6.

63. Lamont, R.J. and H.F. Jenkinson, Life below the gum line: pathogenic mechanisms of Porphyromonas gingivalis. Microbiol Mol Biol Rev, 1998. 62(4): p. 1244-63.

64. Paramonov, N.A., et al., Structural analysis of the core region of O-lipopolysaccharide of Porphyromonas gingivalis from mutants defective in $O$-antigen ligase and $O$-antigen polymerase. J Bacteriol, 2009. 191(16): p. 5272-82.

65. Zaric, S.S., et al., Sialylation of Porphyromonas gingivalis LPS and its effect on bacterialhost interactions. Innate Immun, 2017. 23(3): p. 319-326.

66. Darveau, R.P., et al., Porphyromonas gingivalis lipopolysaccharide contains multiple lipid A species that functionally interact with both toll-like receptors 2 and 4. Infect Immun, 2004. 72(9): p. 5041-51.

67. Paramonov, N., et al., Structural analysis of a novel anionic polysaccharide from Porphyromonas gingivalis strain W50 related to Arg-gingipain glycans. Mol Microbiol, 2005. 58(3): p. 847-63.

68. de Diego, I., et al., The outer-membrane export signal of Porphyromonas gingivalis type IX secretion system (T9SS) is a conserved C-terminal beta-sandwich domain. Sci Rep, 2016. 6: p. 23123.

69. Taguchi, Y., et al., Involvement of an Skp-Like Protein, PGN_0300, in the Type IX Secretion System of Porphyromonas gingivalis. Infect Immun, 2015. 84(1): p. 230-40.

70. Bostanci, N. and G.N. Belibasakis, Porphyromonas gingivalis: an invasive and evasive opportunistic oral pathogen. FEMS Microbiol Lett, 2012. 333(1): p. 1-9.

71. Plaza, K., et al., Gingipains of Porphyromonas gingivalis Affect the Stability and Function of Serine Protease Inhibitor of Kazal-type 6 (SPINK6), a Tissue Inhibitor of Human Kallikreins. J Biol Chem, 2016. 291(36): p. 18753-64.

72. Potempa, J., R. Pike, and J. Travis, Titration and mapping of the active site of cysteine proteinases from Porphyromonas gingivalis (gingipains) using peptidyl chloromethanes. Biol Chem, 1997. 378(3-4): p. 223-30.

73. Sundqvist, G., et al., Phagocytosis and virulence of different strains of Porphyromonas gingivalis. Scand J Dent Res, 1991. 99(2): p. 117-29.

74. Sims, T.J., et al., Immunoglobulin $\mathrm{G}$ response of periodontitis patients to Porphyromonas gingivalis capsular carbohydrate and lipopolysaccharide antigens. Oral Microbiol Immunol, 2001. 16(4): p. 193-201.

75. Daep, C.A., et al., Structural dissection and in vivo effectiveness of a peptide inhibitor of Porphyromonas gingivalis adherence to Streptococcus gordonii. Infect Immun, 2011. 79(1): p. 67-74.

76. Orth, R.K., et al., Synergistic virulence of Porphyromonas gingivalis and Treponema denticola in a murine periodontitis model. Mol Oral Microbiol, 2011. 26(4): p. 229-40.

77. Tan, K.H., et al., Porphyromonas gingivalis and Treponema denticola exhibit metabolic symbioses. PLoS Pathog, 2014. 10(3): p. e1003955.

78. Grenier, D., Nutritional interactions between two suspected periodontopathogens, Treponema denticola and Porphyromonas gingivalis. Infect Immun, 1992. 60(12): p. 5298-301.

79. Lin, X., et al., Role of differential expression of streptococcal arginine deiminase in inhibition of fimA expression in Porphyromonas gingivalis. J Bacteriol, 2008. 190(12): p. 4367-71. 
80. Han, Y.W., et al., Interactions between periodontal bacteria and human oral epithelial cells: Fusobacterium nucleatum adheres to and invades epithelial cells. Infect Immun, 2000. 68(6): p. 3140-6.

81. Lamont, R.J., et al., Porphyromonas gingivalis invasion of gingival epithelial cells. Infect Immun, 1995. 63(10): p. 3878-85.

82. Lamont, R.J., et al., Interaction of Porphyromonas gingivalis with gingival epithelial cells maintained in culture. Oral Microbiol Immunol, 1992. 7(6): p. 364-7.

83. Andrian, E., D. Grenier, and M. Rouabhia, In vitro models of tissue penetration and destruction by Porphyromonas gingivalis. Infect Immun, 2004. 72(8): p. 4689-98.

84. Sandros, J., et al., Porphyromonas gingivalis invades human pocket epithelium in vitro. J Periodontal Res, 1994. 29(1): p. 62-9.

85. Handfield, M., et al., Distinct transcriptional profiles characterize oral epitheliummicrobiota interactions. Cell Microbiol, 2005. 7(6): p. 811-23.

86. Dorn, B.R., W.A. Dunn, Jr., and A. Progulske-Fox, Porphyromonas gingivalis traffics to autophagosomes in human coronary artery endothelial cells. Infect Immun, 2001. 69(9): p. 5698-708.

87. Yamatake, K., et al., Role for gingipains in Porphyromonas gingivalis traffic to phagolysosomes and survival in human aortic endothelial cells. Infect Immun, 2007. 75(5): p. 2090-100.

88. Backert, S. and M. Selbach, Tyrosine-phosphorylated bacterial effector proteins: the enemies within. Trends Microbiol, 2005. 13(10): p. 476-84.

89. Cozzone, A.J., et al., Protein phosphorylation on tyrosine in bacteria. Arch Microbiol, 2004. 181(3): p. 171-81.

90. Cozzone, A.J., Role of protein phosphorylation on serine/threonine and tyrosine in the virulence of bacterial pathogens. J Mol Microbiol Biotechnol, 2005. 9(3-4): p. 198-213.

91. Wiley, D.J., et al., The Ser/Thr kinase activity of the Yersinia protein kinase A (YpkA) is necessary for full virulence in the mouse, mollifying phagocytes, and disrupting the eukaryotic cytoskeleton. Microb Pathog, 2006. 40(5): p. 234-43.

92. Gao, B., et al., Development of recombinant Escherichia coli whole-cell biocatalyst expressing a novel alkaline lipase-coding gene from Proteus sp. for biodiesel production. J Biotechnol, 2009. 139(2): p. 169-75.

93. Royan, S.V., et al., Enteropathogenic E. coli non-LEE encoded effectors NleH1 and NleH2 attenuate NF-kappaB activation. Mol Microbiol, 2010. 78(5): p. 1232-45.

94. Manai, M. and A.J. Cozzone, Endogenous protein phosphorylation in Escherichia coli extracts. Biochem Biophys Res Commun, 1982. 107(3): p. 981-8.

95. Stulke, J., More than just activity control: phosphorylation may control all aspects of a protein's properties. Mol Microbiol, 2010. 77(2): p. 273-5.

96. Ge, R., et al., Phosphoproteome analysis of the pathogenic bacterium Helicobacter pylori reveals over-representation of tyrosine phosphorylation and multiply phosphorylated proteins. Proteomics, 2011. 11(8): p. 1449-61.

97. Parker, J.L., et al., Analysis of the phosphoproteome of the multicellular bacterium Streptomyces coelicolor A3(2) by protein/peptide fractionation, phosphopeptide enrichment and high-accuracy mass spectrometry. Proteomics, 2010. 10(13): p. 2486-97.

98. Schmidl, S.R., et al., The phosphoproteome of the minimal bacterium Mycoplasma pneumoniae: analysis of the complete known Ser/Thr kinome suggests the existence of novel kinases. Mol Cell Proteomics, 2010. 9(6): p. 1228-42. 
99. Sun, X., et al., Phosphoproteomic analysis reveals the multiple roles of phosphorylation in pathogenic bacterium Streptococcus pneumoniae. J Proteome Res, 2010. 9(1): p. 27582.

100. Lin, M.H., et al., Phosphoproteomics of Klebsiella pneumoniae NTUH-K2044 reveals a tight link between tyrosine phosphorylation and virulence. Mol Cell Proteomics, 2009. 8(12): p. 2613-23.

101. Ravichandran, A., et al., Ser/Thr/Tyr phosphoproteome analysis of pathogenic and nonpathogenic Pseudomonas species. Proteomics, 2009. 9(10): p. 2764-75.

102. Voisin, S., et al., The cytoplasmic phosphoproteome of the Gram-negative bacterium Campylobacter jejuni: evidence for modification by unidentified protein kinases. Proteomics, 2007. 7(23): p. 4338-48.

103. Soufi, B., et al., Insights from site-specific phosphoproteomics in bacteria. Biochim Biophys Acta, 2008. 1784(1): p. 186-92.

104. Macek, B., et al., The serine/threonine/tyrosine phosphoproteome of the model bacterium Bacillus subtilis. Mol Cell Proteomics, 2007. 6(4): p. 697-707.

105. Macek, B., et al., Phosphoproteome analysis of E. coli reveals evolutionary conservation of bacterial Ser/Thr/Tyr phosphorylation. Mol Cell Proteomics, 2008. 7(2): p. 299-307.

106. Soufi, B., et al., The Ser/Thr/Tyr phosphoproteome of Lactococcus lactis IL1403 reveals multiply phosphorylated proteins. Proteomics, 2008. 8(17): p. 3486-93.

107. Grangeasse, C., et al., Tyrosine phosphorylation: an emerging regulatory device of bacterial physiology. Trends Biochem Sci, 2007. 32(2): p. 86-94.

108. Jers, C., et al., Bacillus subtilis BY-kinase PtkA controls enzyme activity and localization of its protein substrates. Mol Microbiol, 2010. 77(2): p. 287-99.

109. Grangeasse, C., S. Nessler, and I. Mijakovic, Bacterial tyrosine kinases: evolution, biological function and structural insights. Philos Trans R Soc Lond B Biol Sci, 2012. 367(1602): p. 2640-55.

110. Tiganis, T., Protein tyrosine phosphatases: dephosphorylating the epidermal growth factor receptor. IUBMB Life, 2002. 53(1): p. 3-14.

111. Zhang, Z.Y., Functional studies of protein tyrosine phosphatases with chemical approaches. Biochim Biophys Acta, 2005. 1754(1-2): p. 100-7.

112. Whitmore, S.E. and R.J. Lamont, Tyrosine phosphorylation and bacterial virulence. Int J Oral Sci, 2012. 4(1): p. 1-6.

113. Chao, J.D., D. Wong, and Y. Av-Gay, Microbial protein-tyrosine kinases. J Biol Chem, 2014. 289(14): p. 9463-72.

114. Bliska, J.B., Yop effectors of Yersinia spp. and actin rearrangements. Trends Microbiol, 2000. 8(5): p. 205-8.

115. Black, D.S., et al., Identification of an amino-terminal substrate-binding domain in the Yersinia tyrosine phosphatase that is required for efficient recognition of focal adhesion targets. Mol Microbiol, 1998. 29(5): p. 1263-74.

116. Persson, C., et al., Localization of the Yersinia PTPase to focal complexes is an important virulence mechanism. Mol Microbiol, 1999. 33(4): p. 828-38.

117. Persson, C., et al., The PTPase YopH inhibits uptake of Yersinia, tyrosine phosphorylation of 130 Cas and FAK, and the associated accumulation of these proteins in peripheral focal adhesions. EMBO J, 1997. 16(9): p. 2307-18.

118. Lin, S.L., T.X. Le, and D.S. Cowen, SptP, a Salmonella typhimurium type III-secreted protein, inhibits the mitogen-activated protein kinase pathway by inhibiting Raf activation. Cell Microbiol, 2003. 5(4): p. 267-75. 
119. Kaniga, K., et al., A secreted protein tyrosine phosphatase with modular effector domains in the bacterial pathogen Salmonella typhimurium. Mol Microbiol, 1996. 21(3): p. 633-

41.

120. Arbibe, L., et al., An injected bacterial effector targets chromatin access for transcription factor NF-kappaB to alter transcription of host genes involved in immune responses. Nat Immunol, 2007. 8(1): p. 47-56.

121. Vincent, C., et al., Cells of Escherichia coli contain a protein-tyrosine kinase, Wzc, and a phosphotyrosine-protein phosphatase, Wzb. J Bacteriol, 1999. 181(11): p. 3472-7.

122. Morona, J.K., et al., Tyrosine phosphorylation of CpsD negatively regulates capsular polysaccharide biosynthesis in streptococcus pneumoniae. Mol Microbiol, 2000. 35(6): p. 1431-42.

123. Ueda, A. and T.K. Wood, Connecting quorum sensing, c-di-GMP, pel polysaccharide, and biofilm formation in Pseudomonas aeruginosa through tyrosine phosphatase TpbA (PA3885). PLoS Pathog, 2009. 5(6): p. e1000483.

124. Ueda, A. and T.K. Wood, Tyrosine Phosphatase TpbA of Pseudomonas aeruginosa Controls Extracellular DNA via Cyclic Diguanylic Acid Concentrations. Environ Microbiol, 2010. 2(3): p. 449-55.

125. Simionato, M.R., et al., Porphyromonas gingivalis genes involved in community development with Streptococcus gordonii. Infect Immun, 2006. 74(11): p. 6419-28.

126. Chawla, A., et al., Community signalling between Streptococcus gordonii and Porphyromonas gingivalis is controlled by the transcriptional regulator $\mathrm{CdhR}$. Mol Microbiol, 2010. 78(6): p. 1510-22.

127. Tribble, G.D., et al., A Porphyromonas gingivalis haloacid dehalogenase family phosphatase interacts with human phosphoproteins and is important for invasion. Proc Natl Acad Sci U S A, 2006. 103(29): p. 11027-32.

128. Yilmaz, O., et al., Gingival epithelial cell signalling and cytoskeletal responses to Porphyromonas gingivalis invasion. Microbiology, 2003. 149(Pt 9): p. 2417-26.

129. Sun, S.C. and S.C. Ley, New insights into NF-kappaB regulation and function. Trends Immunol, 2008. 29(10): p. 469-78.

130. Rahman, M.M. and G. McFadden, Modulation of NF-kappaB signalling by microbial pathogens. Nat Rev Microbiol, 2011. 9(4): p. 291-306.

131. Hodgson, A. and F. Wan, Interference with nuclear factor kappaB signaling pathway by pathogen-encoded proteases: global and selective inhibition. Mol Microbiol, 2016. 99(3): p. 439-52.

132. Lawrence, $\mathrm{T}$. and $\mathrm{C}$. Fong, The resolution of inflammation: anti-inflammatory roles for NF-kappaB. Int J Biochem Cell Biol, 2010. 42(4): p. 519-23.

133. Zhang, Q., M.J. Lenardo, and D. Baltimore, 30 Years of NF-kappaB: A Blossoming of Relevance to Human Pathobiology. Cell, 2017. 168(1-2): p. 37-57.

134. Kunsch, C. and C.A. Rosen, NF-kappa B subunit-specific regulation of the interleukin-8 promoter. Mol Cell Biol, 1993. 13(10): p. 6137-46.

135. Maeda, K., et al., A Porphyromonas gingivalis tyrosine phosphatase is a multifunctional regulator of virulence attributes. Mol Microbiol, 2008. 69(5): p. 1153-64.

136. Hasegawa, Y., et al., Role of Porphyromonas gingivalis SerB in gingival epithelial cell cytoskeletal remodeling and cytokine production. Infect Immun, 2008. 76(6): p. 2420-7.

137. Sasaki, C.Y., et al., Phosphorylation of RelA/p65 on serine 536 defines an I\{kappa\}B\{alpha\}-independent NF-\{kappa\}B pathway. J Biol Chem, 2005. 280(41): p. 34538-47. 
138. Orian, A., et al., SCF(beta)(-TrCP) ubiquitin ligase-mediated processing of NF-kappaB p105 requires phosphorylation of its C-terminus by IkappaB kinase. EMBO J, 2000. 19(11): p. 2580-91.

139. Mattioli, l., et al., Transient and selective NF-kappa B p65 serine 536 phosphorylation induced by $T$ cell costimulation is mediated by I kappa $B$ kinase beta and controls the kinetics of 665 nuclear import. J Immunol, 2004. 172(10): p. 6336-44.

140. Naito, M., et al., Determination of the genome sequence of Porphyromonas gingivalis strain ATCC 33277 and genomic comparison with strain W83 revealed extensive genome rearrangements in P. gingivalis. DNA Res, 2008. 15(4): p. 215-25.

141. Cozzone, A.J., ATP-dependent protein kinases in bacteria. J Cell Biochem, 1993. 51(1): $p$. 7-13.

142. Obadia, B., et al., Influence of tyrosine-kinase Wzc activity on colanic acid production in Escherichia coli K12 cells. J Mol Biol, 2007. 367(1): p. 42-53.

143. Liu, C., et al., Structure-function aspects of the Porphyromonas gingivalis tyrosine kinase Ptk1. Mol Oral Microbiol, 2017. 32(4): p. 314-323.

144. Bechet, E., et al., Identification of structural and molecular determinants of the tyrosinekinase Wzc and implications in capsular polysaccharide export. Mol Microbiol, 2010. 77(5): p. 1315-25.

145. Monds, R.D. and G.A. O'Toole, The developmental model of microbial biofilms: ten years of a paradigm up for review. Trends Microbiol, 2009. 17(2): p. 73-87.

146. Stanley, N.R. and B.A. Lazazzera, Environmental signals and regulatory pathways that influence biofilm formation. Mol Microbiol, 2004. 52(4): p. 917-24.

147. Hansen, A.A., et al., Viability, diversity and composition of the bacterial community in a high Arctic permafrost soil from Spitsbergen, Northern Norway. Environ Microbiol, 2007. 9(11): p. 2870-84.

148. Peters, B.M., et al., Polymicrobial interactions: impact on pathogenesis and human disease. Clin Microbiol Rev, 2012. 25(1): p. 193-213.

149. Tribble, G.D. and R.J. Lamont, Bacterial invasion of epithelial cells and spreading in periodontal tissue. Periodontol 2000, 2010. 52(1): p. 68-83.

150. Socransky, S.S., et al., Ecological considerations in the treatment of Actinobacillus actinomycetemcomitans and Porphyromonas gingivalis periodontal infections. Periodontol 2000, 1999. 20: p. 341-62.

151. Kuboniwa, M. and R.J. Lamont, Subgingival biofilm formation. Periodontol 2000, 2010. 52(1): p. 38-52.

152. Patil, P.C., et al., 1,2,3-Triazole-based inhibitors of Porphyromonas gingivalis adherence to oral streptococci and biofilm formation. Bioorg Med Chem, 2016. 24(21): p. 54105417.

153. Hajishengallis, G., R.P. Darveau, and M.A. Curtis, The keystone-pathogen hypothesis. Nat Rev Microbiol, 2012. 10(10): p. 717-25.

154. Ximenez-Fyvie, L.A., A.D. Haffajee, and S.S. Socransky, Comparison of the microbiota of supra- and subgingival plaque in health and periodontitis. J Clin Periodontol, 2000. 27(9): p. 648-57.

155. Hajishengallis, G., et al., Low-abundance biofilm species orchestrates inflammatory periodontal disease through the commensal microbiota and complement. Cell Host Microbe, 2011. 10(5): p. 497-506.

156. Hajishengallis, G. and R.J. Lamont, Beyond the red complex and into more complexity: the polymicrobial synergy and dysbiosis (PSD) model of periodontal disease etiology. Mol Oral Microbiol, 2012. 27(6): p. 409-19. 
157. Jorth, P., et al., Metatranscriptomics of the human oral microbiome during health and disease. MBio, 2014. 5(2): p. e01012-14.

158. Demuth, D.R., et al., Discrete protein determinant directs the species-specific adherence of Porphyromonas gingivalis to oral streptococci. Infect Immun, 2001. 69(9): p. 5736-41.

159. Daep, C.A., R.J. Lamont, and D.R. Demuth, Interaction of Porphyromonas gingivalis with oral streptococci requires a motif that resembles the eukaryotic nuclear receptor box protein-protein interaction domain. Infect Immun, 2008. 76(7): p. 3273-80.

160. Whitmore, S.E. and R.J. Lamont, The pathogenic persona of community-associated oral streptococci. Mol Microbiol, 2011. 81(2): p. 305-14.

161. Park, Y., et al., Short fimbriae of Porphyromonas gingivalis and their role in coadhesion with Streptococcus gordonii. Infect Immun, 2005. 73(7): p. 3983-9.

162. Periasamy, S. and P.E. Kolenbrander, Mutualistic biofilm communities develop with Porphyromonas gingivalis and initial, early, and late colonizers of enamel. J Bacteriol, 2009. 191(22): p. 6804-11.

163. Bagaitkar, J., et al., Tobacco smoke augments Porphyromonas gingivalis-Streptococcus gordonii biofilm formation. PLoS One, 2011. 6(11): p. e27386.

164. Chaudhry, R., et al., Inflammatory response to Escherichia coli urinary tract infection in the neurogenic bladder of the spinal cord injured host. J Urol, 2014. 191(5): p. 1454-61.

165. Meyle, J. and I. Chapple, Molecular aspects of the pathogenesis of periodontitis. Periodontol 2000, 2015. 69(1): p. 7-17.

166. Di Benedetto, A., et al., Periodontal disease: linking the primary inflammation to bone loss. Clin Dev Immunol, 2013. 2013: p. 503754.

167. Hajishengallis, G., The inflammophilic character of the periodontitis-associated microbiota. Mol Oral Microbiol, 2014. 29(6): p. 248-57.

168. Wang, $\mathrm{H}$., et al., Porphyromonas gingivalis-induced reactive oxygen species activate JAK2 and regulate production of inflammatory cytokines through c-Jun. Infect Immun, 2014. 82(10): p. 4118-26.

169. Tada, H., et al., Porphyromonas gingivalis Gingipain-Dependently Enhances IL-33 Production in Human Gingival Epithelial Cells. PLoS One, 2016. 11(4): p. e0152794.

170. Glowczyk, I., et al., Inactive Gingipains from P. gingivalis Selectively Skews T Cells toward a Th17 Phenotype in an IL-6 Dependent Manner. Front Cell Infect Microbiol, 2017. 7: p. 140.

171. Le Negrate, G., Subversion of innate immune responses by bacterial hindrance of NFkappaB pathway. Cell Microbiol, 2012. 14(2): p. 155-67.

172. Gouin, E., et al., The Listeria monocytogenes InIC protein interferes with innate immune responses by targeting the I\{kappa\}B kinase subunit IKK\{alpha\}. Proc Natl Acad Sci U S A, 2010. 107(40): p. 17333-8.

173. Zheng, C., Q. Yin, and H. Wu, Structural studies of NF-kappaB signaling. Cell Res, 2011. 21(1): p. 183-95.

174. Wan, F. and M.J. Lenardo, Specification of DNA binding activity of NF-kappaB proteins. Cold Spring Harb Perspect Biol, 2009. 1(4): p. a000067.

175. Wan, F., et al., IKKbeta phosphorylation regulates RPS3 nuclear translocation and NFkappaB function during infection with Escherichia coli strain 0157:H7. Nat Immunol, 2011. 12(4): p. 335-43.

176. Kim, D.W., et al., The Shigella flexneri effector OspG interferes with innate immune responses by targeting ubiquitin-conjugating enzymes. Proc Natl Acad Sci U S A, 2005. 102(39): p. 14046-51. 
177. Yang, F., et al., IKK beta plays an essential role in the phosphorylation of RelA/p65 on serine 536 induced by lipopolysaccharide. J Immunol, 2003. 170(11): p. 5630-5.

178. Huang, B., et al., Posttranslational modifications of NF-kappaB: another layer of regulation for NF-kappaB signaling pathway. Cell Signal, 2010. 22(9): p. 1282-90.

179. Ramsey, M.M., K.P. Rumbaugh, and M. Whiteley, Metabolite cross-feeding enhances virulence in a model polymicrobial infection. PLoS Pathog, 2011. 7(3): p. e1002012.

180. Korgaonkar, A., et al., Community surveillance enhances Pseudomonas aeruginosa virulence during polymicrobial infection. Proc Natl Acad Sci U S A, 2013. 110(3): p. 105964.

181. Ramsey, M.M. and M. Whiteley, Polymicrobial interactions stimulate resistance to host innate immunity through metabolite perception. Proc Natl Acad Sci U S A, 2009. 106(5): p. $1578-83$.

182. Nobbs, A.H., R.J. Lamont, and H.F. Jenkinson, Streptococcus adherence and colonization. Microbiol Mol Biol Rev, 2009. 73(3): p. 407-50, Table of Contents.

183. Kuboniwa, M., et al., Streptococcus gordonii utilizes several distinct gene functions to recruit Porphyromonas gingivalis into a mixed community. Mol Microbiol, 2006. 60(1): p. 121-39.

184. Rainey, P.B. and K. Rainey, Evolution of cooperation and conflict in experimental bacterial populations. Nature, 2003. 425(6953): p. 72-4.

185. Bechet, E., et al., Tyrosine-kinases in bacteria: from a matter of controversy to the status of key regulatory enzymes. Amino Acids, 2009. 37(3): p. 499-507.

186. Nadler, C., et al., Cycling of Etk and Etp phosphorylation states is involved in formation of group 4 capsule by Escherichia coli. PLoS One, 2012. 7(6): p. e37984.

187. Kuboniwa, M., et al., Metabolic crosstalk regulates Porphyromonas gingivalis colonization and virulence during oral polymicrobial infection. Nat Microbiol, 2017. 


\section{CURRICULUM VITAE}

NAME: Sarah Whitmore

ADDRESS: 2906 Danzig Place \#201

Louisville, KY 40245

\section{EDUCATION \& TRAINING}

August 2010 to present Interdisciplinary P.h.D. Candidate

Department of Oral Immunology and Infectious Diseases

University of Louisville, KY

July 2012 to April 2016 Doctor of Dental Medicine (DMD)

School of Dentistry

University of Louisville, KY

\section{RESEARCH}

January 2011 to Present

\section{Graduate Research Assistant}

\section{PUBLICATIONS}

June 2011 Dickinson, B.C., Moffatt, C.E., Hagerty, D., Whitmore, S.E., 
Brown, T.A., Graves, D.T., Lamont, R.J. (2011). "Interaction of oral bacteria with gingival epithelial cell multilayers."

Mol Oral Microbiol 26(3): 210-220.

July 2011

Whitmore, S. E. and R. J. Lamont (2011). "The pathogenic persona of community-associated oral streptococci." Mol Microbiol 81(2):305-314.

December 2011 Moffatt, C.E, Whitmore, S.E., Griffen, A.L., Leys, E.J., Lamont, R.J. (2011). "Filifactor alocis interactions with gingival epithelial cells." Mol Oral Microbiol 26(6): 365-373.

March 2012

Whitmore, S. E. and R. J. Lamont (2012). "Tyrosine

phosphorylation and bacterial virulence." Int J Oral Sci 4(1): 1-6.

September 2012

Hendrickson, E.L.,Wang, T., Dickinson, B.C., Whitmore, S.E., Wright, C.J., Lamont, R.J., Hackett, M. (2012). "Proteomics of Streptococcus gordonii within a model developing oral microbial community." BMC Microbiol 12: 211.

April 2013

Takeuchi, H., Hirano, T., Whitmore, S.E., Morisaki, I., Amano, A., Lamont, R.J.(2013). "The serine phosphatase SerB of Porphyromonas gingivalis suppresses IL-8 production by dephosphorylation of NF-kappaB RelA/p65." PLoS Pathog 9(4): e1003326.

\section{March 2014}

Whitmore, S. E. and R. J. Lamont (2014). "Oral bacteria and cancer." PLoS Pathog 10(3): e1003933.

June 2014

Wright, C.J., Xue, P., Hirano, T., Liu, C., Whitmore, S.E., Hackett, M., Lamont, R.J. (2014). "Characterization of a bacterial tyrosine kinase in Porphyromonas gingivalis involved in polymicrobial synergy." Microbiologyopen 3(3): 383-394. 